\title{
(4)
}

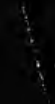

sosing

s.

8 

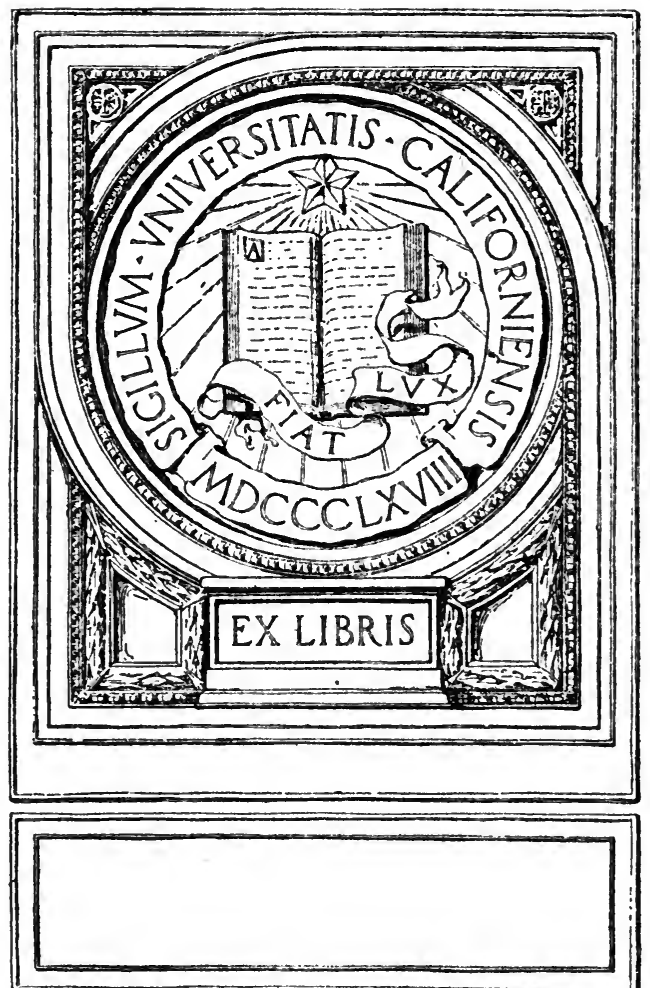
$\frac{A}{00}-\frac{1}{4}$

in:

S

4

to

15:

4

से

.

s

its.

$5 \leqslant$

tr.

: 
Digitized by the Internet Archive in 2007 with funding from Microsoft Corporation 


\section{THE WHOLE TRUTH ABOUT ALCOHOL}




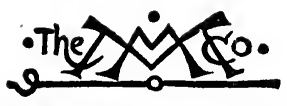

\section{THE MACMILLAN COMPANY}

NEW YORK - BOSTON - CHICAGO - DALLAS

ATLANTA - SAN FRANCISCO

\section{MACMILLAN \& CO,, LIMITED}

LONDON - BOMBAY - CALCUTTA

MELBOURNE

THE MACMILLAN CO. OF CANADA, Lto. TORONTO 


\title{
THE WHOLE TRUTH ABOUT ALCOHOL
}

\author{
BY \\ GEORGE ELLIOT FLINT
}

WITH AN INTRODUCTION

BY

DR. ABRAHAM JACOBI

Medio tutissimus ibis

Ovid

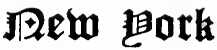

THE MACMILLAN COMPANY

1919

All rights reserved 


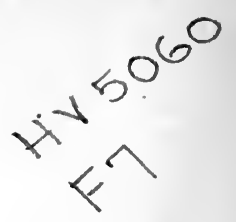

Copyright, 1919

BY THE MACMILLAN COMPANY

Set up and electrotyped. Published, March, 1919

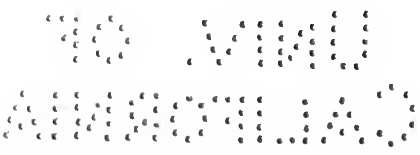




\section{INTRODUCTION}

Mr. Flint has asked me to write an introduction to his book. I could not refuse though, or perhaps because, contrary to my habits, it so happens that personally in several months I tasted no alcohol. Both my habit and my abstinence ought to make me impartial. As a practitioner and dealing with the well and the sick, I have had many opportunities either to order or forbid the use, either in small or large amounts, of an alcoholic beverage. Neither those who were ordered or forbidden enjoyed my interference,least, perhaps, those who claimed to be prohibitionists. I wonder whether Timothy (Chap. V. 23) was pleased or, if he was a prohibitionist, disgusted with his friend, St. Paul, who advised him not to drink any more water, but to use a little wine for his stomach's sake and his frequent infirmities.

The book, which I hope many will enjoy, I beg to introduce to the public. Nevertheless, it contains some things I do not enjoy myself. The author speaks ill of many friends of mine whom he calls "reformers and other extremists." I am no extremist, but mean to be a reformer, and hope to continue to be one; that is why I recommend this book, and trust I shall not be classed with those whom my friend, Mr. Flint, calls "usually a nuisance." So I can not al- 
ways agree with the author, but I admire his ingenuity and the freedom of his expressions. He has a wonderful knowledge of drastic English and uses it to advantage; and a knowledge of popular physiology, and makes no mistake in the use of scientific facts and current medical literature. There are some few medical men whom he disrespects as much as I do. There are some who know so little that they seem ignorant of medical thought; one was a full-fledged prohibitionist. Of this variety is Horsley. I am a doctor myself and think much of Horsley,-or rather, of what he was; and should forgive him for thinking,if he ever thought of me,-as little as I hope he did of me. Though he was a thinking and well-informed person, he suffered from the inadequacy of his specializing tendency and practice. He was a competent surgeon. But no specialist, great or small, outgrows his narrowness. There is no greater praise for any specialist than to speak of him as a good doctor. It may be that you, like me, appreciate the fact that in the profession doctors are getting scarce, and good doctors amongst the specialists are the rarest of birds. If a reader of these lines happens to be one of my colleagues, I take this opportunity to ask his pardon. It is not he of whom I speak; he knows it. So it has happened that some specialistic practitioners,-even a famous specialistic surgeon like Horsley,-got into the thin ranks of radical anti-alcoholists,- "prohibitionists."

The temptation for lay prohibitionists is their ignorance. They do not know, or ignore, the fact that 
the most positive and strongest medicines may exhibit antagonistic features. At the beginning of the past century of medicine, for instance, they had prolonged discussions about opium. They knew that opium was a depressant, even a narcotic; they also fought for opium as a stimulant,-“"non sedat, mehercle non sedat." So was alcohol a stimulant (or irritant) ; in other gospels it was a depressor, a paralyzer. Meanwhile it took as great a pharmacologist as Cushny to prove (lately) that alcohol is indeed a cerebral depressant which manifests itself in a condition not of irritation but of comfort and well-being. Disease is liable to lose its strongest ally when alcohol allays anxiety and worry.

My own experience of more than half a century is that in the worst cases of fatal sepsis,-diphtheria, erysipelas, puerperal fever,-alcohol in the largest doses furnishes the only salvation. Doses differ according to ages and indications. Thus the same material may become a stimulant or a depressant; and in the axioms of the teaching of Salerno, nearly a thousand years ago, wine is called the milk of old age, and milk the wine of the young. And modern hygiene which supplies the soldier with plenty of food renders alcohol superfluous and coffee a substitute for alcohol. My old friend Horatius Flaccus (Epistle I., xix.) knew that quite well, when he stated that no poem written by a water drinker lives a long time. It takes wine to stimulate the poet. "Nulla placere diu neo vivere carmina possunt quae scribuntur aquae potoribus." 


\section{viii}

\section{INTRODUC'TION}

This little book, which it gives me a great pleasure to introduce, is a protest against the outrages of pessimistic prohibitionists. Its positive assertiveness compares favorably with the lying allegations of many of the partisan newspapers or magazines of the wrathful prohibitionists. The author's statements are based on scientific facts and are presented with an undue courtesy, greater than I ought to have expected from the lack of veracity and unscrupulous inventiveness of resentful rage, which characterize the writings of many ardent prohibitionists whose teachings he refutes.

A. JACOBI, M. D. 


\section{PREFACE}

My aim in this work is to tell the whole truth about Alcohol. More dangerous far than an untruth is a half-truth; for, while the half-truth is plausible and misleads, the frank untruth may arouse suspicion. Also, the latter can be more easily refuted.

Undoubtedly alcohol is an evil; but it is not all evil, and I hope to show that alcohol is often of much benefit, and that, when wisely used, it can be a mitigator of pain, a saver of life, and frequently a great comforter to overworked and unnerved humanity in their pitiless vortex of the awful struggle to live.

The way, however, to uplift and to strengthen men is not to make their desired indulgences impossible. The better way is to teach them moderation, self-control and, particularly, self-respect.

While I shall try not to be dogmatic, disagreeable, unjust, or intolerant, I shall uphold the truth, at any price, and regardless of whom it may hurt. In so doing, I shall reason from facts, not fancies; from convictions, not prejudices; and from whole-, and not half-truths.

Assuredly it is not safe to believe everything one hears, reads, or even sees. One should believe only what one understands.

Persons, whose statements can be relied upon im- 
plicitly; that is to say, without proof, or, at least, without some cogent reasons for such statements, are about as rare as the pithecanthropi.

That we can not believe always what is before our eyes is shown by the fact that, when we see a prestidigitateur pull out of an apparently empty hat wriggling live rabbits, we do not believe that a magician has miraculously created cuniculi. Our sense tells us there is some trick, although we do not know what it is. If we understood, our wonder would vanish.

Whence, to fire the reader's understanding, not merely with dry statistics, but with the clear light of reason based upon fact, is that to which I very humbly aspire.

G. E. F. 


\section{TABLE OF CONTENTS}

CHAPTER

INTRODUCTION • • • • • • • • • v

Preface :. . . . . . . . . . . ix

I Human Psychologi and National ProHIBITION • . • . • • • • . • 3

II After Prohibition of Alcohol, What Next? . . . . . . . . . . 16

III Do Citizens Need Nurses? • • • • 19

IV The Trranny of National Prohibition . 25

V The Increase in Drug Addicts . . . . 27

VI National Prohibition Unjust to the INDIVIDUAL . . . . . . . . . . 30

VII The Danger of Habitual Liquor DrinkING . . . . . . . . . . . . 38

VIII The Webb-Kenyon Act and Its Probable Consequences . . • . • • . . . 42

IX Would Private Distillation Follow National Prohibition? . . . . . . 45

$X$ Need of Strict Enforcement of Existing LiquOR LAWS . . . . . . . . 49

XI National Deceit After National ProhiBITION . . . . . . . . . . 52

XII Let the Drink Problem Take Care of ItSELF • • • . • • • • • • . 57 xi 
XIII The Workingman Sans Drinking and SMOKING . . . . . . . . . . 60

XIV The Workingman's Club-The Saloon . 64

XV The Psychology of Fanatics . . . 72

XVI Are Abstainers Superior? . . . . 81

XVII Alcohol aNd Candy . . . . . . . 84

XVIII ALCOHOL AND WAR . . . . . . 88

XIX Alcohol in the Tropics . . . . . 97

XX Alcohol and Efficiency . . . . 103

XXI Alcohol as a Stimulant . . . . 110

XXII Alcohol as a Poison . . . . . . 126

XXIII Ehfects of, and Facts About, Alcohol . 140

XXIV Alcohol, Life Insurance, and Longevity 161

XXV Alcohol and Deficienct . • . . 190

XXVI Alcohol and Poverty . . . . . . 201

XXVII Alcohol ANd CRIME . . . . • . 205

XXVIII Alcohol and Disease . . . . . . 210

XXIX The Non-Alcoholid Cadse of Man's

Physical Deterioration . • • • . 231

XXX How to Prevent Physical Deterioration 248

XXXI A Practical Preventive of Apoplexy . 265

\section{ADDENDUM}

Alcohol Economically and Practically Considered 269 Cardinal Gibbons on the National Prohibition of AlCOHOL . . . . . . . . . . . . 274 INDEX.$\quad \cdot \quad \cdot \quad \cdot \quad \cdot \quad \cdot \quad \cdot \quad \cdot \quad \cdot \quad \cdot \quad \cdot \quad \cdot 279$ 
THE WHOLE TRUTH ABOUT

ALCOHOL 



\section{THE WHOLE TRUTH ABOUT ALCOHOL}

\section{CHAPTER I}

\section{HUMAN PSYCHOLOGY AND NATIONAL PROHIBITION}

IT is a common delusion to believe that we can create. God alone can create. Man can merely direct, reduce, or develop, the created attributes of living matter by modifications of its environment. We must remember also that, in all living matter, the evil attributes can be overcome by the good attributes, only if the latter predominate.

Thus, if the created matter is a man, in whom there is more good than bad, the man is reputed good; whereas, if a man's evil attributes are and remain in the ascendant, despite all environmental influences tending to check their development, such as moral suasion, punishment, etc., then that man is reputed bad, and becomes, after a certain lapse of time, irreclaimable.

Such is the habitual criminal. Yet, while we incarcerate that unfortunate to protect society, let us not blame him. The chronic criminal has always a bad heredity, immediate or remote; and a bad hered- 


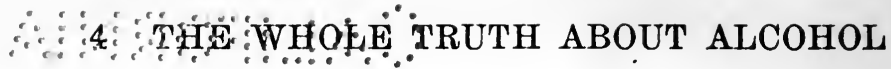

ity goes usually with another handicap, a bad environment.

It is easy to say that faults and weaknesses of character can be overcome. Sometimes they can, and sometimes they can not. No man possesses anything, with which to fight his evil propensities, but his good propensities; and, as the good, as well as the bad, is inherited, or bestowed upon him without his wish, it is hardly his fault if the good in him happens to be weaker than the bad in him. While it is true that what a man does is, in a sense, his own fault, it is not true that he himself is his own fault.

We say, for example, that a weakness for drink can be overcome by an effort of the will. It can, if the effort of the will is made; but if there is no will for the effort, there will be no effort, and, in that case, the weakness for drink will not be overcome.

When a patient manifests alarming symptoms, no good physician, after he has suppressed the symptoms by an injection of morphine, believes that he has cured the disease responsible for the symptoms. If a surgeon should "pack" a wound, thereby preventing the flow of pus from it, the patient would die speedily of septic poisoning.

But like that hypothetical surgeon, who, happily, is only hypothetical, are our well-meaning advocates of National Prohibition.

Let us imagine the dream of National Prohibition to have become a fact. No one can now drink any alcoholic beverage. It is not obtainable, because none is manufactured. One safety outlet, and a large one, 
for the stream of life has been effectually dammed. We shall call this stream, which has been abruptly shut off, The Desire for Stimulation and Forgetfulness.

Naturally, the damming of that stream, so far from having dried it up, has increased its volume enormously. Then, either of two things will happen. The stream will either burst the dam, and flow to alcohol some way or another, or, if its barriers prove impregnable, it will slip around them and seek other mediums for effects similar or nearly similar to those of alcohol. In any event, the stream will inevitably some time burst its bounds; for, its source, though buried deep in the human heart, is fed by three perennial springs: The Desire for Stimulation, The Desire for Rest, and The Desire for Forgetfulness.

It is my firm belief that, so long as those three Desires remain rooted in mankind, State, National, or International Prohibition of alcohol will all prove equally ineffectual.

To extirpate, so as to destroy completely any created human instinct, is as impossible of accomplishment by man, as it would be for him to create a perfectly new instinct; it being no more conceivable that something should become nothing, than that nothing should become something. While instincts can be modified or developed, they can not be destroyed.

Persons there are who appear to be organically incapable of living and letting live. Nevertheless, they must "let live," because mankind will live as it 
sees fit, in spite of them. Fanatics, reformers, and legislators notwithstanding, so long as men wish to drink, they will drink.

The desire for alcohol is not an ordinary desire; it is a powerful desire. Watch men toil, particularly on a hot day; follow them when they wearily wend their way homeward to their evening meal; note with what eagerness they seize the "can" to have it filled at the nearest saloon, and, when they again reach home, half-famished and ready to devour their coarse fare, watch them glue their parched lips to the can, now containing a refreshingly cold creamy nectar that dispels their fatigue and mercifully dulls, for a time at least, the keen sense of the hardness of their lot.

Or look higher. Business men, boon companions, meet. They wish to enjoy a chat. A few drinks stimulate their thoughts, loosen their tongues, lighten their cares, and make them take a better view of life generally. They are normal men. Usually they do not drink to excess. Only exceptionally men become drunkards.

It is not unlikely that the desire for intoxicants is connected also with sexual desire. Before coupling, certain animals, especially birds, work themselves into high degrees of excitement. Mammals paw the earth, howl, and lash themselves into fine fury; birds, such as the woodcock and sharp-tailed grouse, utter loud eries, erect their feathers, beat violently with their wings, and either circle swiftly in air, or run wildly about. 
All which whipped-up excitement in animals is similar to that produced in man by alcohol; it being well-known that alcohol acts like violent exercise in exciting the sex instinct-in fact, alcohol is frequently and deliberately used by man for that purpose.

Possibly the foregoing is a reason, and a weighty one, that the desire for alcohol is so widespread and ineradicable, seeing that the instinct of speciespreservation is as indestructible as that of self-preservation.

Nevertheless, State Prohibition is gaining in this country. According to a statement issued shortly after the presidential election (1916), by the AntiSaloon League of America, there are now twenty-four out of forty-eight states, one-half of the states of the Union, which have declared for State-wide Prohibition, and over 60 per cent. of the population and 85 per cent. of the area of the country are now under prohibition law.

Yet, that does not mean that the remaining "wet" states, or that even any of them, will follow suit. One thing, however, might induce them-Federal or National Prohibition. But, fortunately, before a Nation-wide Prohibition could be declared by the Federal government, an amendment to the Constitution of the United States would be necessary.

The Honorable Elihu Root, one of the brainiest and ablest, if not the ablest, statesman in this country, thus expressed himself, in a letter to the National Association Opposed to Woman Suffrage, on December 7th, 1916; his remarks being equally applicable to 


\section{THE WHOLE TRUTH ABOUT ALCOHOL}

the injustice of imposing prohibition "on the states which do not wish for it":

"I am against having the Constitution of the United States amended so as to impose Woman Suffrage on the states which do not wish for it. . .

"For the vital reason: It would be the destruction of the right of self-government and a subjection of the people of New York to the government of others. ... .

"I think such an attempt would be contrary to the principles of liberty upon which the American Union was established and without which it could not endure.

"Without the right of local self-government we should lose the better part of our liberty.

"This country is so vast, the differences in climate, in physical characteristics, in capacities for production, in predominant industries, and the resultant habits of living and of thinking are so great, that there are necessarily wide differences of view as to the conduct of life; and to subject any section of the country, in its local affairs, to the dictation of the vast multitude of voters living in other parts of the country, would create a condition of intolerable tyranny; and, to use the power of the Nation to bring about that condition, would be to make the Nation an instrument of tyranny.

"It is needless to argue that this would ultimately destroy the nation."

Said former-president Taft, speaking on The $\mathrm{Na}$ tional Prohibition of Alcohol: 
"National Prohibition is a dangerous proposition. It would revolutionize the National government. It would put on the shoulders of the government the duty of sweeping the door-steps of every home in the land. If national legislation be passed, local government would be destroyed. And if you destroy local government, you destroy one of the things that go to make a healthy condition of the national government.

"National Prohibition would be non-enforcing. It would be a confession on the part of State governments of inability to control and to regulate their own especial business and duty. If the matter were placed under Federal control, it would result in the creation of a machinery of government large enough to nominate any President, and would offer too great an opportunity to persons seeking to perpetuate their powers in Washington."

Even in the event of there being a national prohibition of alcohol by amendment of the Constitution (requiring a two-thirds vote in both houses of Congress), before such a federal law would become operative there would be the requirement that the amendment be ratified by the legislatures of threefourths of the states, and there would be allowed to the states seven years for ratification.

A glaring injustice, however, of this apparently just procedure would be that the sparsely inhabited states would have an equal voice with the densely populated ones. For example, the four least populous states in the Union would have just as much weight as the four most populous containing thirty times as 


\section{THE WHOLE TRUTH ABBOUT ALCOHOL}

many inhabitants; and thus a situation might arise in which thirty-six legislatures, representing less than one-half of the population, would impose their will on the remaining twelve states representing the majority.

Logically, if the people are to decide as to whether they do or do not want prohibition, and such is the pretended desire of the Anti-Saloon League, a referendum should be had to the whole country for the guidance of the Congress as well as of the state legislatures.

As it is now, however, should the supposed prohibition amendment to the Constitution be ratified by three-fourths of the states, repeal, no matter how disastrously the law worked, would be almost impossible; any repeal of the Constitution requiring a twothirds majority in both houses, as well as the consent of three-fourths of the state legislatures.

"But any thirteen states-and there are more than that number within the prohibition party to-daywould have the power, by refusing their assent, to make repeal impossible, no matter how insistent and sincere might be the demand for it throughout the other thirty-five states. And a governmental policy fraught with such incalculable consequences, reaching into the very depths of our political and social life, the well-spring of ceaseless strife and of corruption, should be left to chance legislatures in the name of a public opinion they can not truly voice!" 1

Local prohibition waves have spread most rapidly through the South, whence they have percolated along 1 Alcohol and Society, by John Koren. 
the lines of least resistance to the West and Northwest. For that there has been a reason.

In the South "the saloons, purveyors of distilled spirits almost exclusively, had grown notoriously lawless, drunkenness was rampant, and behind all loomed the specter, partly imagined, partly real, of danger from the uncontrolled elements among the negroes. ... In the space of a few years, Oklahoma, Georgia, Alabama, North Carolina, Tennessee and Mississippi outlawed the manufacture and sale of intoxicants. Alabama later recanted her faith, but has once more turned to prohibition." 1

In a word, prohibition, in the southern states at least, appears to have been enacted for the benefit of negroes and white trash; but a measure which would benefit such would not necessarily benefit the vast majority comprising the respectable element of society.

While I believe that the basis upon which Universal Prohibition rests is a quicksand, which, ultimately, will disappear, engulfing with it that hollow shell raised by prejudice, injustice and unreason, some do not share that opinion.

People generally are fearfully and wonderfully gullible. They are not far-seeing, but can easily be made to see immediate effects, for which desired causes are chosen. Nor can such "causes" be readily shown to be not true causes, seeing that, in the absence of a specific cause, almost any cause for any effect is possible.

1 Alcohol and Society, by John Koren. 
Thus the proletariat are deceived by the cleverer and better educated portion of the community who may have more private than public reasons for promoting certain legislation.

Later we shall see how many absurd and absolutely false conclusions are deduced, by the promoters of prohibition, from premises, which, while true, are not the whole truth.

Briefly to give here a specific instance of mendacity masquerading as veracity: We are told that when a small quantity of ethyl alcohol is injected into the veins of a guinea-pig, the wretched animal dies in agony within a short time. That is true. The next assertion of the Prohibitionists is that their cruel experiment proves alcohol to be a "virulent poison." That is only half-true.

The whole truth is: The experiment proves alcohol to be a poison only when injected into the veins of a living animal.

They did not utter that complete truth, because they knew, as scientists, that the extracts of all the animal, and even of all the vegetable, proteins, which are contained in the foods which all men eat, and without which no man could live, are, when injected into the veins of small animals, still more poisonous than is alcohol.

There are reasons why the extracts of proteins and alcohol act as foods, and not as poisons, when taken into the human stomach; and those reasons will be given in their proper place.

Suffice it to say, at this time, that such "injection" 
experiments purporting to prove alcohol a poison, when imbibed, prove nothing of the kind; and we have not heard as yet of anyone taking hypodermics of alcohol, except as a cure for tri-facial neuralgia. The usual mode of administration is, as we all know, a painless imbibition via the alimentary canal.

Elsewhere in this book full details of the above will be given and the whole truth incontestably shown.

Most men can not be induced to cut their own throats, but they can be persuaded gradually to surrender their liberties.

What is it that Congressman Richmond Pearson Hobson, who heroically submerged himself, only to emerge later as a champion of the less heroic, but equally gallant, art of osculation, and now as the undismayed captain of the avid, or, should I say, arid, forces of Prohibition-what is it that Mr. Hobson and his staunch adherents want? Forsooth nothing but a constitutional amendment to enable them to impose their militaristic notions about alcohol upon a public too purblind to see the best for their own welfare!

Even supposing that a half of the $100,000,000$ persons in these United States do not wish to drink alcoholic beverages; there is no law, at present, compelling those 50,000,000 supernormal persons to drink what they do not please, or, rather, what does not please them. They may, therefore, quaff lemonade, sarsaparilla, coffee, tea, and other non-intoxicants, to their hearts', or stomachs', content. 
But, if the Prohibitionists should succeed in trampling upon, and trammeling, the liberties of the remaining 50,000,000 subnormal persons, who do wish to drink alcoholic beverages; then these fifty millions would be compelled by law to drink either sickening concoctions (soft drinks), which their stomachs perhaps could not endure, or plain water.

If it be said that pure water could always be procured, and that this well-known drink, if the prospective drinkers were very thirsty, would taste perfectly delicious, the answer would be that, to expose the fallacy of such a rash statement, it would be sufficient to visit Coney Island, on the crest of a hot wave, at the height of the season. Once there, tired and perspiring, manifest to some brawny waiter your unalterable predilection for the element that, in Noah's time, killed practically the whole of humanity, and all but a couple of birds, beasts and reptiles-in a word, ask for water. You will not get it, unless on the brain, after you have been thrown out on your head.

An unwritten law of all free countries is, that legislatures shall not forbid the manufacture or sale of any substance for consumption, unless such substance has been proved beyond cavil or question of doubt to be dangerously and destructively injurious.

Thus laws against the unrestricted sale of opium, morphine, heroin, etc., are defensible. Furthermore, laws against the unrestricted sale of the powerful alcoholic liquors would be, in a measure, defensible, seeing that the strong liquors, containing from 50 to 
70 per cent. of alcohol, are undoubtedly, in some cases, destructive and habit-forming.

Yet, any law prohibiting absolutely the manufacture, importation and sale of the light alcoholic drinks, and particularly beer, which contains barely four per cent. of alcohol, would be perfectly indefensible for the following reasons: First, beer is not a strong stimulant; second, it is not destructive; third, it is not habit-forming; and fourth, it is neither obviously nor universally conceded to be injurious, but is, in the opinion of the most eminent men, wholesome, tonic and strengthening. There are no beer drunkards.

Why, then, a senseless agitation against a universally popular mild beverage which, according to thousands, does less harm-even if it does no goodthan an excessive quantity of sweets, or than an excessive amount of meat?

I hope, however, that those of my readers who will follow me through this book will agree that the malt beverages, rightly used, do much good, not the least being the blunting of human anguish, anxiety and worry. 


\section{CHAPTER II}

AFTER THE PROHIBITION OF ALCOHOL, WHAT NEXT?

THe injustice which National Prohibition would do to, say, forty millions of individuals, is so obvious that even mentioning it seems superfluous. What is not so obvious, but equally true, is that the passage of so drastic and sumptuary a law, in this supposedly free country, would establish a precedent dangerous to the remaining liberties of the people.

After all the hydra-heads of the Demon Alcohol had been struck off, and the red hot iron of Herculean national legislation had been applied to the stumps to prevent their regrowth, what then would the professional reformers do? Slink into innocuous desuetude? Hardly. They would become aware that mankind was still degenerating, and would seek for some other Universal Cause.

Soon they would discover that the vice of smoking had increased, and, shrieking, Eureka, it is tobacco; down with tobacco! - they would uproot the vile weed, and burn it off the face of the earth.

All that would be necessary to make the highesthanded proceedings possible, would be a few fanatics, some analyses of the poisonous substances contained in tobacco, "efficiency" tests to prove that the weed was 
"slowly but surely" killing everyone, graphic descriptions of "inalienable rights" to breathe pure air, passionate dissertations on the "disgusting and filthy" habits of chewing and smoking, and all cepped with statistics of the amount of money annually dissipated into noxious fumes;-the one important fact completely lost sight of, being, that money used to procure pleasure and relaxation, without doing any especial harm, is well-expended.

The next step of the minds, not clouded by tobaceo smoke at least, would be to enlist the sympathy of women, who are, mostly, of course, non-smokers. Basely it would be pointed out to them that the money, spent yearly by their husbands upon cigars, would far better be expended in feminine capital and mural decorations, as exemplified in coquettish millinery and the latest gowns. No doubt such arguments would interest the fair, and arouse their enthusiasm. To the nucleus of an ebulliently earnest Anti-Smoke Society, the ladies would flock, and, after they had obtained the franchise, they would threaten seasoned politicians, and politicians in embryo, with the loss of their votes, unless they would promise faithfully to favor National Prohibition of tobaceoa kind of black-jack, were it not a petticoat persuasion!

But a world triumphantly deprived of its chief solaces, alcohol and tobacco, would not satisfy our Reformers and self-constituted Brothers' Keepers. "Degeneracy" would still be with us-perhaps more of it. Probably coffee and tea drinking would be 


\section{THE WHOLE TRUTH ABOUT ALCOHOL}

next attacked; then meat eating ; for it could be readily shown that all those substances contained poison.

Finally, the remnants of a vegetarian humanity, pursuing now a truly vegetative and non-resisting existence, would, groaning, give up the ghost. 


\section{CHAPTER III}

\section{DO CITIZENS NEED NURSES?}

BUT a truce to the lugubriousness of the last chapter. That harrowing picture could never be. In this world of exhausting labor, keen competition, and nervous strain, man needs some sedative; and, of all sedatives, alcohol and tobacco have been chosen, by the majority of mankind, as being the most comforting and satisfying, as well as the least harmful and dangerous. To stop the alcohol and tobacco habits of the entire population of this country, would, therefore, be practically impossible. But, that to curtail them would be possible, is proved by the fact that it has already been done.

Figures show that, so far from there having been an increase in intemperance in late years, there has been a decided decrease. At present, a great deal more of malt liquors (mildly alcoholic), than of distilled liquors (strongly alcoholic), are being consumed.

In 1890, the manufacture of malt liquors furnished employment to 34,800 persons, and yielded a product worth $\$ 182,700,000$; while during the same year, the manufacture of distilled liquors employed but 5,343 persons, and yielded a product worth $\$ 104,000,000 .^{1}$

1 Twelfth Annual Report of the Department of Labor, p. 27. 
Again, looking at the consumption of alcoholic beverages generally for a series of years, we find a marked and steady decline in the amounts consumed of the stronger varieties. Since 1840 there has been a constant substitution of malt for distilled liquors in the total consumption; the consumption of the latter having fallen from 2.52 gallons per caput to 1 , while the consumption of the former has risen from 1.36 to $\mathbf{1 5 . 1 6}$ per caput.

Although the foregoing figures show a considerable increase in the total quantity consumed of the lighter drinks, yet the substitution of those for the stronger drinks has resulted in a diminution of the amount of alcohol consumed per caput. Moreover, while the consumption per caput of malt liquors has remained nearly stationary since 1890 , the consumption of distilled liquors has fallen by nearly one-third. ${ }^{1}$

That creditable temperance record, however, has not been due to reformers so much as to the good sense of the people themselves.

The behavior of certain reformers toward the public, nowadays, is like that exhibited by overzealous nurses toward the healthy children entrusted to their charge, with the difference that the authority of the reformer is self-delegated. Excited, he runs back and forth like a hen about her chicks, when they venture near the water; neither the hen nor the reformer realizing that the chick's or the child's natural instinct will prevent it from destroying itself.

As the great labor unions in England have become

1 Economic Aspects of the Liquor Problem, by John Koren. 
larger and wealthier, says, in substance, a report of the Committee of Fifty, investigating the liquor problem, they have been steadily emancipating themselves from the public houses by having their own meeting places; and the need of keeping sober during strikes and lockouts has impressed itself ever more strongly upon them. They have found it, too, to their interest to elect to their higher offices only temperate men; while the ramifications of their elaborate system of insurance give each member a direct interest in the sobriety of his co-workers.

Workmen are human, and they have more sense than many well-meaning meddlers, whose acts indicate a singular lack of faith in every one but themselves.

The vast majority of these intelligent workmen are aware that it pays to be steady and to keep sober at all times; moreover, as they scarcely enjoy contributing to their respective organizations any part of their hard-earned wages toward the support of the idle and dissolute, they encourage in every way possible, among their number, general industry and sobriety.

Among the rules of the Iron, Steel and Tin Workers, one is, that if a man is discharged on account of drunkenness, no steps shall be taken to reinstate him. Among the Metal Polishers, the Core Makers, the Iron Moulders, the Retail Clerks, and the Knights of Labor, any man belonging to any of those organizations who connects himself in any way with the liquor traffic, whether he remain sober or not, is expelled from the union. 
And the Iron Moulders, the Blacksmiths, the Amalgamated Society of Carpenters and Joiners, the Wood Workers, the Painters and Decorators, the Leather Workers on Horse Goods, the Tobacco Workers, the Cigar Makers, and the Retail Clerks, go still further, by excluding such a member from the benefits to which he would be entitled in case of sickness, accident, or non-employment. Many Unions, also, fine, or otherwise punish, those who attend meetings in an intoxicated condition.

As an instance of how men can be depended upon to take care of themselves without the aid of a paternal government, I quote the following: "In Canada the men who are called lumberers live in camps far away from civilization. During the whole winter they fell the trees, and these are dragged along the snow to the nearest river, where they are made up into rafts. These men will not have any alcohol near them in the winter. On one occasion a man conveyed a cask of whiskey into one of their camps, and the first thing they did was to take an axe, and knock a hole in the cask, so that the whole of the whiskey ran out. The reason of this was, they did not dare to leave the whiskey there, for, if it was there, they felt quite sure they would drink it, and, if they drank it, they were likely to die." 1

Evidently, the lumberjacks were average sensible men, who knew from experience, without demonstra-

1 Alcohol and the Human Body, by Sir Victor Horsley, M.D., p. 145. (Quoted by Horsley from Sir T. Lauder Brunton, in the Action of Medicine.) 
tions by the laboratories, that, while the ingestion of an excessive quantity of liquor would give an immediate sensation of warmth, that would be succeeded by a loss of heat (owing to radiation of heat from the blood sent by alcohol to the surface of the body), and that if, by chance, any of their number should drink until he fell into a stupor, and should lie down in that cold region and sleep, he might never awaken.

So the common lumberjacks Carrie-Nationed the cask without the moral impetus of a single reformer!

"Some time ago," continues Sir T. Lauder Brunton, "Sir Joseph Fayrer was out deerstalking in the north of Scotland. He offered his flask to the keeper. The keeper said, 'No, Sir Joseph, I will not take any to-day; it is too cold.' ",

Now, why, when the keeper knew there was no law against it, did he not take the nip? Is it possible that he himself had the strength to refuse?

The discovery that alcohol lowered bodily temperature was of considerable importance, and many careful investigations were made by Sir Benjamin Ward Richardson, M. D., before he laid the facts before the British Association in 1866. Alcohol is now occasionally used as an antipyretic.

Still another instance of the soundness of permitting large bodies of men to govern themselves, without compulsory law, and, incidentally, an example of the importance of better treatment as a factor in the furtherance of sobriety, are furnished by the Burroughs Adding Machine Company.

"That firm (employing several thousand men) vol- 


\section{THE WHOLE TRUTH ABOUT ALCOHOL}

untarily shortened their working day from nine and one-half hours to eight hours. A noticeable decrease in drinking followed, and, what is equally gratifying from the economists' stand-point, there was also a slight average increase in the output." 1

Men drink less alcohol, when they require less; that is, when they are not exhausted by hard work. Thus, practically considered, alcohol seems to fill a need.

1 Alcohol-Its Influence on Mind and Body, by Edwin F. Bowers, M.D. 


\section{CHAPTER IV}

\section{THE TYRANNY OF NATIONAL PROHIBITION}

IT would not be democracy; it would not be free republican rule; but it would be tyranny for any government to arrogate to itself the right to dictate to millions of free men what they should drink; and if National Prohibition should ever be accomplished, which I, for one, do not believe, it would be the most damnable and outrageous assault upon personal liberty ever perpetrated, and, so terribly would it be avenged, that its instant repeal would be demanded by its own instigators.

That alcohol in excess is harmful to health, everyone knows, and nobody disputes. But that alcohol is harmful in moderation, millions of persons, among whom are thousands of leading physicians and scientists, do not concede, but, on the contrary, emphatically maintain, that, in many cases, alcohol is of distinct benefit.

While alcohol does not agree with all, it agrees with many; and, therefore, sweepingly to forbid even the light alcoholic beverages to everyone, would be flagrantly unjust.

One great cause of ill-health is worry, and that is more wearing than work. If alcohol lessens worry, 
certainly a predisposer to disease, then alcohol is of some use.

The general physiological effects of alcohol will be discussed in another chapter.

The belief that the entire population of the United States could be forced to stop drinking is chimerical; but they could be placed under such improved paying and working conditions as would make them desire to drink less.

All that fairly could be done would be to induce them to see the great harmfulness of excessive indulgence both to themselves and to those dependent on them.

Once the normal man understood that his acts were prejudicial to his interests, he would modify, if he did not wholly suppress, those acts. 


\section{CHAPTER V}

THE INCREASE IN DRUG ADDICTS

A Government which permits eruelty to many of its citizens, in the form of over work and underpay, must not deny them the solace of after stimulation, or of partial narcotization, to procure rest. If the government should deny them that solace, it would subject them to the dangerous temptation of seeking substitute drugs, a hundred times more destructive than were those to which they had become accustomed.

In the prohibition states drug taking has become common. In Maine drinks that look and taste like beer, and are very popular, are drugged with ether; and there a concentrated concoction known as the ether cocktail, is now the favorite "knocker-out."

Assistant District Attorney Unger declared recently, at the New York City Hall, before a legislative committee, seeking information upon which to base new legislation, that there were 200,000 drug addicts in the State of New York; that this number was greater than it had ever been; that it comprised a large number of children; and that the evil was increasing daily. Mr. Unger said, also, that the Tombs physicians alone had handled 12,000 cases. He suggested that it was a mistake to make the possessor 
of drugs a criminal, since that prevented him, through fear, from asking for treatment.

Dr. Ernest C. Bishop, who had studied the subject in State institutions, supplemented Mr. Unger's remarks by asserting that there were at present, in the Workhouse, "swarms of youngsters in their 'teens who are drug victims."

Dr. Bishop added that, "despite the new laws, there are more drugs, principally heroin (a derivative of morphine), passing through illegitimate channels than ever before, and that doctors, lawyers, ministers and clerks out of number were drug addicts." He urged great care, however, in the drafting of legislation, "to shut off these men suddenly."

And still more of this horror. Dr. Charles F. Stokes, Medical Director of the Board of Inebriety, in charge of the City Farm Colony, of Warwick, for the treatment of inebriates and drug victims, stated, at a recent meeting of the City Club, that there were fully 500,000 drug habitués in the United States, possibly $1,000,000$; and that 80 per cent. of them were heroin "snuffers."

The Committee of Fifty found that there had been in all the prohibition states of this country "abnormal increases in the consumption of patent medicines, containing alcohol."

In Norwegian prohibition districts they discovered that ether and perfume drinking had become common, and that even hair-oil was resorted to by the desperate.

In Germany, the following figures, which the Committee presents, show, without need of comment, the 
enormous increase in the import of opium, since the anti-alcohol agitation:

In $1907,29,200 \mathrm{~kg}$.; in $1908,54,200 \mathrm{~kg}$.; and in $1909,73,400 \mathrm{~kg}$. Later figures are not available; but the steady increase, from 1907 to 1909 , is sufficiently significant.

The foregoing statements are what we should expect would follow from a partial suppression of alcohol. Men and women worry; they have cares; they are more or less afflicted with disease, and they have frequent-bitter disappointments. If alcohol is not available, there are other drugs that induce forgetfulness; and it is hardly surprising that men should turn to them.

Thus Temptation paves the way to Perdition. 


\section{CHAPTER VI}

NATIONAL PROHIBITION UNJUST TO. THE INDIVIDUAL

So long as the world remains imperfect, there will be trouble. But have not the authorities enough to do, in suppressing crimes and in enforcing necessary laws, without concerning themselves with private individual interests?

Every individual, under ordinary conditions, has the right to live his life as he pleases, provided he does not unduly interfere with, or injure, his neighbor. But if the government can tell him what he shall drink, it can assume further rights, as has been said before, and tell him whether or not he may smoke, what and how much he may eat, and even what he must wear.

The Government might also intrude itself into the individual's private intellectual pursuits. Thus, if he were a student and writer, or an artist, it might decide that his work was mediocre, and that he would better be engaged in some work more useful and beneficial to himself and mankind generally-might make him work a specified number of hours daily in some government plant, for example.

Really, no one can think for the intelligent man nearly so well as he can think for himself. The brain of such a man is impressionable. He learns by his 
experiences and his observations, and thus comes to know the mode of life best suited to his individuality. He knows the kinds of foods and the kinds of drinks, which best agree with him, just as he knows the particular profession best suited to his mental capability; and he knows those purely personal things better than any other man, be he king, president, governor, mayor, congressman, senator, or reformer, knows them.

Hence, the utter absurdity of any person, or persons, in authority, telling that normal experienced man that he shall not drink such and such beverages, which he likes, which he knows, by their repeated effects upon himself, do not harm him, but which, as he firmly believes, do him good. If he is mistaken, he suffers the consequences; but that is his affair.

I, myself, have found that I can not drink lemonade, without some gastric distress. Nor do the socalled soft drinks, such as soda water with syrups, sarsaparilla, ginger ale, etc., agree well with me. Again, many persons, among them myself, can not drink sweet milk, without becoming upset and constipated.

On the other hand, there are those who find that, of all drinks, new ale, or light beer, is, for them, the most agreeable and wholesome.

And yet, no man's private right to drink ale or beer, they being occasionally intoxicating in large quantity, extends to the point that he may so stupefy himself, by means of either, that he makes of himself a common nuisance, and thus brings harm upon himself, his family, and his friends. 
Habitual drunkenness is a grave evil, and, as such, should be fought; not, however, with exaggerated, false and misleading statements, but by drastic applications of the laws we already have covering such cases. All confirmed inebriates, being more or less deficient and degenerate, should be at least restrained, if they can not be cured.

It is axiomatic that we have the right to interfere with him only who interferes with us. The thief, the murderer, the confirmed alcoholic, the drunk and disorderly roustabout, should be made war upon, restrained and constrained; but we have no right, by any law of God or man, to shackle the liberty of the unoffending citizen, who drinks moderately for sociability, or for his health's sake, and, at times, to relax the never ceasing strain to live; or who chooses to smoke occasionally to soothe nerves irritated by the stress of trials impossible to avoid.

In so far as the laboring classes are concerned, if you take away the laborer's glass of beer, you deprive him of food. Not that the beer, though nourishing, is sufficient food for him. It is not. But the working man goes into a decent saloon, and with his glass of beer, costing only five cents, he may have crackers and good cheese, bologna sausage with bread, and, not infrequently, hot soup, or a nutritious beef stew; all those excellent foods being free for the taking.

Moreover, any unprejudiced observer will affirm that the average workman is a normal individual who rarely drinks to excess. He will drink perhaps two 
glasses of beer, and those, with the generous "free lunch" to which he usually helps himself, constitute a satisfying, cheap and nourishing meal.

Would Prohibitionists, then, to satisfy their peculiar obsession, rob that vast army of normal men, who outnumber hugely the abnormal, that is to say, the occasional drunken loafers, of their daily food and refreshment? It seems that they would.

Free American citizens have believed heretofore that they knew what was good for them. That some do not; that a great many do not, is conceded. Yet when individuals transgress, whether by inebriety, or by more serious offences, those units only, and not the masses, should be punished.

Any mature man, who drinks habitually to excess, is abnormal ; and, often, he is more troublesome and embarrassing to the authorities than are more degenerate offenders.

Occasionally a confirmed alcoholic can be cured; more often, he can not. In any event, pending his possible reformation, he should be treated like any other defective; humanely and charitably, in his own home, if harmless ; firmly and correctively, in an institution, or on a farm, if dangerous.

The great statistical discovery of the Prohibitionists, that the children of drunkards are more likely to be defective than are the children of abstainers, is merely their whimsical way of saying that children born to the abnormal are more frequently abnormal than are children born to the normal.

Of course! Certainly!! The surprising part, be- 


\section{THE WHOLE TRUTH ABOUT ALCOHOL}

ing not the statement of the fact, but the fact of the statement.

Alcohol does not ruin men-men disgrace alcohol. Alcohol does not produce deficiency; but original deficiency seizes upon alcohol, and abuses, instead of uses, it, thereby perhaps increasing the original deficiency.

The abuse of alcohol is, ipso facto, a manifestation of deficiency.

The habitual drunkard could be saved, only if his defectiveness could be modified. But simply damming his desires in the drink channel would not dry up the source emanating from the defective brain. If that were done, however, the defective would seek other outlets for self-gratification. Once the manufacture, sale and importation of all alcoholic beverages should be prohibited, and it would be found necessary to put likewise under the Federal ban all narcotic drugs and all medicines containing the least alcohol, including those required for the therapeutic practice of medicine.

Why? We answered that question when we told of the extraordinary spread of patent-medicine drinking, and of drug addiction in prohibition and other states, despite the law and informing, but uninformed reformers.

Extreme propaganda of any kind is unwise; but to shut off absolutely from human individual consumption every kind of alcoholic beverage, including ale, beer, and stout, considered by physicians of the highest standing to be the greatest lactogogues for nursing mothers known, would be sheer insanity. 
A Latin proverb, constantly proved true by human experience, says : Medio tutissimus ibis. ${ }^{1}$

Reformers and other extremists, who have no faith in Nature, should learn that proverb, and apply its teaching.

To call professional Prohibitionists, Abstainers, would be to compliment them too highly. Abstainers mind their own business. An abstainer does not drink, because he does not wish to. That is his affair. A temperate man drinks moderately, because he does wish to. That is his affair. No more reason is there for an abstainer to forbid a moderate drinker to drink, than for a drinker to insist that an abstainer drink also. Each has the equal right to do, within reason, what he pleases. For, there are moderate drinkers, who believe as firmly in the healthfulness of their habit, as do the abstainers in the healthfulness of their abstinence.

If "Reformers" would use a tithe of their extraordinary energy to advance their own interest, and let ordinary individuals alone, the world would be happier; and a happier world would be healthier.

A world without alcohol and tobacco-for, tobacco would go next-would mean that instead of, as now, a few thousand thin-armed, narrow-chested, palefaced, non-smokers, teetotalers and dyspeptic vegetarians, afraid to take a deep breath lest they be wafted to Heaven, there would be millions such.

Besides, I ask the reader, would you be amiable and nice if, when you came home dog-tired, you could

1 In the middle course lies safety. 
find no claret, beer or even a light wine to cheer and comfort you? And if, after a drinkless meal, you had snuggled yourself into an easy chair, your attentive spouse could not fetch you a cigar, or light your pipe-that form of poisoning depending upon the robustness of your income-would you, or could you be happy thus?

A few lions roaring loudly will drown the feebler grunts of the thousands of other lions, quite as powerful, but not nearly so noisy. The loud lions, however, inevitably occupy the center of the stage.

We read a great deal nowadays about the ravages of alcohol in books, so-called, but which are really only compilations of the "knocks" which have been. conscientiously and constantly administered to our most popular beverage for the past hundred years. But that which we rarely hear is what we have termed the whole truth; for that, to the tyrannical sects fast overriding this country, would be too embarrassing.

Yet soon, the more celebrated physicians and scientists, hitherto silent, will speak with no uncertain voice, but temperately, authoritatively, and convincingly; their language having the more weight, when the great public contrasts it with the intemperate and absurd claims made by the Anti-Alcoholists.

They will say, among other things, that alcohol is, at times, the most valuable stimulant known to medicine; and that, when intelligently used, it is often a prime necessity for maintaining the health and happiness of the major part of normal mankind. 
Recollect, too, that the sane scientists, though not noisy, greatly outnumber the blatant pseudo-scientists connected with the "great" Anti-Alcohol Movement. 


\section{CHAPTER VII}

THE DANGER OF HABITUAL LIQUOR DRINKING

I wouLd now state plainly that I am unalterably opposed to habitual liquor drinking, unless in strict moderation. In beer there is only three or four per cent. of alcohol; in ale, from five to eight per cent.; in claret and champagne, about ten per cent.; whereas in gin, rum, whiskey, brandy, absinthe and vodka, the habit-forming drinks par excellence, there are, in the order named, about thirty, fifty, fifty-five, fifty, sixty, and sixty-five per cent.

Now, considering those percentages comparatively, we readily see the far greater danger of contracting chronic alcoholism from the stronger, than from the much milder drinks, such as beer.

In all my experience I can affirm that I have never seen an habitual drunkard, or even a steady "tippler," who did not indulge mostly in strong drink, usually whiskey. I have heard of beer, ale and "light"' wine drunkards, but I have never seen any such, and I do not believe they exist. Some irreclaimable "sots" assert that they drink "only beer," but careful watching will prove that they do not tell the truth.

To accustom one's self to repeated powerful stimu38 
lations of any strongly alcoholic liquor is suicidal; for, after a time, the healthy organism, through gradual adaptation, learns to lean, and to depend upon, those stimulations. The confirmed whiskey drinker, for example, feels " shaky" in the morning when he gets up; his hands tremble and can be steadied only by his customary potion.

Not so, however, is it with the ale or beer drinker; the trifling amount of alcohol in the beer-three per cent., as contrasted with whiskey's fifty-five per cent. -being just sufficient to stimulate him pleasantly, lighten his cares, lessen his worries, sharpen his appetite, and aid his digestion.

Of course, the remarks relative to whiskey drinking apply to those only who drink whiskey habitually to excess. Rightly used, whiskey is a good tonic, and, often an excellent medicine. But one can not drink whiskey as one drinks beer. Whiskey, owing to its high alcoholic content, is dangerous, and may form a habit; beer never does.

I believe I am not biased, and I wish it to be clearly understood that, while I favor moderate drinking as promoting a healthful and happy life, I am opposed to excess, and particularly to an excessive indulgence in liquor.

The case of Italy shows how strong drink will "get" a nation which had been temperate. So long as the Italians remained a wine-drinking people they were reputed to be among the most temperate in Europe, notwithstanding the fact that the figures showing their annual consumption of wines were high; and 
neither in Spain nor in Portugal had the habitual use of natural wines produced alcoholism with its brood of evils. But, when returning emigrants from the United States and the Argentine introduced a few years ago the whiskey habit into those afore-named countries, their governments were compelled to enact laws to curb the fast-growing traffic in spirits. In Italy, in 1913, a law was adopted, becoming effective on January 1, 1915, providing, among other things, that no drinks containing more than twenty-one per cent. of alcohol may be sold without a special license, and their sale on Sundays, holidays and the days preceding election, was absolutely forbidden. No restrictions, however, were applied to the lighter drinks.

Morphine is, as we all know, a powerful narcotic; tobacco is also a narcotic, but the latter, being extremely mild in its action, is comparatively harmless, is comforting and soothing, and anything "soothing," in our constantly ruffled existence, is a not inconsiderable promoter of health.

There is everything in degree. Because alcohol, in large quantity, is poisonous, is no proof that, in small quantity, it is not beneficial; for we know that all the foods are poisons, in immoderate quantities.

It is a moot question, just now, in the minds of the brightest scientists, whether excessive meat-eating is not more prejudicial to health and long life, than is even rather heavy drinking.

We shall have more to say about the poisons contained in foods later on.

For the sake of completeness, we must say a word 
about the dipsomaniac. He differs from the tippler, in that he imbibes enormous amounts of alcohol periodically, and not comparatively small amounts daily. The dipsomaniac's "sprees" may end, after a time, either in alcoholic insanity, or in delirium tremens. The periodical cravings of the dipsomaniac are said to be irresistible. 


\section{CHAPTER VIII}

THE WEBB-KENYON ACT AND ITS PROBABLE CONSEQUENCES

RECENTLY an important decision was rendered by the United States Supreme Court, which the New York World commented upon, editorially, as putting "a doubie set of teeth into the prohibition laws of all the 'dry' States."

The decision affirmed the constitutionality of the Webb-Kenyon act, designed to prevent the importation of any alcoholic beverage into any prohibition state that specifically forbade such importation.

As a consequence, dry states may, hereafter, remain really dry; all inhabitants of such states being now forbidden by Federal, as well as by State, law, to obtain alcoholic liquors.

Previous to the above decision, the Interstate laws over-rode the state laws, by permitting any one living in a prohibition state to obtain all the alcoholic liquor he wished, by importing it directly from a "wet" state, whether the dry state forbade such importation or not.

Drinking, therefore, instead of being decreased in the so-called dry states, was, in many cases, actually 
increased, owing to certain of their citizens importing great quantities of liquors, probably to be prepared for "a rainy day."

Nor was such an untoward result surprising, seeing that most men are likely to drink more from a superabundant supply at hand, than they would had they to go out to get it.

Now that none of the citizens of the "fortunate" dry states will be able longer to circumvent their own legislation, it will be interesting to observe the consequences of drastic State Prohibition. Will some, in those henceforth arid states, become desperate and resort to dangerous and destructive drugs, until a popular clamor arises for the restoration of alcohol; or will all quietly acquiesce and continue to lead sober, righteous and godly lives?

Doubtless one effect will be to unclasp the hands of hypocrites, and bring their eyes back to earth; for, no longer able to reform their fellow men, without at the same time reforming themselves, they will believe that a little liquor is not so very harmful to their brothers, after all. Indeed, it would not be surprising to see a "dry" storm that might end in drenching most of the country again.

Although the aforementioned momentous decision of our highest court was received with joyful acclamations by Prohibitionists far and wide, it may prove a boomerang, as there is no more effective way of destroying a bad law than actually to enforce it.

Moreover, when the question of National Prohibition again presents itself before Congress, that august 


\section{THE WHOLE TRUTH ABOUT ALCOHOL}

body may decline to consider it, on the ground that all the States having now plenary power to deal with their own liquor problems, there exists no need for further Federal interference. 


\section{CHAPTER IX}

\section{WOULD PRIVATE DISTILLATION FOLLOW NATIONAL PROHIBITION ?}

ONE untoward result, more disastrous and far-reaching than any which has followed State Prohibition, might follow a country-wide prohibition, I refer now neither to an increase in drug addicts, nor to importations of alcohol sub rosa; I refer to the danger that millions of individuals, continuing to crave alcohol, would learn how to manufacture their own drinks-a private industry, which all the governments in the world would be powerless to suppress.

All will grant that a higher power than a State or a Federal law is required to change human nature; and that if men want alcohol, and can not get it, they will make it.

How could they make it? Easily; but most easily they could make a poisonous, distilled, fusel-oil concoction. All the "machinery" required for a complete domestic distillery would be a kitchen stovewith a good fire in it-a tin tube, a bucket of water, a tea-kettle, any fermented fruit or grain, and a can, at the end of the tube, to catch the concentrated distillation.

Look at the record of Sweden when the household 45 
manufacture of spirits was rife. The consumption of spirits rose to extraordinary proportions and with terrible effects. "The very marrow of the nation was sapped; moral and physical degradation were everywhere, and all those grim legions of evils that ever range themselves under the banner of intemperance took possession of the land." It was officially recorded that the amount of drunkenness at that time was almost unparalleled; and one chronicler added: "The like of which history scarcely records."

Now, if such was the case in Sweden, the amount of debauchery that would ensue in such an immense country as this, were cheap liquors manufactured in but one home in every fifty, would be inconceivably horrible.

Children would, in all probability, drink as freely of the abominable stuff as would adults; and, as a consequence, their stunted bodies and blighted brains would present a problem to our government infinitely more difficult of solution than the comparatively simple present-day problem of occasional adult drunkenness, or the still rarer one of chronic inebriety.

If any one believe that here such a situation would not be tolerated, the answer would be that what many millions of men want, they will get one way or another. Besides, the magnitude, not to say the impossibility, of the task of preventing by law the manufacture of any distilled concoction, in all the private homes, covering the entire United States, is so selfevident as to require only mention. 
Naturally, under such conditions, drinking would increase to an extent never before known, as home manufacture of alcoholic liquors would not only greatly augment the supply, but would also much lessen the cost.

The temptation to drink to excess would, consequently, be vastly increased; and, besides, ales and beers being more difficult to make than the distilled liquors, the latter drinks, containing probably sixty or seventy per cent. of alcohol, would be preferred to the former.

The gravity of a general sudden change from the lighter to the stronger drinks can be partially grasped when we consider that only the stronger drinks are the habit-forming ones.

As has been mentioned before, the effects of repeated doses of whiskey are very different from the effects of a few glasses of beer. Indeed, while the latter wholesome beverage, when used moderately as an adjuvant to vigorous muscular exercise, may make a man out of a weakling, the former pernicious habit will, in time, sap the strength and stamina of the strongest.

Invariably, the chronic hopeless drunkard, the poor physical derelict, the favorite frightful example to careless youth, is a whiskey, brandy, absinthe, or cocktail drinker.

I repeat that never does beer, ale, or any of the lighter wines, make a drunkard. When drinkers of the lighter beverages go "down and out," as some- 


\section{THE WHOLE TRUTH ABOUT ALCOHOL}

times happens, it is because they have "switched" to the always dangerous spirits; - the fault in those cases being in the brain which can not remain satisfied with a normal sufficiency. 


\section{CHAPTER X}

THE NEED OF STRICT ENFORCEMENT OF EXISTING LIQUOR LAWS

Not more laws, but a stricter enforcement of existing laws, would lighten the liquor evil immensely. There are now many towns and villages scattered throughout the country, which are not dry, but where, owing to strict enforcement of the liquor laws, drunkenness is at least not in evidence.

The Committee of Fifty (Economic Aspects of the Liquor Problem), make some very interesting observations concerning the habits of the populations living in the Stock Yards Districts of Chicago. They state: "Our very competent investigator describes the Stock Yards District of Chicago in the following words :

"Probably 80 per cent. of the families registered are dependent in some way upon the United Stock Yards and affiliated packing-houses. They are practically all of resident families. Very few homeless men ever apply [for charity] at the office."

The population is mixed and the death-rate is high; but the latter is owing to poor sanitation, and to a constant cloud of smoke hanging over the neighborhood, which irritates the throat and lungs. 
"The wage system at the Yards is such as to demoralize character. All pay is by the hour, and all the plants have a capacity far beyond their needs, so that it is seldom necessary to keep stock any length of time. Hence work is extremely irregular, and almost always less than full time. Many families earn less than six dollars a week the year round.... Again, many firms pay in checks, which can be cashed, ordinarily, only in saloons. Every entrance to the Yard is surrounded by saloons, and it is customary for the men to come out and sit around the saloons on benches, provided for the purpose, and eat their dinners. In the winter the saloons provide rooms with benches and tables, where the lunches may be eaten. Hence the pail of beer is an almost invariable accompaniment of the meal.

"Taking the District as a whole, I should not call it by any means an intemperate one. Drunken men are very seldom seen, and a very large percentage of the drinking is from 'growlers.' (Italics mine.) There are few low grade dance halls-not more than four or five in the whole neighborhood-only one or two gambling dens, practically no houses of ill-fame, and no lodging houses, or like disreputable resorts. The entire territory, included in the above description, comprises about five square miles, with about 150,000 inhabitants."

In other places mentioned in the report, intemperance was more rampant, where employment was irregular, and saloons were many; but this was shown to be due to a lax enforcement of the liquor laws, in 
regard to closing hours, and the sale of liquor to minors.

In still other places, showing a more than average amount of intemperance, Pawtucket, R. I., being one, it was learned that the Associated Charities of Pawtucket dispersed alms directly to the needy from its own funds.

Naturally such unthinking philanthropy proved singularly alluring to the unworthy poor; so, to Pawtucket and its adjoining town, Little Falls, shuffled hundreds of the indolent-beggars, tramps and topers.

The investigations of the Committee of Fifty of the comparative incidence of inebriety in the large cities, disclosed the fact that foreigners were more given to intemperance than were the natives. Hence, the proposed legislation to keep all alcoholic drinks away from every one, would especially affect foreigners-information that should please our altruistic reformers. 


\section{CHAPTER XI}

\section{NATIONAL DECEIT AFTER NATIONAL PROHIBITION?}

Finaluy, after National Prohibition, think of the millions of normal men and women who would cruelly miss the cup that soothed their irritations, comforted their sorrows, and lightened their misfortunes; and many would feel the absence of their panacea to be prejudicial to their health. Think you that a demand so widespread would not be supplied?

Suppose that even a majority of all adult citizens of these United States should vote for forced universal abstinence, there would yet remain a huge minority that had voted passionately against it.

Now what would this minority, consisting of many millions, do? Probably before resorting to substitute drugs, and before efforts were made privately to manufacture liquor, there would ensue a general civic deceit, which would attain colossal proportions, and which would eventuate, were it only partially successful, in such an universal contempt of law, as to constitute near-anarchy.

Moonshiners, boot-leggers, and panderers of all kinds to the nearly ubiquitous demand for alcohol would arise in all parts of this immense country. While the government might suppress some, a great number would remain which would not be reached.

Let us review briefly the influence the steady ac- 
quisition of "dry" territory by the prohibitionists, from 1896 to 1906, had upon the drinking habits of the people of this country. A decrease in the consumption of spirits set in about 1860, and continued steadily until 1896. "After that a continuous rise took place, which by 1906 about doubled the visible consumption of spirits. This was not a fortuitous happening; but coincided with the large acquisition of dry territory between 1896 and 1906 . The demand for intoxicants showed no signs of diminishing in consequence, but it could not be supplied by malt beverages [comparatively harmless], which are not manufactured within dry territory (there are no moonshine breweries), and which are too bulky as a rule to be welcomed by the illicit trade. The rise in the consumption of spirits [the habit-forming drinks] since 1896 is thus one of the results of local and state prohibition." There has also been an "immense growth of illicit distillation which the Federal government seems unable to check, and which, according to official testimony, has been a concomitant to the enactment of prohibition in so large a portion of the South." 1

And what resulted in Russia, when the Czar suppressed the manufacture of vodka, shortly after the outbreak of the Great War? At first there was some ardor for the unaccustomed virtue of abstinence. And then-" What the government denied the people, it soon began to supply by illicit means. According to the reports of the Minister of Finance, during the six months following the prohibitive measures, revenue 1 Alcohol and Society, by John Koren. 


\section{THE WHOLE TRUTH ABOUT ALCOHOL}

officers discovered 1,825 secret distilleries [think of how many they did not discover!] manufacturing a special brand of whiskey known as kumuska; 160 distilleries fitted out with the most modern machinery for making vodka; 92 distilleries especially designed for filtering lacquer and varnish; and 60 distilleries engaged in filtering denatured alcohol." 1

"So insistent has been the demand for alcohol that substitutes in the form of denatured alcohol, eau de cologne, politura, and the like have been consumed in large quantities, despite their dangerous effects. From Kiev, Riga, Tambou, Penza, Simbirsk, Vilna, Nijny, Novgorod, Charkov Kursk, Moscow, Petrograd, and innumerable other places come reports of deaths and poisonings from these liquids. Many persons' sight has been impaired by drinking denatured and wood alcohol, varnish, and so forth. Dr. Novoselski, writing in the Ruski Vratch (Petrograd), cites the official returns of deaths from delirium tremens and remarks: 'Before prohibition the mortality figures varied and changed without definite regularity; after prohibition they show a regular and constant increase. As prohibition regulations became stricter and at last complete, the mortality from alcoholism increased!' He argues from the mortality statistics that substitutes for vodka 'are used not only by confirmed drunkards, but generally by those classes who before prohibition used to drink moderately.' The recent victims of alcoholism in Petrograd were 'persons of all ages and all occupations!'

1 Ryetch, Petrograd. 
"Such is the saddening answer to the well-intended prohibition of vodka, for which no substitute was offered. . . . There also come reports that the village folk are becoming addicted to gambling and that a passion for it is seizing the whole mass of peasantry." 1

At a public conference held lately in Petrograd, beers and wines were held to have a desirable effect on village life, and the ministry was requested to act accordingly. The Minister of Commerce has already recommended that the sale of beer and wine, containing not more than sixteen per cent. of alcohol, be permitted. ${ }^{2}$

No one but an Utopian dreamer could consider it practically possible to change suddenly and by force our almost universal drinking into complete abstinence. The mere fact that fanatical Prohibitionists believe in their power to do that permanently, is proof that their faculties are non-reasoning. Quite as impossible would it be to force the entire world instantly to stop smoking.

It is well-known that, after tobacco-smoking had been introduced into England by Sir Walter Raleigh, who had learned the practice from the Indians of the newly-discovered continent of America, the habit spread like air introduced into a vacuum.

Then came the inevitable denouncers of the practice. To smoke tobacco meant to smoke in another nether world later. The habit was described as extravagant, filthy, wasteful, senseless and injurious;

1 Alcohol and Society, by John Koren.

2 Birzhevya Vyedomosty, Petrograd. 


\section{THE WHOLE TRUTH ABOUT ALCOHOL}

yet it spread, until now more tobacco is consumed yearly, by smoking and chewing, than ever before in the earth's history.

Finally-to return to alcohol-even should it be possible so to work upon the passions of the multitude that a majority voted unthinkingly for the banishment of alcohol, there would succeed the inevitable reaction. After the "victory," the pressure exerted by fanatical misrepresentation and exaggerated statement would be withdrawn. Sanity would then reassert itself, and the American people would demand the re-establishment of their age-old right to drink how and what they liked. 


\section{CHAPTER XII}

LET THE DRINK PROBLEM TAKE CARE OF ITSELF

As a matter of fact, the drink problem, with reasonable restrictions, would take care of itself, were it allowed to do so. "Live, and let live" is an old adage, apparently forgotten by the age we live in. Reformers, usually a nuisance, are fast becoming a menace to individual rights and liberties.

Even an obscure dentist, a Dr. Pease, succeeded, by sheer nerve, bombast and whimpering, in securing new laws, and in amplifying existing ones, against smoking. And this specimen of professional disturber and trouble-maker, to attain his meddlesome ends, himself wrote an eulogistic letter about himself, and signed it, with the greatest effrontery, "Annette Hazelton," a creature found afterward to exist only in the doctor's imagination! But Dr. Pease does not smoke, and therefore wishes no one else to smoke.

I have mentioned the above to illustrate the power that one screaming jackal can sometimes exercise over the comfort and happiness of millions of superior, and hence quieter, animals.

The peculiar psychology of cranks, fanatics, and certain reformers, is discussed at length in another part of this work. 
Railroad heads, superintendents of factories, and managers generally of large numbers of men, encourage their employés not to drink, and discharge those who indulge to excess during working hours. Some, indeed, will not tolerate even the moderate drinker.

Employers are within their rights in demanding strict sobriety on the part of their workmen; it being proper that they should conduct their business as they see fit. Doubtless they have found it easier to enforce abstinence, than to keep large bodies of men, many of whom are employed temporarily, within moderate limits. But all that is their business, and no one else's-not even the government's.

Now, if it is not the business of the government when men choose not to drink; neither is it the government's business when men do drink, unless the government employs those men.

Employers and employés are free men, not slaves, prisoners, paupers, lunaties, nor degenerates; and, as free men, they have the right to eat, drink and dress, as they, or the men for whom they voluntarily work, prescribe-provided that, in so doing, they commit no outrage upon public decency or decorum.

I contend that the above simple reasoning is sound; and that, even though a majority of the population of this country should vote for Federal interference in the matter of moderate drinking, such interference would not therefore be justified, but would be rank tyranny to the millions of the minority opposed to it.

I would also say here that I consider State Pro- 
hibition, and even local option, an injustice to thousands; for no sumptuary legislation, affecting, as it does, men's private habits, could be decided properly at the polls. 


\section{CHAPTER XIII}

THE WORKINGMAN SANS DRINKING AND SMOKING

AN ingenious argument of reformers, which is a fallacy on its face, is that of computing how much the immense army of labor spends annually upon drink and tobacco, and then suggesting that this "enormous" sum be set aside for use as a defense fund for strike purposes. At the end of a few years, it is pointed out, if those men had saved all their drink-and smoke-money, they could then demand shorter working days and more pay, with the threat that, were their demands not granted, they would quit work in a body, and live for an indefinite time in luxurious idleness.

But the capitalists, aver these fallacious reasoners, would immediately "give in," knowing that their workers were independent, because of their ample supply of funds.

Than that could anything be more ridiculous? In the first place, if all the workers should absolutely stop drinking and smoking, and should put aside the sums which they would have spent for those "foolish" purposes, the amount saved per man, "after a few years," would not suffice to maintain his family and himself for more than a few weeks while he remained idle, the average workingman expending no more than about one dollar a week on his "drinks" and 
"smokes." Of course, the hypothetical aggregate sum would be large; but when that was being used to support an immense number of idle men and their families, it would soon dwindle. Hence the capitalists could stand their workmen's brief holiday better than the workmen could.

But does any sane man believe that the workingmen would do any such thing? Even in the event of their stopping, to a man, both smoking and drinking, would each one, or a bare majority, willingly contribute to a visionary fund all the money which they had formerly spent gladly for needed pleasure and relaxation? Certainly they would not; and every Prohibitionist knows they would not.

It is an economic mistake to assume that money not spent for liquor would be saved. Such an assumption credits the poor with more forethought and prudence than they possess. But money diverted from liquor might be used for gambling purposes, or otherwise wasted.

Besides, one could argue in the same way about any saving. For example, there are many luxuries, other than drinking and smoking, which it would be easier and pleasanter to do without. One need not go to a picture show; nor are visits to the theatre essential. One could live without butter, or without eggs, or without meat; and if all the working people should eschew any one of those luxuries, and should put the money thus ascetically saved into a fund, they might be able, after a lapse of years, to demand better wages, or to buy so much stock in the concerns employing 
them, as virtually to own them, etc. But everyone knows all that; and, though the reasoning is specious, it is elementary, foolishly visionary, and wholly impracticable.

Among all large bodies of men a certain percentage save; but there has yet to be devised a scheme which would persuade or force all to save.

Again, what would the workingman do with his spare time, his periods of ease, if he could neither smoke his pipe, nor drink a glass of beer with a comrade? We do not know.

He might gamble, which would be more expensive and more demoralizing than drinking. He might acquire some drug habit, which would kill him more quickly and unpleasantly than alcohol. $\mathrm{He}$ might visit cheap picture shows; but those would pall upon him. Some, of course, after their day's work, would go home to their wives and children; but many workingmen do that now, and to change those, who had found the social atmosphere of saloons more congenial than the constraint felt in their "homes," into "family" men, would require more than the mere closing of saloons. Such workmen would find other and probably worse diversions elsewhere.

Would the workingman, then, be any better off if deprived of the saloon? We must say that we doubt it. Men who work with their hands-and such labor is honest and useful-are not as a rule, interested in art, in literature, or in science. Perhaps they would become so. But that would not help us, nor them either; for another question would arise: Who 
would do the actual work of the world-scientists, physicians, men in political preferments, college professors, and millionaire capitalists? Hardly-seeing that men, able to work effectively with their brains, would find coarse and practically automatic manual labor little to their liking. Yet has the arduous work of the world to be done, and some must do it.

And so, why not let the honest workingmen employ those talents, with which they have been endowed, to the best advantage?

Meddlesomeness in men's private affairs, and even with their private vices, if reformers will so call drinking and smoking, can end only in disaster. 


\section{CHAPTER XIV}

THE WORKINGMAN'S CLUB-THE SALOON

Aт least something should be said for the much abused saloon. The saloon has been called the workingman's club. Is it? Let us see.

That some saloons are low, even vile, it would be useless to deny. But such attract the vile, never the honest, among the poor. Most saloons, however, are not vile; for, the majority of men not being vile, many vile saloons would fail, through a lack of patronage.

There are three main types: The low-class, the plain, "decent" kind, and the high-class saloon. All are modifications of rich men's clubs.

In the club, the bar is not in evidence; but there is much evidence of the bar. Men sit in lounging rooms, in ultra-comfortable chairs, chatting with fellow members, and ever and anon ordering their favorite drinks. Tiring of talk, they may repair to the grill-room, if hungry; or to the billiard room, if they wish amusement. Besides, they have a library to stimulate the mind, and a gymnasium in which to exercise the body.

On the other hand, the honest workingman knows no club, except the menacing one held by some self-constituted reformer. His "place" consists of a clean room, plainly furnished with tables and chairs, and in which is a bar. Newspapers and back numbers of 
magazines are often thrown upon the tables. But here he may chat with a friend, smoke his pipe, and drink a glass of beer. If hungry, he may "dip" into the free lunch. Should he desire amusement, he may throw dice with the bar-keeper, or borrow a pack of cards from the same obliging functionary, and play seven-up or pinochle with a select coterie of his pals. Or, in an adjoining room, there may be a pool-table, with an always "open" game. In addition, some saloons contain pianos, more or less cracked, victrolas, or phonographs. The gymnasium, the workingman can dispense with, as, having to work hard for his living, he feels little need of exercise.-Not much difference in the two "clubs," after all.

"Decent" saloons-and most are that-so far from encouraging intoxication, discourage it. Not because saloon men are more moral than other men. They discourage intoxication for business reasons. Saloon keepers are philosophers in their way, and know human nature. They have discovered that more than ninety per cent. of their patrons are decent, temperate men, and that it pays to cater to the respectable element. Drunken men are noisy, quarrelsome and generally obnoxious. They are not wanted in saloons, because they annoy other patrons, and, consequently, hurt trade.

In support of the above assertions, which some may view as mere expressions of opinion upon my part, I can not do better than quote excerpts of the report of Mr. Ernest Carroll Moore, who, at the request of the Committee of Fifty, undertook a personal investiga- 
tion of conditions existing in the nineteenth ward of Chicago.

"That section covers an area of about eight-tenths of a square mile. Its population of 48,191 is made up of twenty-five or more nationalities ; the predominating ones being: Americans, 6,184; Germans, 6,721; Italians, 5,784; and Bohemians, 2,944. It is a workingman's district; its population being typical of unskilled labor in general. As to moral conditions, neither the extremes of vice, nor of virtue, are reached; while the general moral tone is rather healthful.

"There are about two hundred saloons in the ward, and, in perhaps no other large city, has the saloon enjoyed such a minimum of legal restrictions and maximum of liberty, within those restrictions, as in Chicago. These saloons were visited at various hours of the day and night. We [Mr. Moore and his associate investigators] did the things which other men do in the saloons. They were our loafing place, news centre, place for discussion, and common meeting ground; while the free lunch counter served in large part as the basis of food supply."

The summary of Mr. Moore's experience follows :

"In the first place, the saloons of the nineteenth ward do not stand for intemperance among their patrons. In visiting something over two hundred saloons in the ward, at various times of the night and day, I saw just three drunken men. Thus, the saloons, which have been the subject of this inquiry, do not 'trade in, or batten upon, intemperance.'

"As to the general character of the patrons of the 
saloon, it must be said unequivocally that it does not 'personify the vilest elements of modern civilization,' unless the modern civilization all about us in this locality be regarded as monotonously vile. There are, in all, but two saloons, known to the police and to the public at large as headquarters of gangs of thieves; and there is one that is a well-known assignation house. But it is as unfair to generalize, from such facts, that the saloon personifies such elements, as it would be to declare that the home personifies them; inasmuch as many more homes than saloons are contaminated by their presence. There is no saloon in the ward which is a house of prostitution, and no saloon which is a gambler's headquarters. There are certain saloons in other localities which personify such elements; but it is because the locality personifies them also. (Italics mine.) ...

"What is it one sees inside one of these saloons? Not a riotous company intent upon reducing itself to intoxication; but, instead, a well-behaved little group of men, who play cards together, read, smoke, and drink a glass of beer. In not a single one, of the many such groups observed, did drinking seem to be the most important thing. One can watch card games, in the Italian quarters, for hours, without seeing a single drink ordered. So, also, in Irish saloons, famous discussions are carried on, in which no drop of liquor figures. In the German and Bohemian districts a single glass of beer seems a sufficient stimulus for a prolonged period of meditation.

"Of 157 saloons, of whose inducements an accurate 
list was kept, 35 contained chairs and card tables; 92 offered lunch free; in 70 , patrons might find papers, and an opportunity to read them ; 58 contained pooltables; 3 offered the use of a piano or [an] organ; in 2 were well-equipped gymnasiums; and 1 offered the use of a hand-ball court free."

I have quoted the above report verbatim, because of the rarity of such an investigation being undertaken in so intimate and personal a way. Besides the intense human interest of the report, the facts and observations deduced appear to be unbiased, and, at the same time, fairly typical of saloons in general.

Many substitutes for the saloon have been tried and found wanting; possibly, because no man likes what someone thinks he ought to like, but only what he himself can not help liking. When some well-meaning uplifter tells a beer-drinker that coffee, tea, lemonade and sarsaparilla, are a great deal better than beer, the listener may smile indulgently, but he will continue to drink the beer, if he prefers it. The reformer's preferences will neither influence nor interest him.

To the workingman, the saloon exemplifies luxuries rarely present in his home, and not found in such profusion in other public places. The saloon, in winter, is warm and brilliantly lighted; in summer, it is cool and usually fairly clean; but, above all, the saloon is social; and the workingman, like every other human being, craves the society of his kind.

Nevertheless, the saloons in this country could undoubtedly be improved. First, let us ask, what is the 
good of the saloon? Evidently the social side; the bad, is the drinking. Ergo, to improve the saloon, there should be more sociability and less drinking. In France there are cafés, and in Germany, beer gardens-family places. Over there the drinking places are not in the same disrepute that they are here, and for obvious reasons. A man usually behaves himself and does not become intoxicated in a place where he takes, or could take, his wife and family. The presence of respectable married women exercises a wholesome restraint on drinking. If the saloon, particularly the low class ones, must go, why not replace them with larger and more commodious "gardens" similar to those abroad? It could be done; it would pay, and the whole country would be much benefited. There could also be many attractions added, besides drinking. Card tables, billiard and pool tables, bowling alleys, reading rooms, music, and even a room for dancing, would promote sociability and discourage immoderate drinking.

Such places would not be the failures that reformers' restaurants, coffee houses and temperance saloons have been, for the simple reason that men who frequent saloons do so because they do not like "soft stuff," and therefore when they are offered soft stuff, even with "trimmings," there is no appeal.

In the past, before high license, saloons were numerous, and many of them were vile. Then came the high-license system which, according to the reformers, was to be a long step toward the regeneration of mankind. The result of high license was, 
however, rather disappointing. True, it weeded out some hell-holes, facilitated supervision, eliminated many unsubstantial dealers, and thus elevated to some extent the tone of the trade. But high-license had other effects which were not so desirable. For example, it meant expense to the saloon keeper which he had to make up from the dear public in trade. He, therefore, in so far as he was able, pushed the sale of distilled liquors, they being more profitable than the malted drinks -indeed, dealers selling only the latter, in high-licensed places, led a precarious existence.

Yet the high-license system has accomplished good - good, however, that would be much better, were a uniform taxation not exacted. Tax the saloons, by all means; but do not tax all alike.

In Norway, Sweden and Denmark, beers containing not more than 2.8 per cent. of alcohol, by volume, are not taxed at all; the natural consequence being a great stimulation in their production and substitution for the strongly alcoholic drinks. In Norway, malt beverages, above 2.8 per cent., are taxed proportionally to their strength; but no beers, containing more than five and one-half per cent. of alcohol, may be manufactured.

"Physiologically," says John Koren, "there is a wide gulf between the possible injury from the ordinary use of pure light beers, and the indubitable damage to the individual as well as to society through a habitual indulgence in distilled spirits. The recent Alcohol Commission of Norway says on this point: 'At the outset it must be conceded that the danger to 
society from alcoholic drinks differs utterly according as their alcoholic strength is large or small. Furthermore, it seems clear that while the strongest of them -that is, whiskey-must be subjected to particularly severe regulations, the opposite is true of the weakest drinks of this sort. Quite on the contrary, the latter should be subjected to lenient regulations, since an increasing extension of their use will serve to replace the stronger beverages, and therefore, in the opinion of the majority, represents an essential means in the warfare against the abuse of alcoholic beverages.' ",

Were temperance advocates really such, they might get somewhere ; that is, they might encourage drinkers, by new tax regulations along the lines suggested above, to substitute the milder for the stronger beverages.

While intemperate temperance reformers will not take the hint, others with a ray of reason may. 


\section{CHAPTER XV}

\section{THE PSYCHOLOGY OF FANATICS}

Avid Prohibitionists class with anti-tobacco agitators, vegetarians, raw-food advocates, fruit-and-nut cranks, fresh-air fiends, etc.;-all being more or less abnormal. The food-faddist is usually dyspeptic; those who "must have" doors and windows wide open "no matter what," have often a consumptive tendency; denouncers of smoking "can't stand" tobacco; while the more rabid prohibitionists find drink almost irresistible to their weak wills.

Before portraying the peculiar psychology of the extreme anti-alcoholist, it will be interesting and additionally clarifying to discuss the psychic workings of other fanatics.

First, let us take the religious fanatic-not including, of course, the sane and sincere religionist. Scientifically considered, a close affinity exists between religion and eroticism; and, as a matter of fact, rabidly religious persons are usually erotic.

During adolescence, many young girls, naturally erotic, are brought up very strictly. They are taught that all erotic thoughts are sinful and must be suppressed; and that the discussion of sexual subjects is taboo. 
Being well-mannered young women, they learn to suppress their natural desires by a process of sublimation, or a relegation of their conscious, but forbidden, longings, to the realms of the subconscious. Later there ensues a struggle between the desires which have become subconscious, and the early training which has insisted that those desires be not expressed.

Now, ordinarily, the struggle results in a just mean being found, and, as a consequence, most women remain normal. But, occasionally, when either the suppressed desires are exceptionally strong, or the early training has been extraordinarily strict, what psychologists call the "purity complex" supervenes. Yet, even in the latter case, the struggle to repress desires, inculcated from the dawn of puberty to be disgraceful, continues.

The unhappy subject now strives to erect barriers to prevent her overwhelming desires, no longer subconscious, from finding expression. So, often, she embraces religion, with intense fervor, as a defense action; in short, to prevent satisfaction of her "libido," she becomes a religious fanatic.

If it be asked why religion, rather than something else, is seized upon for that purpose, the answer is that religion is most closely affiliated with eroticism.

The hysteria frequently manifested by religious cranks results from the contest between the longing to forget and the desire to act and procure gratification. Thus all "cranks" are more or less diseased, or, at least, are abnormal.

Hysteria has for its basis the unfulfilled desire. Its 


\section{THE WHOLE TRUTH ABOUT ALCOHOL}

symptoms are the manifestations of hyperactivities and overcompensations opposed to the powerful demands of Nature; for, when objectionable desires are deflected, they become manifest as violent prejudices.

Fanaticism is neither more nor less than hysterical conduct at its climax.

The danger of complete suppression of the natural instincts is well exemplified in girls educated in the seclusion of convents. There nothing sexual is breathed, or, supposedly, even thought. No male person, during the entire period of the inmates' adolescence, obtrudes either his physical or his psychical personality upon their feminine consciousness.

But the girls grow, and, at last, when their wings are sufficiently strong, they take their flight out into the wide world. Men are there; and, often, the convent-bred girl falls desperately in love with the first one she meets.

On the other hand, had the young woman, "standing with reluctant feet, where the brook and river meet," mixed with boys in girlhood, and with young men in early womanhood, she would not offer her sweet purity to any man, but only to some man,- - the man of her dreams. All which, however, is general. There are exceptions.

In this connection may be mentioned the commonlyknown fact that when youth is allowed light alcoholic beverages at the family table, there rarely occurs abnormal alcoholic craving after adult age.

Whatever is forbidden becomes mysterious; and mystery possesses always a subtle fascination. 
And here the psychology of love deserves passing notice.

Love may change to hatred, but never to indifference. If a man's wife leaves him ; and he follows and kills her ; the crime attests his overwhelming desire for her. If he had not loved her, he would have remained indifferently at home.

The reason for the metamorphosis (love becoming hatred) is that, while extreme love gives extreme pleasure, a sudden desertion changes the extreme pleasure of being loved into the extreme pain of not being loved; the pain begetting the insane anger and hatred, exactly as the pleasure begat the love.

Some remarks of Dr. B. S. Talmey, writing in the New York Medical Journal, anent divers fanatics, will help us to understand the no less interesting psychology of the extreme prohibitionist, which we shall soon briefly discuss.

"The fanatic purist, who clamors the loudest against obscenity, and who would entirely eradicate nudity from this world is, in his nature, a sensualist. Beneath the pretensions, or rather beneath the honest desire for purity and sinlessness, lie very ordinary elements. ...

"He seeks freedom from the [subconscious] obscenity wish by losing himself in what he considers social service. The pseudo-virtuous indignation over the nude or obscene is only an outlet for his natural ardor for the obscene and the nude. In his eagerness to find a defense against his unconscious [subconscious] tendencies, his fantasy becomes twisted and 
distorted. Everything in life [to him] bears an obscene stamp. . . . His loud clamor against the sacrilegious evil of the representation of the [to him] obscene in literature and art, is only the defensive fence he has built around himself against his unconscious [subconscious] desires for the very things he is clamoring against."

Concerning the relentless feminine persecutors of the prostitute, Dr. Talmey says: "The turbulent zealot, the perverted morality hunter, who is shocked and hurt over the sins of the scarlet woman, and plumes herself upon her self-placed halo, and prides herself upon her superiority, has in her makeup certain traits of her she hates so relentlessly. She is by nature a varietist. Under different circumstances she herself would have become a priestess of Venus Vulgivaga. ... The symbolic reminiscence of the cravings toward variety [possessed in her early life] determines her sanctimonious behavior. The persecuting zeal of the reformer represents nothing but the defense action against the symbolical reminiscence."

Of the anti-vivisectionist, Dr. Talmey observes: "The fanatic anti-vivisectionist harbors in his nature certain features [traits] of the sadist. $\mathrm{He}$ is by nature cruel. But, early in his youth, he received the mandates of parents and teachers to be kind to animals. These teachings [afterward] come into conflict with the cruel tendencies in his character."

The result, in that particular fanatic's case, is that the cruel tendencies, checked by the early human 
teachings, are repressed, but appear later as "symbolical reminiscences" (imagined delights of cruelty), which latter determine the fanatic ravings against vivisection; those ravings being only defense actions against his subconscious cruelty.

"He is cruel enough," Dr. Talmey adds, "to sacrifice millions of sick children, if only his beloved rabbits are safe."

The fanatic anti-semite, the half-crazy socialist, and the long-haired, somber anarchist, receive no better treatment from Dr. Talmey.

Those who may consider the point of view of the great psychopathologist extreme, should remember that he is not arraigning the few sincere uplifters of mankind, but only the ever-increasing number of fanatics, who, as he believes, are abnormal and perverted.

There have been eminent, but bitter, opponents of noise, who were themselves noisy. For example, biographical history records that Thomas Carlyle hated noise so thoroughly that he had his studio built sound-proof and situated in one of the most secluded spots in Chelsea; and the diary of his wife, Jane Wels, is filled with entries describing the torture she endured, because of her husband's rage and annoyance at noise. She said he continually harped upon the impossibility of thinking or of even existing in such noisy surroundings.

Yet, Carlyle himself was so loud a talker that he was a nuisance to his friends. Charles Darwin said of Carlyle, whom he met on the occasion of a visit he 
made to Herbert Spencer: "That unbearable man sat for three hours and talked to me continuously about the 'sacred force of silence!","

Carlyle, like a great many less prominent men, was so full of emotion himself, that he could not endure it in others. And here we see the basis of the reciprocal attraction of those opposite in temperament. The noisy, talkative man likes a quiet, sedate woman; and vice versa. So jealous are we of our own traits, that they seem insufferable in others.

John Stuart Mill, who was fanatical on calm and rest, and who was an arch-enemy of noise on almost all occasions, once hired a boy to beat a drum, in a room adjoining his, "to stimulate his thoughts."

Charles Dickens went so far as to edit a pamphlet, in 1864, containing all conceivable arguments against noise. But, although an implacable foe to noise, Dickens could not stay away from the clatter of London for more than a few weeks.

Really, noise is a measure of culture; the most cultivated being the quiet and refined.

Every faddist harbors in his subconsciousness a complex in opposition to his fad; his pretense of detestation of certain acts or habits being an exaggerated procedure to protect himself from what he secretly craves, but knows he would be better without.

The excited prohibitionist is an example of one defending himself desperately from the "drink complex." In his youth he received strict injunctions against the saloon, and the vice of drinking. But, unfortunately, through inheritance or for some other 
reason, he possesses an abnormal love of liquor. The resulting "drink complex" is the psychopathological state ensuing from the terrific struggle of the powerful alcoholic craving, on the one hand, and the severe commands against yielding to the craving, on the other.

To understand such a defective's agonizing state of mind, one must imagine the suffering produced by the conflict between a maddening desire to drink, and the powerful inhibitive moral training, reinforced by the realization of ultimate ruin if the desire wins.

Always present in the unfortunate's mind is the "symbolical reminiscence"; that is to say, the imagined gratification of his craving, to be followed by the unholy, and hence trebly desirable, delight of intoxication.

So, is it wonderful that such an one, afflicted with a secret and almost irresistible desire for alcohol, should either become a confirmed sot, or should seize upon fanatical prohibition as a last desperate defense action?

Question the man in the street who can not resist liquor, and he will tell you that he favors prohibition; in other words, he would protect himself, though the rest of the world suffer in consequence.

The New York Medical Journal, for December 2, 1916, remarks under Interclinical Notes: "Reformed drunkards and drug victims are always the most anxious that alcohol and narcotics shall be universally prohibited."

Jacob Miller, proprietor of the Hotel Hot Springs, 
Arkansas, while attending the National Hotel Men's Exposition, held at the Grand Central Palace, on November 23, 1916, related the following incident: "Not long ago sat in my hotel a party of men who, before they left the table for good-or it may have been for evil-disposed of 121-count 'em-121 quarts of whiskey and 1200 cigars. When they left us, those folks went over to Little Rock and cast votes which made our part of the state dry."

Small wonder that men weak enough to drink that amount of liquor at a sitting, should vote for prohibition-anything to protect them from their folly. But, were liquor the deadly poison we are assured it is, would any one of them have been able to cast a vote at all?

I ask the reader now, fairly, would not National Prohibition be unwise legislation in that it would be passed chiefly by defectives and for defectives; thus favoring subnormals above normals-nay, would such legislation be even sane? 


\section{CHAPTER XVI}

\section{ARE ABSTAINERS SUPERIOR?}

A RATHER interesting question, which I admit I can not answer positively is: Are abstainers, taking them en masse, and estimating their worth by their works, and not by laboratory experiments, superior to the army of moderate drinkers? Are abstainers superior mentally even to many immoderate drinkers; it being well-known that some of the most brilliant geniuses have been, unfortunately, over-addicted to alcohol? Unbiased statistics on that question would be interesting and illuminating.

Nervous persons, usually the more intelligent part of the population, are most likely to use alcohol, though not necessarily to excess; and it has by no means been proved by physicians, scientists, or even by the sapient insurance companies, that such persons would live longer and enjoy better health without alcohol.

It is almost a truism that the richer and more highly endowed physically and intellectually a country is, the greater is its consumption of alcohol.

In Finland and Norway, poor countries, alcohol consumption is lowest. "In Flanders, where all the pathological maxima are heaped up," says Vandervelde,-_"mortality, ignorance, criminality,- the con- 
sumption of spirits is much less than in the rich and industrial Wallony."

According to the United States Statistical Abstract for 1914, page 61, the average percentage of illiteracy in the eight Prohibition states-Georgia, Kansas, Maine, Mississippi, North Carolina, Oklahoma, Tennessee, and West Virginia-is 11.9 ; meaning that in those states about twelve out of every hundred citizens can not read or write. On the other hand, by the same authority, the eight "wet" statesCalifornia, Illinois, Indiana, Minnesota; Nebraska, Ohio, Vermont, and Wisconsin-harbor only 3.1 per cent. of illiterates; that is to say, those wet states did harbor that percentage in 1914, but in 1916 Nebraska went dry, and that may, in time, alter the illiteracy figures.

Again, for the most part, our cities are "wet," and our country districts are "dry." Yet, our countrywide draft shows many more rejections for physical disabilities of men from villages and small towns (dry places), than from cities (wet places). Also, medical boards know that there are more defectives in country schools than in eity schools.

If abstainers are superior either physically or mentally to moderate drinkers, such superiority is neither apparent nor real.

Intemperance and a craving for excitement have always been characteristic of strong dominant races. All warlike peoples have shown a love of intoxicants. In a word, the warlike and creative spirit have, in the past, always accompanied intemperance. 
Finally, alcohol has played a not inconsiderable part in the religious rites and ceremonies of a bygone age, in treaties and political discussions, in the proclamations of war and of peace, and it has had much to do in the socializing and amalgamation of all the races of the world. 


\section{CHAPTER XVII}

\section{ALCOHOL AND CANDY}

IT is curious that men, when deprived of alcohol, crave candy and other sweets.

A Brooklyn boy, Arthur Lang, while on the Mexican border, wrote to Dr. Charles P. Peterman as follows: "The food here has been pretty poor, and all the water we get is very warm, but we are glad to get it, as there are some days when we haven't a drop. But it is a very funny thing, everyone of us, from the youngest to the oldest, is crazy for candy, and we can not get it." Mr. Lang closes his epistle with an earnest request for candy.

The editor of the Medical World, commenting upon an article in the Confectioners' Journal regarding the value of candy as a preventive of alcoholic eraving, thus addresses us: "If any man doubts that candy will cure him of the drink habit, he can easily test it. The man who puts lots of molasses on his wheat cakes at breakfast will find himself gradually forgetting to stop in for his customary drink on his way to work. ....

"It has often been noted that, in theatres where candy is sold during intermission, 'going out to see a man' does not prevail to anything like the extent it 
does in other theatres where no candy selling is permitted."

Truly an easy "cure" for the "boozer": - "Lots of molasses on his wheat cakes at breakfast;" and candy, loads of it, when he attends the theatre in the evening. We wonder if someone will discover as easy a cure for the morphine, cocaine and heroin habits!

And our erudite editor believes that the liquor men long ago discovered that benign effect of sweets (How could such "defectives"' discover anything!) ; for, he adds: "It is a significant fact that the free-lunch counters, run in connection with bars, furnish every imaginable thing but sweets. ... The proprietors know their business. The more sugar and sweets a man takes at a meal, the less alcohol he wants. Conversely, nearly every drinking man will tell you that he has lost his taste for sweets. The more candy a nation consumes, the less alcohol it imbibes.'-And we had always thought that candy was for women and children!

Now, if a man accustomed to alcohol, when suddenly deprived of it, craves candy, there is a reason. Or, conversely, if the eating of candy lessens the desire for alcohol, there is still a reason. What is it?

A truth, which I have failed, after diligent search, to find in prohibition literature, is that every particle of sugar taken into the human stomach is changed into alcohol, carbonic acid and water, by the digestive ferments. And all carbohydrates, such as, potatoes, bread, macaroni, rice, cereals, peas, kidney and lima beans, lentils, Boston baked beans, pastries and the 
farinaceous puddings, are, likewise, after their ingestion, changed, within the bodily economy, into alcohol, carbonic acid and water. In the case of carbohydrates (starches), however, the starch is changed by diastase into sugar, before it becomes alcohol, etc.

Thus alcohol, so far from being a poison produced only by the diabolical machinations of man, is produced constantly by Nature herself, and is, therefore, a normal constituent of the human economy.

Again, plant physiologists affirm that alcohol is found in plants as well as in human tissues. The intracellular respiration of the plant acts upon its carbohydrates to form alcohol; or, more simply, the ordinary metabolism of the plant necessitates the formation of alcohol from the sugar contained in its fibre.

Now, what are we to infer from all this? And why do not school girls, who consume their candy by the pound rather than by the piece, become intoxicated with alcohol, although they may never have even smelled of that "terrific" poison?

The answer to the latter question is, that alcohol is very volatile, and has also a strong affinity for oxygen. So, of the comparatively small amount, which would be formed from the candy, what was not given off by the lungs and skin, would be quickly burned up, or oxidized, almost completely within the body, with no ill effects.

To answer the first question: We may reasonably infer that candy is, to a certain extent, a more or less satisfactory substitute for alcohol, especially for the moderate drinker. I am very sceptical, however, that 
a confirmed toper would exchange his successive diurnal drams for any quantity of molasses, or of candy. It looks, too, very much as though alcohol were a bodily necessity, seeing that, when it is not supplied, the body craves substances (starch and sugar) from which it can manufacture alcohol.

Personally I believe candy-eating to be infinitely worse than moderate drinking; one reason being that it is very hard to eat sweets in moderation. The temptation, when one eats candy, is always to take "just one piece more"; and too much sugar soon produces fermentation and hyperacidity.

Finally, while a mild alcoholic drink will usually increase the appetite, candy and "soft" drinks will quickly destroy it. 


\section{CHAPTER XVIII}

\section{ALCOHOL AND WAR}

The Anti-Alcohol Movement in Europe, which is alleged to have begun from the publication of von Bunge's Die Alkoholfrage, in 1886, was given a tremendous impetus at the outbreak of the general European war in 1914.-Why?

Were the dynasties, limited monarchies, republics, and governments generally represented, especially interested in the welfare of their units, or were they perchance more vitally interested in their own royal safety? Let us see.

Alcoholic beverages are, in a measure, luxuries; and all luxuries can be dispensed with. Again, alcohol, especially in the form of ale, is both a nutrient in itself, and an aid to the assimilation of foods in general. It tends, therefore, to increase weight; moreover, alcohol, being a nerve sedative, promotes good nature and satisfaction with the life ordinary.

On the other hand, alcohol hardly creates a craving for hard physical exercise; nor does it foster belligerency, so desirable in war times-unless, of course, it be used to excess. In short, alcohol agrees better with the comfort of the individual, than with the ambitious designs of the government which intends to use him to promote its cause. 
Now the Powers, when confronted by grim War, find it difficult to gather in recruits from among their stout, good-natured and easy-going subjects. The Powers, unlike Cassius, prefer men who are lean, hungry-who, in fact, would rather fight than eat.

Hence the unanimous shout of all the belligerent nations was: "Down with alcohol and luxury, and up with pugnacity and individual sacrifice!"

And so, Anti-alcoholism was preached to the masses to induce them to become of the stuff of which soldiers, according to the governmental idea, are made. After they had enlisted, however, and had been considerately placed in the trenches alcohol was allowed them in goodly amounts.

According to the British Medical Journal two and one-half ounces of rum are issued to each man in the British army twice a week. For men in the trenches, three ounces, twice a week, under ordinary weather conditions, and, in bad weather, two and one-half ounces, daily, are allowed. The regular ration of two and one-half ounces is estimated to contain 25.5 grams of alcohol.

The French soldier receives, daily, fifty grams of rum, containing 20 grams of alcohol.

The German soldier is allowed 1,793 grams of beer and 20 grams of brandy a day. The beer, which is of the ordinary lager variety, has a low alcohol content of about 3.5 per cent.; yet this quantity would amount to 70.7 grams of alcohol a day.

Austrian soldiers are given 0.5 of a liter of wine daily, equivalent to 40 grams of alcohol. 
Sir Victor Horsley informs us (Alcohol and the Human Body, p. 310), that, in the present war:

"(1) Ordinary canteens for the sale of alcoholic liquors are allowed in the camps. (Although it was stated in the House of Commons, by Mr. Tennant, that spirits would not be sold to the men in France.)

"(2) Certain powers under martial law are in the hands of the Commanders to put local public houses 'out of bounds,' but are sparingly used.

"(3) Although abroad, i. e., in France, certain commanding officers put the local drink shops 'out of bounds'; nevertheless, rum, in a daily ration of $21 / 2$ ounces (5 tablespoonfuls), is issued to all the troops."

In military hospitals, the surgeons use alcohol when necessary, despite the bitter denunciations against it.

It may now pertinently be asked, why the inconsistency of exhorting the common people not to drink, and of then furnishing drink to those same common people after they have become soldiers?

One reason might be, that if the masses be given more drink in service than out of service, they would be encouraged to enlist; and another reason is: Soldiers have to endure the rigors, exposures, and almost insupportable fatigues of trench-life, often with insufficient food; the governing bodies know that, and also that alcohol will enable many to withstand those hardships, who, otherwise, would succumb.

Hence, while all the Powers begrudge alcohol to their non-combatants, they allow it to their soldiers.

Experiments have been tried to prove whether sharpshooters were made still sharper, or worse, 
shooters by alcohol. The result of the tests showed, according to the anti-alcoholists, that there was some lowering of the marksmen's efficiency.

But that outcome was not surprising. Healthy men, and soldiers are supposed to be such, have steady hands and good eyes. Now, if such men, needing no stimulant, are given one, there will be some effect; and that effect can be only to unsteady them, seeing that, being already perfectly steady, they can not be made more steady by stimulation.

On the other hand, were a marksman in an abnormal condition-unsteadied say, by a recent debauchalcohol would, in his case, have a steadying, rather than an unsteadying effect, and thus make him shoot better.

The moral of the above is : Do not drink at any old time, but only when you need a drink. It requires a mere modicum of intelligence to refrain from issuing rum rations at a time when men need their eyes to be quickest, their hands steadiest, and their wits most alert.

But because alcohol should not be given to the soldier just before he engages with the enemy, does not say that alcohol should never be given to the soldier.

Alcohol lessens tension, deadens the sense of fatigue, and partialy dulls the senses that they may rest, and become ultimately refreshed.

Hence, after the engagement, when the soldier's nerves have almost cracked under the strain, and he is "all in," is the time to give him alcohol. At such a 
time, alcohol does the most good; for, then it will be most thoroughy oxidized and utilized to refresh the body. Moreover, when the soldier is exhausted, he can take a large quantity of alcohol, without becoming intoxicated; because he needs it.

There are times to drink, and there are times not to drink; just as there are times to eat, to relax, and to sleep, and times to be extraordinarily wide awake.

Although sleep reduces efficiency to zero; yet sleep is valuable. Alcohol acts like sleep, though in less degree; for, by relieving tension, it conduces to both physical and mental restoration.

But alcohol, in large amount, and when not needed, may inflame the senses, deaden the idea of danger to recklessness, and awaken the brute instincts, usually subconscious in the minds of men.

Those extreme effects of alcohol have been and are still deliberately produced by some commanders, before ordering a bayonet change. In the hand to hand conflict, when men strive to kill by shooting, stabbing, and slashing, alcohol has been not infrequently used to goad men to fight with insane fury and demoniacal strength.

The late Lords Kitchener and Roberts, however, were sternly opposed to alcohol being used in the army at all; their reason being that, among large bodies of men, it is difficult to limit precisely the amount of drinking.

In war time, there comes into the army a great influx of volunteers, many of whom drink more or less. Those who drink more, that is excessively, are not 
so efficient as those who drink less, or not at all. It is therefore natural that, in time of war, which is a time also of social stress, both soldiers and civilians should be exhorted to remain temperate. But the term "temperate" is elastic; hence, total abstinence is favored as the safest course.

Once allow a heterogeneous mass of soldiers to drink moderately; and some will inevitably drink immoderately-their own portions, and the portions of others who are more temperate.

Undoubtedly, immoderate drinking, by multiplying the wanton atrocities, adds to the horrors of war. When an invading army finds drink easily accessible, the danger to conquered civilians is always greater; and more rapes, robberies, and brutal mutilations occur, than when the soldiers remain sober.

We come now to the chief reason for the bleeding nations of Europe's composite cry: "Away with Alcohol!"

It is economic. In 1913, there were $1,932,321$ acres of land in the United Kingdom (Great Britain) under barley cultivation; producing $65,600,000$ bushels of barley. That year, $22,000,000 \mathrm{cwts}$. of foreign barley were imported.

Now, it takes about $3 \frac{1}{5}$ pounds of barley to make one gallon of ale, containing only a half-pound of solid nutrient matter.-A rather expensive use of barley.

Other substances used by the brewers, according to the evidence given before the Departmental Committee on Beer Materials, are: Malt, corn, gelatine, mo- 


\section{THE WHOLE TRUTH ABOUT ALCOHOL}

lasses, raw sugar, cane sugar, honey, dextrine, black malt sugar, hops, etc.

The distillers prepare malt whiskey, by fermentation from malt and yeast. In making distilled liquors, such as whiskey, gin, or "Schnapps," the starch is obtained from rye, maize, or oats, and largely from potatoes.

Vodka, the strong drink interdicted in Russia shortly after that Empire had declared war against Germany, was made originally in pot-stills of rye, with the addition of 20 per cent. of barley malt for saccharification. But, at the time its manufacture was forbidden in Russia, it was being made from potatoes, maize, and green rye malt.

Moreover, the public manifesto against alcohol, in England, in December, 1916, states that alcohol, during the war, has monopolized between $60,000,000$ and $70,000,000$ cubic feet of space on merchant ships; while the freightage of the cargoes carried for the drink trade, by British war-time vessels, has exceeded 2,500,000 tons. Besides, within twenty months, the manufacture of alcoholic beverages has consumed over $2,500,000$ tons of food, with sugar sufficient to last the nation for eighty days; thus using up more sugar than the entire army uses in many months.

Alcohol, according to the manifesto, also wastes financial strength; 1,500,000,000 dollars having been spent by British subjects on alcohol in twenty months.

Finally, the manifesto complains, alcohol diverts the nation's strength, by using 500,000 workers, $1,000,000$ acres of land, and 1,500,000 tons of coal in 
a year; and, since the war began, it has involved the lifting and handling, on road and rail, of a weight equal to $50,000,000$ tons.

Now, keeping the foregoing facts in mind, and considering the economic straits, which all the warring nations confess they are in, can we wonder that, in their desperation, they exhort their people at least to curtail their consumption of alcohol?

The European nations need their barley, malt, corn, rye, oats, rice, potatoes, sugar, etc., to feed their populations; and they recognize the economic mistake of permitting such enormous quantities of valuable foods to be made into malt and spirituous liquors.

In Germany, at the present time, potatoes are scarce, as are sugar, flour and other food-stuffs; and, recently, in England, and later, in France, "sugar cards" were issued to limit the consumption of that indispensable commodity.

Furthermore, the warring nations need all the space on ships they can get, to transport foods and other necessities; they need their coal for their munition factories, and their men, who are not fighting, to work in them; and, last, but not least, they need the money men spend on their pleasures, for their enormous expenditures in carrying on the war.

All which moves me to suspect that the recent diatribes against the Demon, Alcohol, depicted horribly as an insidious poison slowly but surely destroying the nerves, muscles, and even the bones of the human race, are not quite sincere.

The whole truth might be-in Europe: Do not 


\section{THE WHOLE TRUTH ABOUT ALCOHOL}

drink alcohol. It consumes, not you, but more food, space, time and money than we can really afford just now.

Nevertheless, so necessary is alcohol considered, that not one of the European nations, after nearly four years of war, has as yet prohibited the manufacture of alcoholic drinks, excepting vodka and absinthe, long recognized as being especially destructive, owing to their excessively high alcoholic content. 


\section{CHAPTER XIX}

\section{ALCOHOL IN THE TROPICS}

"IT has been clearly shown that, in the tropics, abstinent soldiers are healthier than others."

That is the bald assertion of Ernest Gordon (The Anti-Alcohol Movement in Europe). Is it true? Mr. Gordon does not prove it; nor does he offer the slightest evidence to support his statement. When, where, and by whom, has it been "clearly shown that, in the tropies, abstinent soldiers are healthier than others?"

As a matter of fact, mere declarations of opinion, involving, as they may, strong personal prejudices, are almost valueless.

The late Lieut. Colonel Charles E. Woodruff, M. D., in his classical, Medical Ethnology, states, as the result of his prolonged observations in the Philippines, that those who drink alcoholic beverages in the tropics enjoy better health than those who do not-an opinion from first-hand experience directly contrary to that of Mr. Ernest Gordon.

A reviewer of Dr. Woodruff's book, writing in the Lancet for June 10, 1916, an English publication, professes great astonishment at such a conclusion coming from so eminent a source.

Whereupon, Dr. F. Lucas Benham, of Exeter, South 
Australia, writes a spirited letter in defense of Colonel Woodruff, which was published in the Lancet for September 23, 1916.

Dr. Benham says: "Your reviewer speaks of the author's [Colonel Woodruff's] surprising conclusion that those who drink alcohol in the tropics enjoy better health than abstainers. I can not see anything surprising in this. I should rather be surprised, if the contrary were maintained. It is, as in other climates, a matter of quale, quantum, and quando. I should have thought that there was plenty of evidence in print of the wholesomeness of alcoholic beverages everywhere. To give a single instance of an active hard-working man in tropical Africa, let me refer your reviewer to Sutherland's Adventures of an Elephant Hunter, p. 169. I think he will admit that there are, at any rate, exceptions to his own views.

"Nowadays, when there is so much bigoted antagonism to the use of alcoholic drinks, and it is often looked upon as a virtue to abstain, it is well to take broader views and recognize the beneficence of their action, and to encourage the moderate and judicious use of them.

"What would the British nation have been without beer and wine, and what would it sink to if it gave them up entirely?"

Not having in my possession the Adventures of an Elephant Hunter, I procured the book, turned to page 169 , and read the following:

"In the evening, when I have finished my day's work and bathed, I always indulge in a stiff whisky 
and soda; with dinner, I regularly consume half a bottle of port wine (it really is port wine), and ere retiring to bed another strong peg or two of whisky. For a few months' hunting, it is quite immaterial what one eats or drinks, but I find that, to endure month in month out, year in year out, the arduous work and strain of elephant hunting, in a hot and enervating climate, a considerable quantity of alcohol is absolutely essential to my physical well-being, and seems to help in the assimilation of my food, and give me refreshing sleep at night.

"Of course, during actual work, and in the heat of the day, alcohol is certainly prejudicial, and when in a temperate climate I feel little or no desire for stimulants in any shape or form.

"After years of this dietary and hard life, I feel in perfect physical condition, and a recent medical examination revealed that all my organs were sound and healthy."

The foregoing will, no doubt, be poor reading for Prohibitionists, and, more especially, for the sincere ones.

Yet Mr. Sutherland's personal experience with alcohol is most interesting, and should give pause to those who would deprive all of alcohol in any form.

Mr. Sutherland's assertion that he found alcohol to be "absolutely essential to his physical well-being" in the hot and enervating climate of Africa, while not proving that everyone would experience the same need in that climate, does prove that one man experienced that need very decidedly; and that, as he differed in 
no essential way from other normal men, the inference seems not illogical that others, were they living in the same environment, and under the same conditions, would derive like benefits from the same stimulation, though not necessarily from the same quantity of it.

It is also to be noted that Mr. Sutherland does not claim that alcohol increased his efficiency while working; for he says: "During actual work, and in the heat of the day, alcohol is certainly prejudicial."

In my chapter on Alcohol and Efficiency I shall give the reasons for that.

That Mr. Sutherland was "some" big-game hunter, and was able to endure a great amount of fatigue, in spite, if not because, of alcohol, is attested by the fact that, during ten years, he shot and killed 447 bull elephants, establishing a world's record.

And what is surprising in such statements about alcohol? Common sense bears them out. The occasional abuse of alcohol has made certain persons hysterical over its temperate use.

Man, mighty as he is, is 95.6 per cent. water; and to keep this amount of water-continually lost in perspiration, through the lungs, and through the grosser excretions-constant, copious water drinking is necessary, particularly in hot climates.

Now few persons drink enough water. But, in the tropics, where perspiration is profuse, they must, in order to remain healthy. Experience proves, however, that all human beings do not do what they should; they do usually what they wish to do. The 


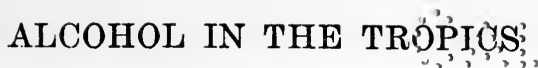

question is, then, how can they be made to wish to drink water?

By man's ingenuity in rendering water palatable by the admixture of fermented grape juice; or of fermented barley, malt and hops: The former process giving us water in the agreeable form of champagne and wines, and the latter giving us the cheaper, and therefore more widely popular beverages.

Now the English gallon of ale, which is larger than our gallon, contains about nine pounds of water, onehalf pound of alcohol, from four to five ounces of extractives and salts, from two to three ounces of maltose, and from one-half to three-quarters ounce of aibuminoids.

Hence when one drinks ale or beer, or whiskey, or brandy and soda (high ball), the favorite southern beverage, he is drinking a great deal of water, a little alcohol, and various more or less nourishing substances.

The entirely arbitrary assertion that the small amounts of alcohol contained in the above nutritious and comforting liquids, are injurious, is borne out by neither fact nor observation.

When sugar or carbohydrates (starches) are fermented-changed into alcohol-before they are swallowed, our digestive organs are saved that much trouble; since every physiologist knows the fact, already mentioned in the chapter on Alcohol and Candy, that such sugar and starch as we ingest are changed in the human economy, by a process of physiological fermentation, into alcohol and carbonic acid, and that 
the alcohol thus naturally produced, so far from acting poisonously, induces no unpleasant reaction, but, on the contrary, improves the appetite, assists the digestion, and hastens all reparative processes.

Abstainers are usually candy-eaters, probably because a part of their systemic need is alcohol.

Now it is apparent that most persons will consume more water when it is rendered palatable, than when it is unchanged; and in hot climates the consumption of much water is especially desirable, seeing that water cools and thins the blood, thus quickening the circulation, and stimulating the kidneys, while at the same time, it lessens their irritation by diluting their secretions.

Nephritis-inflammation of the kidneys-frequently attacks soldiers on the march, when deprived of sufficient water.

While the ingestion of alcohol apparently warms us, really it does not. The sensation of warmth arises from the fact that alcohol sends the blood to the surface of the body, but there the blood loses heat by radiation; so that, actually, there is a lowering, instead of a rise, in the bodily temperature.

Should we be astonished, therefore, that the opinion of so acute an observer as Lieut. Colonel Charles E. Woodruff, sustained by others with tropical experience, should be that the drinkers of alcoholic beverages in the south-where such beverages contain much water-are healthier than abstainers, particularly when we consider that the latter abstain notoriously from all liquids, including aqua pura? 


\section{CHAPTER XX}

\section{ALCOHOL AND EFFICIENCY}

RECENTLY the Anti-Alcoholists have made some great discoveries, but the one over which they gloat especially is that alcohol lessens efficiency.

According to some painstaking experiments of German scientists, the effect of one glass of beer is to lessen a man's efficiency by seven per cent.

"Think of it, ladies," exclaimed a woman physician, lecturing to a class of women on the evils of alcohol, "German scientists have found that a single glass of beer lessens a man's efficiency by seven per cent.!" The doctor then considerately warned the maidens to marry, if possible of course, 100-per-cent., and not 93-per-cent. men. And what a fate would be hers did any member of the class "capture" a degenerate who perchance had "guzzled" ten beers! She would have only a 30 per cent. man.

But the scientists no doubt know; so let us assume that their conservative-they are always conservative -estimate is correct. Still, we may reason further and discover some additional truths.

Suppose we should test the efficiency of a man whose stomach was empty, who, in fact, was hungry. In that condition, most men are more or less nervous and irritable; and at such a time their reflexes respond 103 


\section{THE WHOLE TRUTH ABOUT ALCOHOL}

to stimulation with supernormal quickness. We have proof of this in that, when a man feels more than usually irritable, owing to hunger, mental stress, or worry, he can not endure external annoyances (stimulations), such as noise, trifling interruptions, opposition to his will, and the like, with nearly the same equanimity which he would display ordinarily.

Now, after testing that hungry, and consequently more or less irritable man's efficiency (i. e., the quickness of his responses to stimulations), and finding it, let us say, 100 per cent., give him a hearty meal of corned-beef and cabbage, boiled potatoes, pudding, and pure water. Then again test his efficiency-his all around efficiency-and it will be wonderful if it has not been reduced by 20 or 25 per cent.

But the Anti-Alcoholists maintain that, if the drinking of one glass of beer reduces one's efficiency by seven per cent., the fact is proof that the act commits an efficiency suicide; and that therefore no glass of beer should be drunk.

All which illustrates once more the danger of the half-truth; for, should the reformers append to their half-truth the additional truth that a good dinner, without alcohol, would still further reduce efficiency, they would, in order to remain logical, be forced to advise us not to eat. All are aware how tired and sleepy one feels after a heavy meal.

Nor are alcohol drinking and indulgence in wholesome food the only acts which lessen efficiency. The fatigue produced by exercise-and exercise is universally conceded to be beneficial-lowers efficiency con- 
siderably; and sleep, the prime necessity to life and sanity, absolutely annihilates efficiency.

Surely the point is now plain that to prove that alcohol lowers a man's efficiency does not prove that alcohol injures him.

We shall now try to show that the lowering of efficiency by alcohol is beneficial.

The desire for alcohol, if not excessive, is the normal craving which all healthy humans have for some agent to give them surcease from the cares, troubles, anxieties, and consequent mental and physical fatigues, inseparable from the struggle for existence.

Americans are nervous and live often under intense strain. To blunt their too acute sensibility, and to relax their supertension, is perhaps the most important function of alcohol.

Nervous persons are nervous because their tension is too high; and that hypertension makes them crave some sedative to relax it. Deprive such persons of alcohol, and there is little doubt they would form some other drug habit.

Of course, efficiency is greatest when one is keyed to a high pitch, just as the taut strings of the violin vibrate beneath the bow drawn across them. But that condition ean not be maintained indefinitely without something giving way. Alcohol relaxes and rests us, to prepare for new and greater efforts later on.

No human being could remain one hundred per cent. efficient for long and live. Perhaps, as I have said, the chief value of alcohol, indulged in moderately, is that it relieves tension; and that effect no 
doubt lessens a certain kind of efficiency, but only to increase it ultimately through the partial rest. We see this in the comforting and sedative effect of a glass of ale, or of beer, or of Guinness' Stout, upon the overwrought and overworked mothers of numerous children.

If alcohol did not reduce efficiency-procure restno one would want it; and, to retain any efficiency at all, it is necessary regularly to reduce it, to relax; thus giving Nature a chance to restore the normal quantity of it. Efficiency is nothing more than energy intelligently directed; and, as energy, being continually expended, can not remain constant, so, efficiency, is reduced, restored, again reduced, and again restored, and so on.

One reason that Americans wear out quickly and die young is that they do not relax often enough and long enough.

Test a man's muscular response to stimulation when his muscles, from recent use, are hot with blood. Then let his muscles relax thoroughly, and test them again, and their efficiency will be found to be reduced. Nevertheless, their relaxation was physiologically desirable; for no one would argue that muscles in a state of tension could remain highly effective for an indefinite time.

Now the brain requires rest, as do the muscles; and, for that reason, alcohol, when moderately used, is beneficial. By relaxing cerebral as well as somatic tension, alcohol rests alike brain and body.

Contrast German stolidity and efficiency with Amer- 
ican nervousness and exhaustion. Consider also that German children do not make such nervous wrecks of their mothers, as do many American children. The Germans worry less than the Americans. Is it that German beer quiets German worry?

I tried the following interesting experiment with an American mother who was near nervous prostration through continual worrying about her children. I suggested that if she drank a moderate amount of ale, it would increase her appetite, improve her rather poor digestion, and, best of all, quiet her nerves, so that she would stop worrying uselesssly. She followed my advice, and it worked well. She grew stouter and more contented, while her children's health also improved, as she quit tormenting them as well as herself.

Professor Kassowitz describes an experiment with a dog. This dog, on a pure sugar ration, ran 24 kilometres daily in a machine called a running drum. When one-third of the sugar ration was replaced by alcohol, of the same number of calories, the dog did one-fourth less work. The carbonic acid output of the dog was also less on the alcohol days.

Now, since muscular activity and the elimination of carbon dioxide are always in ratio, the dog, undeniably, worked less on the days he not only looked at but lapped up the alcohol. Certainly the poor beast, partially intoxicated, and made more or less lethargic by his unusual indulgence, soldiered at his work.

But what of it? If some human beings work too hard, and if alcohol would make them work less, then 


\section{THE WHOLE TRUTH ABOUT ALCOHOL}

alcohol would do those who worked too hard good.

Again, if scientists can not tell us positively whether it is the water, or the hops, or the alcohol, in the beer-or the fusel oil, or the alcohol, in the whiskey, which cuts short our youthful careers, we would better continue to take a chance with some one of those popular palate pacifiers, alcohol and all, as has been from time immemorial our custom.

As showing how vague is the notion in the minds of scientists as to just what injures us in any particular drink, I quote the following from Alcohol and the Human Body, page 133: "In the case of people who suffer from gout, certain individuals say perfectly truly that if they take a small quantity of a particular kind of alcoholic drink, champagne, for example, it will invariably produce an attack; whereas they can take another kind [form] of alcohol with apparent impunity."

To conclude this chapter, I shall take the liberty of quoting the following trenchant statement of Professor C. E. A. Winslow, of Yale University:

"Passing from actual damage [of alcohol] to the question of lowered efficiency, we must take into account the laboratory studies of Kraepelin, Vogt, Aschaffenberg, and others, and the remarkably clear and convincing investigations first reported by $\mathrm{Dr}$. Benedict.

"There were persons who had lived long lives and done good work, yet who had consumed enormous amounts of alcohol. But if a responsible man had anything important to do, he did not take alcohol 
before doing it. A surgeon about to perform a delicate operation did not take alcohol before entering the operating room. No man about to undertake severe, exact mental work would take a drink of whiskey beforehand. When they wanted cool, concentrated energy, they laid drink aside."

I agree with the above; but to say that alcohol should not be taken just before important or delicate work, is saying nothing against alcohol, or nothing that is not already known. Alcohol is usually best taken when the day's work is completed, although not a few authors find that a certain amount of it serves to stimulate their creative faculties.

Each man, however, should be a law unto himself. No sensible person drinks alcohol while working, if he finds it interferes with his work; and, strangely enough, some wisely refrain, without the advice of scientists. 


\section{CHAPTER XXI}

\section{ALCOHOL AS A STIMULANT}

ALCOHOL is a stimulant as well as a sedative. In large doses it is a narcotic. In moderate amount its effects are sedative upon some human functions, and stimulative upon others. It is distinctly a heart stimulant and a cerebral vaso-dilator; an anaemic headache, caused by too little blood in the brain, being instantly relieved by alcohol. The experiments of V. I. Berezin (Roussky Vratch) upon carp and rabbits proved that alcohol dilates the blood-vessels in the brain.

It has been observed that some lecturers, after they had partaken moderately of alcohol, could speak better, were wittier, and appeared at better advantage, than when they had not indulged. Here, in my view, is the explanation of that effect which, to those who insist that alcohol in any amount is a narcotic, seems paradoxical:

There are orators, particularly those of "nervous" temperament, who, on the important occasion of a public speech, 'suffer greatly from diffidence. Now, nervousness, inhibiting, as it does, forceful expression, is most undesirable in a public speaker. Indeed, when the nervousness is extreme, it produces what actors call "stage fright," when all ideas disappear, 
the tongue is tied, and a "break down" ends the agony.

Alcohol allays that nervousness as nothing else can. It acts by inhibiting the inhibitors of free speech; and, more, it infuses into the orator just the dash of recklessness he needs for the courage of his convictions. In other words, alcohol, by inhibiting the minor cerebral functions, prevents distracting thoughts obtruding upon the main current of consciousness, thus favoring concentration. The speaker, then, unhampered by disturbing fears, appears at his best.

On the other hand, when immoderately used, the effects of alcohol are no longer confined to the inhibition of ideas interfering with the main idea, but include an inhibition of the creative powers, hitherto unaffected. The result in such cases is dullness, incoherency, and sometimes complete disability. In fine, while alcohol in moderation may help the speaker much, in excess, it may stupefy him.

The foregoing may explain also why a moderate quantity of alcohol conduces to sociability and breaks down constraint: It modifies manvaise honte.

Really, the question whether alcohol is a stimulant, a sedative, or a narcotic is not erucial. Its devotees have always maintained it a stimulant, while its detractors have tried in all ways to combat that "dangerous claim" in its favor. Indeed, the most elaborate experiments have been made, countless authorities have been cited, and all resources of argument have been exhausted, to prove that alcohol is not a stimulant. 
Now alcohol is a stimulant; but if it were not, it would not be disgraced.

All irritants are stimulants; because stimulation is only a degree of irritation. The prick of a pin stimulates, though the stimulus is not exactly healthy. The disease known as pulmonary tuberculosis, while acting generally as a depressant, stimulates certain organs, such as the sympathetic nervous system, and the adrenal and thyroid glands. In diabetes, the sugar. laden blood excites and greatly stimulates the function of the kidneys; but who would wish that disease to promote renal health?

Toxins (poisons) produce a fever; and fever is the effect of decided stimulation. Even depressive emotional states stimulate the sympathetic nervous system, sometimes so strongly as to result in a rise of the temperature of the body.

To realize more clearly the amount of energy required to bring about a rise in the bodily temperature, some calculations of Dr. Francis N. Pottenger are helpful. Dr. Pottenger, a recognized authority on tuberculosis, concluded from cold calculations, that an increase in body temperature of 5 degrees Fahrenheit required an increase of about 45 per cent. of the total body heat of the normal individual-some stimulation!

From ordinary observation there is strong reason to believe that, while alcohol dulls certain brain-centres, it stimulates others.

As we have lately said, an orator, or an after-dinner speaker will often speak particularly well after 
having partaken moderately of alcohol, probably owing to the dulling of certain of his minor cerebral centres whose activities would interfere with his main and desired thoughts. And that two-edged effect of alcohol, namely, that of stimulating the main, or creative faculties, and of obfuscating others, becomes most interesting when we consider genius.

Genius connotes a transcendent capacity for new and strikingly original concepts. It is a divine principle in man, is perhaps latent in all men, but is manifest in few, owing to inhibitions or suppressions. Yet the spark is there, and when the ashes covering it are cleared away, it flies upward, sometimes to blaze so brilliantly as to dazzle the world.

That is genius-a spark; and who can say that alcohol, by lighting up the best-the creative, and repressing the gross, conceptions within us, does not, in rare cases, release that spark? Strictly speaking, of course, man can not create anything; but he can often hit upon new combinations, make original inferences, and thus discover new truths.

Do we know that Charles Lamb, Byron, Goethe, Burns, Coleridge, Poe, Ben Jonson, Tennyson, Cervantes, Balzac, Addison, Swift, Guy de Maupassant, and others, would have created what they did, without alcohol? And could not even tuberculosis have etherealized the conceptions of Bronté, Rousseau, Milton, Ruskin, Kingsley, Locke, Hawthorne, Madame de Staël, Scott, Shelley, Keats, and Robert Louis Stevenson?

That alcohol is not a stimulant has never been 
proved; that it is a stimulant, in certain respects, is only what is patent from every-day experience. When an intoxicated man talks loudly, sings, becomes quarrelsome and aggressive, wishes to fight, or dances, it is plain that some centre of his brain has been stimulated. If he continues to drink until stupefied, he is narcotized by the drug which at first stimulated him.

But is not that true of many other substances? Before one is completely etherized, there is a period of excitement-stimulation. Strychnine powerfully stimulates in small doses; whereas, in large doses, it paralyzes. All drugs, in fact, have effects varying with the amounts administered.

To state dogmatically, however, just how much alcohol would be needed for stimulation, and how much for narcotization, would be impossible; for the reason that an amount which would only stimulate one man might completely narcotize, or paralyze another.

Again, the same man's physical condition at different times would modify the effects of identical quantities of alcohol. If he were very ill, and his system were crying out for aid (stimulation), he could imbibe a relatively large amount, without the least intoxication resulting; or, thoroughly septic, he might take enormous doses, and not become drunk in the accepted sense of the term.

To me it seems strange that the Anti-Alcoholists fail to realize that when they say that alcohol is not a potent stimulant, they are saying a great deal in its 
favor; for had their efficiency experiments proved alcohol to be an exceptionally strong stimulant, that would have been a damning fact, classing alcohol with cocaine and its derivatives, and with strychnine: The latter drugs being, as we shall see presently, potent stimulants.

While alcohol, in moderate quantity, is a stimulant, it is not, ordinarily, a powerful one. But alcohol becomes more stimulating, within limits, as more is used. Thus whiskey, containing. a relatively large percentage of alcohol, is more dangerous, because more likely to ereate a habit, than is beer, which is only slightly alcoholic.

To show still more strikingly how the danger in using drugs increases directly with the degree of their stimulation, I shall quote some remarks of Dr. W. H. R. Rivers on the extraordinarily stimulating effects of cocaine upon fatigue; - the imminent danger to even occasional cocaine users of contracting the cocaine habit being well known.

"Of all the drugs which are supposed to influence the condition of fatigue, none has a greater reputation than cocaine. It is stated that the natives of South America are enabled to perform great feats of endurance under its influence, and to withstand severe hunger and thirst, owing to its effect.

"This popular reputation is not belied by the results of experiment. The fullest work on the drug was published by Ugolino Mosso in 1890, in which ergographic observations [recorded tests of the strength and endurance of certain muscles] on him- 
self formed only part of a systematic investigation into the physiological action of the drug. Experiments on dogs showed that in doses of 0.0005 gramme per kilogramme of body-weight of the animal no effect was produced on muscular activity; that 0.001 gramme per kilogramme had a stimulating effect; and that doses of 0.003 gramme per kilogramme diminished the amount of work performed by the muscle, or produced complete paralysis; the paralytic effect being very sudden when the dose was strong.

"Before this time Aschenbrandt had found that doses of 0.1 gramme cocaine increased the resistance of soldiers to fatigue; Freud had shown that doses of 0.1 to 0.15 gramme increased the strength of contractions with the dynanometer. Mosso found that a dose of 0.1 gramme taken by the stomach had a decided effect on the amount of work produced by means of electrical stimulation of the muscle; the increase reaching 23 per cent.

"Further observations showed that the stimulating effect of cocaine became even more decided if the muscle was fatigued. After work had been done to exhaustion by means of electrical stimuli, a dose of 0.05 gramme had a very decided effect on the contractions produced by electrical stimulation, and a still more marked effect on voluntary contractions.

"Mosso also compared the effect of the drug in the fasting condition and after violent and prolonged exercise. In each state the drug had a most pronounced beneficial effect, both on the general condition and on muscular activity, as shown by the ergograph 
[a machine for recording strength tests]; the amount of work being doubled both with electrical and voluntary contractions. He concluded that the beneficial effect is-at any rate in part-due to the direct action of the cocaine on the muscle, and that the drug is able to abolish the effects of fatigue directly, though he does not suggest any exact mechanism by which this can be brought about.

"Another work on cocaine is that of Benedicenti, who chewed the leaves of coca, and found that in consequence the amount of work with the ergograph was not only doubled, but that the effect lasted longer than that of other substances (tea, coffee, mate and guarana) which had been tested under similar conditions."

We have in the above a reason for the taking of cocaine by eriminals when about to commit crimes requiring strength and nerve. Many outrages against persons and property have been done by cocaine users, whose acts could not have been accomplished without the stimulus of the drug.

Dr. Rivers sums up the effects of strychnine upon man, in varying minute doses, as producing "a decided increase [in the amount of work done], followed by a reaction."

Now contrast the potent stimulations resulting from comparatively small doses of cocaine, or of strychnine, as proved by the foregoing experiments, with the slightly stimulating, and often relaxing effects of small doses of alcohol-to be demonstrated presently-and we shall see that the Prohibitionists' 
claim that alcohol is not a stimulant, or, at least, not a powerful stimulant, is highly complimentary to the substance making the subject matter of this book.

Of course, the more powerful stimulants are, the more likely it is that their habitual use will engender habits afterward impossible to overcome, and the more profoundly injurious are their effects.

The results of specific tests, designed to determine the stimulating, or the relaxing effects of absolute alcohol, in doses of from 30 to 45 cubic centimetres, upon the neuro-muscular system of man, are well shown by the experiments of Dr. Walter B. James, reported at a meeting of the National Academy of Sciences, on April 6, 1916.

"In their data these average results showed two particularly significant marks of reliability: 1 . Similar processes were similarly affected and in similar degree; 2 , in general, the larger dose of alcohol showed the greater experimental effect. The effect of alcohol was calculated in all cases by comparing the differences between the 'normals of the day' and subsequent periods on the normal and on the alcohol days. The greatest percentage effect was found in the reflexes. In the patellar [knee] reflex, alcohol increased the latent time ten per cent.; while it decreased the amount of quadriceps thickening fortysix per cent. In the protective lid reflex, it increased the extent of lid movement nineteen per cent. It increased the latent time of the eye reactions five per cent., and that of the speech reactions three per cent. Memory and the free associations were only slightly 
affected [italics mine]. Sensitivity to faradic stimulation decreased fourteen per cent. after alcohol. [Quite different from the doubling of sensitivity after cocaine administration.] The number of finger movements decreased nine per cent., and the velocity of the eye movements decreased eleven per cent., as a consequence of the ingestion of alcohol." -All demonstrating certain relaxing effects of alcohol.

"Quite in contrast to the general depression of the neuro-muscular processes at all levels of the cerebrospinal system, was the effect of alcohol on the pulse rate. Under all experimental conditions alcohol produced a relative acceleration of the pulse. In only a few cases with a large dose did this relative acceleration become a positive acceleration; so that the pulse rate in the periods subsequent to the ingestion of alcohol was faster than during the normal of the day; but in practically every instance alcohol prevented the regular pulse rate retardation that accompanied the successive periods of mental and physical work on normal days."-Demonstrating alcohol's stimulative effects.

On the whole, the above experiments showed more the relaxing than the stimulating qualities of alcohol.

Yet, that alcohol, in heroic doses, can stimulate in certain cases to the point of dragging the moribund from the very portals of death, is made plain by Dr. Abraham Jacobi, in a paper on Alcohol Medication, excerpts of which follow:

"I do not care to class alcohol anywhere. It has been called, or eulogized as a stimulant, a sedative, an 
anesthetic, an inhibitory and depressant power, aye as a paralyzer. I do not contest observations and experiments either on healthy or diseased men, and on animals. Indeed, I have great respect for experiments and observations in and out of our laboratories. One of the most profitable laboratories, however, is a hospital and the private bed-side. They have the advantage over an experiment on a dog or a rabbit, for while an experiment on the latter is not infrequently devoid of clinical observation, when he publishes his result, the clinician seldom, if ever, appeals to the attention of his peers before he has confirmed his observations by scores or hundreds of cases. Great clinicians are more circumspect than loud. Hippocrates, the great, says more frequently than any of his successors, 'it seems to me.'

"Having been in uninterrupted contact with diphtheria since 1858 when it began its renewed murderous attack on our part of the world, I have anxiously looked for means to mitigate or heal what too often manifests itself as absolutely fatal. The virulent epidemics of forty years ago have furnished the formidable examples of sepsis and gangrene which in the past were mitigated by $\mathrm{my}$ introduction of nasal irrigations, and sometimes restored to final health by local doses of alcoholic beverages. I shall return to that. "No mixed infection is amenable to the action of antitoxin. It is only the omnivorous pages of a medical journal that boast of successes. Each new method of treating bad cases of diphtheritic sepsis and mixed infections merely followed its predecessors. It will 
not do to doubt the favorable reports of the medical magazines, nor to disparage the joyous enthusiasm of a colleague who is anxious to communicate a new mode of successful treatment to those who anxiously strive to avoid further calamities. As a rule, however, the number of cases thus treated and reported is small, and if you wait long enough for your defeats they will come to you. Just wait. When in 1860 I began to tracheotomize in diphtheritic laryngitis, I had three recoveries in my first five cases. They were published. Then-lo and behold, in the early seventies I had more than one hundred operations without a single recovery. So I learned wisdom and caution. That is why after sixty years of practice when I trust in alcohol as a powerful remedy in cases of diphtheritic and other sepsis, I may be credited with ample experience both in successes and failures extending over half a century. What I offer is no theory, and no laboratory experiments on the well or sick guinea pigs. My laboratory has been different. My life has been spent among the sick only, and the recovering and dying.

"A few stray specimens of my observations are as follows: With one of my most respected colleagues I saw thirty-five years ago a boy of five years. Membranes covered his fauces and mouth and part of his lips, and were visible in the nares. Round the neck were big lymph body swellings, now known to all of us as the sure proof of thorough mixed infection. Some membranes could be removed by forcible injections into the nose. It had been bleeding and oozing, the odor was foul. The second heart sound, still 
slightly perceptible, pulse 160 , hardly felt at the wrist. Boy restless in his semi-coma, tossing about, feet bluish, not cold, covered with erosions and subcutaneous hemorrhages of different sizes. His whole surface discolored, from drab to blue; hemorrhages small and large in and under the skin. No intestinal hemorrhage. Urine could not be obtained. My friend told me I was not called by him but by the family of the dying boy; he was going down town and on his way would order the undertaker to send the coffin after dark. I begged him not to do that, but to wait until to-morrow. The undertaker, however, came after dark and left disgusted. Meanwhile I had permission to act. The boy's stomach retained my whiskey, from one to two teaspoonfuls every 15 or 25 minutes, diluted in water, occasionally in milk or coffee, and his rectum retained a few doses. Within a day he took a pint and a half, perhaps more. We kept on, the boy and I. He was alive when I happened to meet him twenty years afterwards.

"A girl of seven years I found in about the same condition thirty years ago. She was a patient of one of our great physicians who, when he died suddenly a year ago, proved to the world that there are some men who are indispensable. He said, 'Now here I have given your whiskey but she will die.' How much is she taking? 'Beside her other drugs she is taking as much as half a pint each of these two days, and retains it.' Very well, just continue, and I will give her my additional half-pint. So we did. She took a pint or more daily, and got well. 
"A boy of three years with the formidable symptoms of mixed infection was 'given up.' I held out the hope of recovery provided the doctor would succeed in getting into him, with other appropriate medication, at least a pint of whiskey daily. He did succeed. Five days afterwards the father called in despair, saying his child was alive but insane. So he was. The boy was better, in fact on the way to recovery, but drunk. To me that was a welcome occurrence, for I knew, and want my readers to know, that no amount of whiskey will lead to intoxication when its effect is wanted to combat sepsis. I repeat: No amount of alcohol will intoxicate a thoroughly septic person. As soon as my little patient did no longer require his big dose of alcohol, it made him 'insane,' intoxicated. I had enjoyed that experience before, in many cases, and have since. May be my first case of the kind was that of a refined lady who had typhoid fever fifty years ago. I learned the alcohol practice from Dr. Ernst Schilling, who sixty years ago treated many hundreds of cases of typhoid and typhus amongst the immigrants on Ward's Island. My lady patient, thoroughly septic, took a quart of whiskey daily ten days in succession until the beginning of her recovery; no other drop since.

"I want these specimens of alcohol treatment to suffice for my purpose, which is to make facts tell their stories. My cases of thorough sepsis relieved or cured by alcohol extend over more than half a century. My cases have not all been cured. I belong to the class that has to meet failures. But I have 
seen what was considered hopeless to take a favorable turn. There are in diphtheria, cases which are not influenced by antitoxin in small or big doses. That class of cases is not always hopeless when the doctor has hope and discrimination and the courage to fight infection and to cheat the undertaker. I refuse to deal in theories. I can not tell the cause of the antiseptic action of alcoholic beverages when administered in sufficient doses. I merely refer to occurrences and observations extending over half a century and more. Let somebody else explain. Meanwhile take the hint." 1

Dr. Beverley Robinson, Emeritus Clinical Professor of Medicine, University Bellevue Hospital Medical College, remarks anent alcohol medication in severe cases of grippe pneumonia:

"For stimulants or heart tonies, there are only two worth considering-one is strophanthus, the other is old brandy. The strophanthus should be given in small doses, one to two minims, every two or three hours, at the same time as the brandy. The latter may be given in doses from a teaspoonful to a tablespoonful in a very little water, or Vichy water, ice cold.

"The nutriment should consist of fermented milk, beef juice, panopepton, light broth of chicken, or mutton, jelly, eggnogg [a mixture of milk, eggs and spirits], curds, etc. In addition, a little hot, well-made tea or coffee is frequently valuable. Dry champagne

1 Alcohol Medication, by A. Jacobi, M.D. (American Medicine, September, 1913). 


\section{ALCOHOL AS A STIMULANT}

is also helpful, and oxygen inhaled frequently, without increased fatigue to the patient, will lessen dyspnoea [difficult breathing] and relieve cyanosed [blued] lips and extremities." 1

And so, there are physicians of the highest standing, who still believe in alcohol, as a stimulant, as a tonic, and as a saver of life, when all other medication fails.

1 Grippe Pneumonia, by Beverly Robinson, M.D. (New York Medical Journal, January 20, 1917). 


\section{CHAPTER XXII}

\section{ALCOHOL AS A POISON}

Alconol, whether in small or in large doses, is always a poison. So say the Anti-Alcoholists.

Well, we are willing to be shown; but we must be shown. Let us examine, therefore, the evidence.

At the outset it seems strange that, if alcohol were a poison, nature should manufacture it within the body itself; for, we have already shown that all the starch and sugar we ingest are changed into alcohol and carbonic acid within the organism.

Of course, there are poisons formed in the body; but sugar would hardly be considered our most valuable food were a deadly poison (alcohol) its chief by-product.

At a symposium, held at the New York Academy of Medicine, on April 6, 1916, Dr. Charles R. Stockard, of Cornell University, described a number of experiments he had made, with alcohol, upon the eggs of fish and of hens. Needless to say, the solutions of alcohol into which the fishes' eggs were placed did not agree with the embryos; nor did it tend to make the potential chicks robust, to hold the eggs, from which they were soon to emerge, over a funnel emitting strong alcohol fumes. "Magnesium chloride, 
however," the same learned physician declared, "had much the same effect."

Dr. Stockard next directed his kind attention to guinea pigs. Whenever he treated prospective parents of those inoffensive animals, with alcohol, results upon their progeny were weird and depressing.

We outcast moderate drinkers, however, can form no very clear idea of the value of Dr. Stockard's experiments upon guinea pigs, as just how badly the little creatures were treated Dr. Stockard saith not. Naturally, if they were thoroughly saturated with alcohol, such treatment would not much enhance their health; nor would it conduce to the breeding of startlingly splendid offspring.

Such arguments are rather absurd, as no sane person contends that it would be good for anybody to soak himself in alcohol-unless he happened to be a corpse, when alcohol would be an excellent preservative. But we must say there are few substances which a man can abuse as regularly as he does alcohol, and "get away with it."

The next in this grave symposium to contribute his ideas was Dr. Frederick S. Lee. He reported results of the action of alcohol upon muscles. "Some doctors," he said, "asserted that alcohol in small doses augmented the activity of nervous tissues, and in large doses depressed it (Binz). Others (Schmiedeberg) believed that there was always a depressing action, whatever the quantity of the drug."

Such conflicting testimony determined Dr. Lee to experiment and find out for himself. So he, assisted 


\section{THE WHOLE TRUTH ABOUT ALCOHOL}

by Drs. Salant and Levine, "took" a frog, which was of course the doom of that batrachian. One thigh of the amphibian was ligated (tied), in order to obtain a control muscle for comparison, and a solution of ethyl alcohol was then injected into the stomach. A half hour later the frog was killed, and both the thigh muscles, one normal and one alcoholized, were removed and stimulated until exhausted. It was found that, when the doses were small, alcohol increased the working power of the muscle, both by lengthening the working period, and by increasing the amount of work performed; whereas, in large doses, it decreased the working power.-Showing that man may drink a little, but not too much.

The inference Dr. Lee drew from his experiment was that, while in small quantity alcohol may be utilized by living tissues both as a food and as a source of energy, in larger quantity, its action was mainly toxic.

The physicians from inebriate institutions and farm colonies, who were heard at the symposium, were naturally rather pessimistic in their views on alcohol as a health food.

When Dr. Abraham Jacobi arose he said he felt sorry for Dr. Stockard's guinea pigs, but that his experience of over fifty years in practice gave strength to his positive assertion that there was no remedy to equal alcohol in cases of mixed infection. There were septic diseases that could not be treated or cured unless large doses of alcohol were given. Mixed infection in diphtheria could not be cured by anti-toxin, 
but treated with large doses of alcohol the sufferers might be saved.

He said he had seen many such living, dying, or moribund patients since 1858 , who had recovered absolutely through taking whiskey.- "They were not guinea pigs, however, but human beings," he ended dryly.

It should now be interesting to discuss two perfectly contradictory assertions of Sir Victor Horsley, as to the effect of alcohol upon tissue-waste or oxidation. But that I may be accused neither of inaccuracy nor of making false statements, I shall quote Sir Horsley verbatim.

On page 182 (Alcohol and the Human Body) is the following: "The problem as to whether alcohol may be regarded as saving the waste of the tissues has been frequently investigated, and, as the methods of science have improved, the experiments of Binz (1888), often quoted in favour of the value of alcohol in saving tissue waste, have been disproved. For instance, Romeyn, when he gave to starving individuals large doses of alcohol, on no occasion observed any diminution in the elimination of nitrogen [showing no saving in tissue waste], but, on the contrary, in some cases, there was a very decided increase. This means that the body waste was not saved, but increased by alcohol. [In other words, alcohol increased tissue-oxidation.]

"In fact, it is strongly insisted on, by those who have collated recent observations on this point, that, in tissues unaccustomed to the presence of alcohol, its 
administration is almost invariably followed, for a short period at any rate, by increased nitrogenous waste.

"We still need more knowledge on this difficult point; but the evidence as it stands shows the taking of alcohol has no tendency to save tissue waste."

Alcohol, then, according to Sir Victor Horsley's own emphatic statement, not only does not, but has not even a tendency to save or to delay tissue waste. But on page 182, from which we have just quoted, Sir Victor was anxious to disprove a supposedly valuable property of alcohol, namely, that of retarding tissue-waste; for, if alcohol should retard tissue waste, that would argue alcohol to be either a good food per se, or, at least, a good substitute for food.

Later, however in the same book, Sir Victor desires to demonstrate something wholly different, i.e., that alcohol retards oxidation, and thereby poisons the body by allowing the accumulation of waste products. So, on page 227 , Sir Victor delivers these contrary opinions :

"The greatest possible difference exists as to the rate at which oxidation goes on. When there is nothing to hinder its occurrence the poisonous toxines [What is a non-poisonous toxine?] and waste matters which form in our bodies are rapidly burnt up and eliminated, and health prevails. On the other hand, when various things interfere with oxidation, our vitality and vigor become necessarily impaired.

“Alcohol a Cause of Deficient Oxidation of 
Tissue. From what has been stated it is clear that anything which interferes with the process of oxidation is to be regretted, as tending to delay the normal elimination of waste material. Alcohol is admitted to have this unfortunate effect. It has long been considered to have the power of interfering with and lessening oxidation [italics mine]; this being explained on the theory that it robs the tissues of the oxygen which they would otherwise use for combustion. [We shall examine that theory presently.]

"Therefore when alcohol is present the tissues are starved of oxygen, hence their normal rate of metabolism or tissue combustion is delayed, and they cannot adequately get rid of their waste material. Thus the body becomes hampered by the presence of many effete substances, which ought to have been eliminated, had oxidation not been interfered with. As a consequence of this, ill-health of various degrees is liable to occur." - But we have quoted enough, and are surfeited with prolix contradictions.

We understand that, on page 182, "The taking of alcohol has no tendency to save tissue waste. . . But, on the contrary, leads to increased nitrogenous [tissue] waste." Then, while we are digesting that interesting and unequivocal assertion, that comfortable process is suddenly arrested, on page 227 , by the opposite statement in bold, black type, just as emphatically argued, that "Alcohol [is] a Cause of Deficient Oxidation of Tissue."

To find the light in this labyrinth of darkness will now be our task. 
We should remember that alcohol, being easily oxidized, is consumed almost completely within the body, unless immoderate quantities are ingested; and just how a substance can act in any way where it is not, is difficult, for me at least, to see.

As to experiments showing the gruesome effects of alcoholizing dogs, cats, and guinea pigs, many should be taken cum grano salis. Frequently we are not told whether the alcohol is injected into the veins, or given by the mouth; and, the effects of those two procedures being vastly different, that is a grave omission. Again, we are not always informed of the precise amount of alcohol injected or ingested, also a detail of importance.

What we do know is that we, mere human beings, are not dogs, eats, guinea pigs, etc.; and that fact, too, makes considerable difference, inasmuch as many substances are poisonous to some animals and innocuous to others. Cattle growers assert that some species of larkspur are fatally poisonous to cows and harmless to sheep. The nicotine of tobacco will kill a dog when placed on its tongue; yet there are centenarians who have been inveterate smokers from boyhood.

Now, regarding alcohol's affinity for oxygen, we admit that alcohol combines with that gas readily. But how do the Anti-Alcoholists put that truth? They say that alcohol, because of its strong affinity for oxygen, extracts an excessive quantity of that precious substance from the blood; the result being that our food and tissues are insufficiently oxidized (Alco- 
hol and the Human Body, p. 227, but not p. 182), and a toxaemic (blood-poisoned) condition follows. ${ }^{1}$

They are careful, however, not to tell us the whole truth, which is, that, when the blood needs oxygen, it absorbs it quickly from the lungs, and that, therefore, the food is not deficiently oxidized, and does not poison the blood.

A fire burning in a room consumes oxygen, but, if a window remains open, the amount of oxygen in the room space would not be materially reduced. In the case of the blood, the open window is the lungs.

The tenacity with which the blood maintains its normal composition, under even abnormal conditions, is extraordinary. The reason for the stability of this balance rests in the general activity, adaptability, and elasticity of the organism. Frequently disturbed by alternate conditions of repose and of exercise, by the ingestion of various foods, and, occasionally, of alcohol, the physiological content of the blood remains constant for the reason we have given.

So, when Prohibitionists contend that alcohol permanently robs the blood of its oxygen, thereby so reducing its power as an oxidizing agent that it becomes poisoned by deficiently oxidized material circulating within it, they are either deliberately mendacious, or else wofully ignorant of the laws of physiology.

Again, scientists have injected small quantities of ethyl alcohol, or of alcoholic liquids, into the veins of

1 Alcohol-Its Influence on Mind and Body, p. 77, by Edwin F. Bowers, M.D. 


\section{THE WHOLE TRUTH ABOUT ALCOHOL}

guinea pigs and other small animals, killing them, after great torture. Thereupon the Prohibitionists have exclaimed triumphantly that such experiments conclusively proved alcohol to be, even in small amount, a terrific poison.

To illustrate the length to which certain fanatical Prohibitionists will go for their "cause," let us read this hair-raising and harrowing description by Captain Jacob, quoted in the Anti-Alcohol Movement in Europe, pp. 241 and 242, of the death throes of a guinea pig which has been inoculated with a quarter of a cubic centimetre of absinthe essence :

"At first it seems thunderstruck. It remains fixed in one place as if stunned. At the end of two or three minutes there follow on this stupor the most frightful agonies. Suddenly it stiffens on its paws and then makes, all at once, a prodigious leap into the air. The poor little creature, ordinarily so harmless, takes on an entirely unexpected expression of ferocity. It resembles an hydrophobic animal, with its convulsed face, its twisted lips, covered with foam. In its eyes -wide open, haggard, convulsive, mad, one reads an impulse to kill. It is now a prey to hallucinations. Directly its spine curves in a half-circle. Its membranes and whole body are thrilled with shocks, interrupted by little plaintive cries. Then a brief moment of calm. The attack recommences, showing at each fresh crisis, signs of accumulated violence. Finally it dies after a half-hour of agony.

"Is it not enough to frighten one when one reflects how many men drink this poison absinthe? One 
meets in the cities, Saturday evenings and Sundays, gallows-birds with the glare of an homicidal mania at the bottom of their pupils. Take care, my friends, such an one is a dangerous tippler, ordinarily inoffensive enough, it may be, but with absinthe in him, an evil demon. Such are brutes who plant their knives in others' backs; who, returning to their wretched lodgings, break chairs and dishes, hammer the wife, and cripple the children,- the children trembling and screaming with terror, crouched under the table or behind the stove. Oh, yes! You know well that I do not exaggerate. The poster in the corridor with the inscription in big red letters, "Absinthe Makes Maniacs,' is no lie."

The above literary gem occurs in Discours $d$ ' un Capitaine à ses Soldats, by Captain Jacob, of the 109th Infantry.

Ernest Gordon (The Anti-Alcohol Movement in Europe) says of Captain Jacob's book, that it has been crowned by the French Academy, and that two chapters of its Anti-Alcohol teaching have been printed separately and supplied with stereopticon slides for use in the army. "They constitute," says Mr. Gordon, "one of the most powerful attacks on drinking habits of which the writer [Mr. Gordon] knows."

But, oh, Half-Truth potent for evil, what is not perpetrated in thy name! With relief we now turn from ignorant rabidity to the broad knowledge of calm intellectuals.

Dr. Victor C. Vaughan, than whom none is more honored in the domain of medicine, performed some 
quite interesting experiments upon guinea pigs himself. His, also, were injection experiments, but with substances known to be not only wholesome, but indispensable to life.

Dr. Vaughan injected small quantities of the proteins, extracted by a special process, from all kinds of animal substances, into the veins of small animals, which simple procedure killed the animals with neatness and dispatch. He next experimented with vegetable proteins, and found that these, when injected into the veins of animals, were quite as virulent as were the animal proteins.

The most poisonous substance he found was the casein extracted from fresh milk; a single gram of this, furnishing sufficient poison to kill eight hundred guinea pigs, provided, of course, it was injected intravenously (into the veins), or intracardiacly (into the cavity of the heart).

"Think of that," Dr. Vaughan exclaims, "all mammalian young are reared, during a certain period of their lives, on milk, and still you can obtain from one gram of casein enough poison, when injected intravenously or intracardiacly, to kill 800 guinea pigs!

"You will understand," he adds, "that given by mouth these substances are not poisonous. They couldn't be because we are eating all kinds of proteins, more or less bacterial proteins, and, of course, animal and vegetable proteins. Now why are they not poisonous when taken by mouth? For two or three very good reasons. In the first place, the digestive 
ferments of the alimentary canal break up these poisons into harmless substances. In the second place, even though they were not broken up, they are not diffusible and would not pass through the walls of the intestines; so, as long as they are confined to the alimentary canal they are not poisonous."

Dr. Vaughan concludes: "Whatever the origin of the protein may be [bacterial, animal, or vegetable], it contains a poisonous substance, and this poisonous substance is grossly the same in its [fatal] action."

The above shows strikingly the danger of a little knowledge-half-truths; for suppose we should have one day in our midst anti-milk cranks, could they not show, on the unimpeachable authority of Dr. Vaughan, that a single gram of casein, extracted from fresh milk, would kill eight hundred guinea pigs, when injected into the veins?

And now in the steady light of the whole-truth, which we have tried to present, what becomes of the argument of the alcohol-phobe, Captain Jacob, whose book was "Crowned by the French Academy?"

Inasmuch as Captain Jacob injected into the veins of his guinea pig his "quarter of a cubic centimeter of absinthe essence," he proved merely that absinthe essence, like the proteins of the foods which we eat daily with impunity, was poisonous when injected into the veins. But, in the light of what we have just learned, that fatal injection did not prove, although Captain Jacob implied that it did, that the same dose, or even a much greater dose of absinthe would have produced the same effect by mouth. In- 
deed, we know now absolutely, thanks to the labors of Dr. Vaughan, that absinthe essence, taken orally, would not, or could not, have had anything like the same effect.

Yet please understand that the above critical exposition was not designed to encourage the drinking of absinthe, which, personally, I believe to be injurious in excess, and dangerous even in moderation; I tried merely to show that Captain Jacob's gruesome experiment proves absolutely nothing in so far as the harmfulness of drinking absinthe is concerned.

Before dismissing the subject of alcohol as a poison, it behooves us to examine further the action of alcohol apon the cells of the body.

In The Anti-Alcohol Movement in Europe, Ernest Gordon, quoting from a lecture delivered somewhere in France, says : "Alcohol is a corrosive poison which destroys the tissues. Its elimination being very slow, certain organs, notably the brain and liver, become saturated with it. Hence lesions, hemorrhages, sores, cramps, vertigoes, tremblings, mental failures, hallucinations, deliriums."

Interesting, but untrue.

When a man weighing one hundred and forty pounds drinks a pint of beer, he introduces into his body 0.05 gramme of alcohol to the pound of his weight. That amount would not worry him did he know that alcohol is found in the organisms of normal persons who have never even tasted it; Nature herself having put it there. True, the amount found has been small; but there has never been observed a 
great amount of alcohol in any of the organs of the body, even in cases of the highest intoxication (Starke). Surmise, therefore, how little alcohol could be found in the organs of a moderate drinker.

Absolute alcohol is detrimental to cells; but no one drinks absolute alcohol, and, certainly, the mild alcoholic beverages, in which the sane part of our population indulges, could hardly destroy cells, seeing that their slight alcoholic content would be quickly volatilized and oxidized.-Hence, as no appreciable amount of alcohol remains in the tissues, it is difficult to see how it could injure them.

Distilled water, a fairly pure substance, is as harmful to living cells as is absolute alcohol; it becomes innocuous, however, when salts, in a certain given concentration, are suspended in it.

Ordinary table salt, indispensable to our organism, in 0.7 to 0.9 per cent. solution, will kill most living cells instantly; and it will have that effect, not only as a pure or absolute salt, but even in strong watery solutions (Starke).

"It has been found that cells of the ciliated epithelium of the air passages, isolated from the mucous membranes and transposed into a slightly alcoholized physiological salt solution remain alive much longer than in a non-alcoholic solution." (Starke.)

If alcohol is a poison, it is such a slow one that it sometimes takes more than a hundred years to kill a man. 


\section{CHAPTER XXIII}

EFFECTS OF, AND FACTS ABOUT, ALCOHOL

ALсоноц abates nervous irritability, and alters the distribution of blood by sending most of it to the periphery (surface of the body). One feels, therefore, after having taken alcohol, a sensation of warmth, which is not illusory, as some contend, but real. The feeling of warmth, however, caused by the rush of blood to the surface of the body, is not lasting, as there the blood quickly loses heat, and the temperature of the organism falls.

Coffee and tea, on the other hand, increase nervous irritability, and draw the blood from the periphery, thereby gorging the internal organs. It is well known that coffee is an antidote to alcohol.

The cells of plants, animals and man know alcohol; it being formed normally in them.

Alcohol is absorbed easily and rapidly by. the stomach, and, when incorporated in the juices of the body, acts like the carbohydrates (starches), in that it creates heat and imparts strength for muscular work.

The action of alcohol on the nervous system depends upon the amount ingested, and upon the immediate needs of the system. If there is little other nourishment available, and the need of the body is great, 
owing to heavy muscular work (furniture movers, truckmen), or, if the system is in a weak and impoverished condition from a protracted illness, the intoxicating effects of alcohol are much reduced. That is shown by the fact that there are times when a small amount will intoxicate, and other times when a relatively large amount will not.

Alcohol's specific action is exerted on the terminal apparatus of nerves, or on the central nervous system. "The nerve trunks are not essentially affected; neither are the blood vessels directly. With the latter, as with the heart, the effect is either on the vasomotor nerves, or on those of the heart; or else, in the case of the heart, this muscle, like any other, makes use of the alcohol as a nutrient material in the performance of its work." [J. Starke.] The carbohydrates [cereals, sugar], which are necessary for us, act in the same way, although their specific effects are decidedly weaker.

"Alcohol stimulates the terminal apparatuses of the nerves of the bodily organs. It stimulates, too, many of the glandular nerves through the medium of the central nervous system, but probably many of them also directly.

"Taken in moderation, alcohol does not act as a poison to the central nervous system, for there is lacking every characteristic symptom of such an action.

"The action consists in functional changes which lie within the range of quite normal play, and not in 'disturbances.' This continues to be the case even 
when alcohol is taken regularly for years in suecession; and no disturbances occur if the use of alcohol is suddenly discontinued." 1

Dr. Starke next speaks of the "inner stimulation" produced by alcohol. "In this condition," he avers, "we breathe freely and deep, the skin is pleasantly warm, our internal organs are grateful for the freedom from too much blood, digestion is unimpeded, and the heart beats full and strong." ...

Further on Dr. Starke says: "The moderate use of alcohol does not affect the procreative capacity, the capability of suckling, or the duration of life." Alcohol, when scientifically, or judiciously used, probably affects all three-favorably. More about that later.

Beer, being made from cereal and producing both heat and energy, has been called "liquid bread." But bread is cheaper, some will say. Now, apart from the fact that what a man pays for his food is his own business, it is not certain that bread is cheaper. As a rule, bread is buttered, and butter is dear.

"A litre of Munich beer contains, in round numbers, 35 grammes of nutritive material in the form of alcohol, and 60 grammes of other nutritive matter. That means 95 grammes of nutritious substances in a litre, and in four litres 380 grammes of chemically pure, therefore concentrated, nutrient material." (Starke.)

According to Ernest Gordon, "a glass of beer costing 25 pfennigs [five cents] has no more nourishment

1 Alcohol-The Sanction for Its Use, by J. Starke, M.D. 
than 1 pfennig's worth of cheese." Well, a pfennig's worth of cheese is a small piece of it, and cheese is concentrated nourishment. Besides, many persons like beer much better than cheese, and beer, being easily digestible, agrees with them better. Neither is the pleasure in drinking a cold draught of beer a negligible factor in the conditions necessary to health. There are those who would drink beer did it contain no more nourishment than sawdust. Finally, beer contains much water, and we can live without food far longer than without water.

When Sir Victor Horsley and others prove by experiments upon men and animals that alcohol decreases the tonus of muscle, they merely demonstrate what everyone already knows. For example, on page 112 (Alcohol and the Human Body), we are told of an experiment in which two puppies are given alcohol in their food (this time the alcohol was not "injected," and so did not kill the animals), while two other puppies were given food and no alcohol; the experiment continuing for several days.

"It was often noted that the normal dogs were playing actively, whilst the alcohol-taking dogs were quiet, and content to do nothing."-An excellent demonstration of the sedative and relaxing power of alcohol, constituting its chief value.

High-strung men and women who take alcohol are often very much better for occasionally remaining "quiet, and content to do nothing." On the other hand, a college crew, just before the boat-race, do not load up on whiskey-if they wish to win the race. 


\section{THE WHOLE TRUTH ABOUT ALCOHOL}

In the drinking of alcohol, as in the eating of food, our sensations tell us when we have had enough; and it is as easy for a moderate drinker to continue to drink moderately, as for a man with a hearty appetite not to gorge himself. There are dishes as seductive to the gourmand, as the finest wines are to the gourmet. We should therefore learn to restrain our appetite for food, as well as for drink; otherwise, we must bear the consequences.

The proof that moderate alcoholic indulgence rarely leads to excess, is the fact that the vast majority of mankind continue to be moderate drinkers. Drunkards are in the minority; and, of these, all, without exception, have some brain defect. If drinking, and not individual defectiveness, were the cause of chronic alcoholism, then practically the whole world would be perennially drunken; for practically the whole world drinks.

Great misfortunes, or supreme indifference to mental and physical well-being, often lead to excess in alcohol, for the sake of stupefaction, or partial oblivion. Not all, however, who are despairing or unfortunate, take to drink. Succumbing to alcohol presupposes weak character and a lack of normal reactionary power. Drunkenness is not a cause, but an effect, of abnormal mentality. Yet there are mental tortures that crave drink as a panacea.

The statistics relative to drink as a cause of insanity, compiled in hospitals for the insane, are not always reliable. That many, or even most, lunatics are alcoholics, proves merely that, as a rule, insane persons 
drink; certainly it does not prove that the sane are made insane by alcohol.

Drinking to excess is one of the signs of insanity. A perfectly sane person stops drinking when he has had enough. An insane person, or a "border-line" case, keeps on drinking, just as he keeps on eating, until he is "full." Only the truly sane have selfcontrol. A fool, or a high-class imbecile (moron), hardly knows enough to put on more clothing when he is cold, or "to come in out of the rain." How, then, would he know enough to drink moderately?

I think that the majority of physicians will agree with me when I say that it would take more than alcohol to upset a sane, well-balanced mind. Neither do blows on the head nor worries often cause insanity. The chief causes are an hereditary taint and syphilitic infection.

When the progeny of the mentally unsound are unbalanced, it is the basic unsoundness, rather than the incidental chronic alcoholism of the parents, that is responsible.

Confirmed drinkers rarely care for women; probably because no man can whole-heartedly serve two masters, or, for that matter, two mistresses.

Again, when we consider that many drunkards positively dislike the taste of alcohol-drinking it purely for its lethal effect,-liquor seems not so seductive as it is accredited with being.

Where the finest and rarest wines are sold, there is the least drunkenness; in the low, poisonous dramshops there is the most. Now, it is well-known that 
the cheap liquors contain fusel-oil. What is fusel-oil? Its chemical name is amyl-alcohol, an ingredient of crude alcohol obtained by distilling grain and potatoes. As its name implies, it is oily, and has a strong odor. It acts with many more times the intensity of alcohol. Whence, it seems reasonable to suppose that the fusel oil, rather than the alcohol, contained in cheap whiskeys, is responsible for some cases at least of chronic alcoholism, particularly when we know that many inebriates prefer the cheap, adulterated liquors, as being stronger than the better brands.

There are no beer alcoholics; nor do persons who use alcohol for stimulation, and not for stupefaction, become drunkards.

In those who lead sedentary lives the blood is unevenly distributed; there is too much in the internal organs and too little at the periphery. Muscular work draws the blood from the internal organs to the muscles and toward the external surfaces generally. Alcohol also sends the blood to the surface of the body. Hence, alcohol, in so far as sending the blood to the skin is concerned, has an effect similar to exercise.

In sepsis, especially that resulting from diphtheria, alcohol is the most potent agent to combat it that we have (Jacobi). Its action in diphtheritic septic conditions is probably antiseptic, although we have no exact knowledge on that point.

Prompt administration of alcohol will abort a chill by sending blood to the surface of the body, and, in that way, may prevent an illness. Alcohol will also stimulate a heart temporarily weakened by disease, 
and will relieve an anæmic headache almost instantly. It acts by dilating (relaxing) the blood vessels of the skin and brain, while, at the same time, it constricts those of the internal organs, with the single exception of the heart, to which it sends more, and not less, blood.

Quite different from the effects of alcohol, are the effects of caffeine and theine. The latter drugs constrict the blood vessels of the skin, and dilate those of the stomach. So, as caffeine (contained in coffee) is an antidote to alcohol, so is alcohol an antidote to caffeine.

Probably owing to those effects of caffeine, heavy coffee drinkers have sallow, muddy skins; whereas moderate indulgers in alcohol have rosy skins and usually clear complexions.

Hence, the modern business man, who drinks much coffee and tea, and who takes practically no active exercise, particularly needs alcohol to stir the stagnant blood in his internal organs.

In this regard, Dr. Starke advises that a man drink more alcohol than coffee and tea; that he drink wine or beer at dinner, and that he follow his café noir with a liqueur or a glass of cognac. Should he, however, avoid alcohol altogether, then he should eschew also coffee and tea, and embrace vigorous exercise.

A coffee and tea drinker, who is muscularly inactive, has usually poor blood and clogged internal organs, is nervous, and suffers from digestive disorders and chronic constipation. Should it have happened occasionally that such a person has lived longer 
than a robust man, who is a moderate consumer of alcohol, his longer life could hardly have been an enviable one.

Now, were the manufacture of all alcoholic beverages wholly suppressed, it would be a serious question whether there would not be more disease, degeneracy and suffering than there now are. For:

Even our arch alcoholphobe, Sir Victor Horsley, says on page 148 (Alcohol and the Human Body), that "the dilatation of the blood vessels of the internal organs is a matter of grave import, seeing that the overengorgement of the internal organs with blood leads slowly and surely to the degeneration of their secreting protoplasm, and, consequently, to loss of that health and efficiency which must be possessed by these vital parts if life is to be prolonged."

But, when Sir Victor wrote the above, he was laboring under the misapprehension that alcohol could cause "overengorgement of the internal organs," for he had said only a few lines back, respecting the effect on the skin of the ingestion of alcohol: "The alcoholic dilatation of the vessels of the skin is frequently an index to the state of the blood vessels of the internal organs." The implication being that because alcohol dilated the blood vessels of the skin, it dilated also those of the internal organs.

Such an assumption is of course absurd; for, there being only a certain quantity of blood in the body, most of it (the blood) could hardly be at the bodily surface and within the bodily organs at the same time. Hence, it must be as plain as that two and two 
make four, that if the veins at the surfaces of the body are dilated by alcohol-and every one, including Sir Victor Horsley, acknowledges that alcohol has that effect,- -then the deeper veins, namely, those of the internal organs, must be constricted by alcohol.

If the point has not yet pricked, it is necessary to add only that there is no conceivable method by which the blood could be forced to the body surface except by constriction of the walls of the deeper veins; any child being able to see that did all veins remain in equal states of dilatation the blood would perforce remain evenly distributed throughout the body.

Now most persons drink coffee and tea; but, if the ingestion of coffee and tea constricts the blood vessels of the skin, and dilates those of the internal organs, the latter become engorged with blood; and that, according to Sir Victor Horsley, "is a matter of grave import, seeing that the overengorgement of the internal organs with blood leads slowly and surely to the degeneration of their secreting protoplasm, and, consequently, to loss of that health and efficiency which must be possessed by these vital parts if life is to be prolonged."

So, once again, after hearing the whole truth, we arrive at the wholly different conclusion from that of Sir Horsley, that alcohol, by dilating the blood vessels of the skin, relieves the engorgement or congestion of the internal organs, and is, therefore, especially wholesome for tea and coffee drinkers, as well as for those taking little active exercise.

It is said, and justly, that worry kills more quickly 
than work. To run is less wearing upon the nervous system even of a horse, than continual champing at the bit. We can work with impunity; but worry may have injurious effects. That alcohol allays anxiety and quiets nervous irritability requires no scientific demonstration. Give a tired, cross man a glass of good ale when he comes home at night, and, in a moment, his ill-humor vanishes, and he grows pleasant, affable and communicative. Mothers, who worry overmuch about their children, view childish pranks and noisy youthful exuberance with more tranquility after a refreshing glass of wine or of beer.

Scientifically speaking, our annoyance at noise is due to hyper-excitability of our reflexes (nervous responses to stimulation).

Alcohol dulls those reflexes; while coffee or tea drinking sharpens them. Furthermore, the immoderate use of caffeine and theine beverages, by quickening the perceptive, conceptive and associative faculties, leads to overwork, through enabling one to do more than he could normally, without stimulation; and that overwork, when prolonged, produces nervousness, insomnia and neurasthenia.

Alcohol acts oppositely, by soothing irritation and dulling sensation generally-stupefying to a certain extent. But partial stupefaction is conservative; for that, by conducing to rest and sleep, institutes just the conditions necessary for the processes of repair.

Somewhat similar to the effect of a large dose of alcohol is that of overwhelming grief. The poignancy 
of the shock of a great calamity, such as the sudden loss of a large fortune, or the unexpected death of a dearly-loved child or companion, is usually and normally followed by a kind of numbness characteristic of despair. In that condition, we feel nothing, care for nothing, experience neither pleasure nor pain, and are indifferent as to whether we live or die. Gradually, however, our apathy wears away and we recover slowly our normal interest in affairs mundane.

The despair succeeding grief is an effect designed by nature to protect our faculties and our lives. No ordinary person feels acute mental anguish for long; because great pain, whether mental or physical, quickly deadens sensation-numbs. When one's limbs are horribly crushed there is little pain, until afterward, when the limbs begin to recover.

Now, when nothing effects us, our responses to ordinary and even to extraordinary stimulations are nil; and that means complete mental and physical rest, during which nature restores the body to its pristine vigor.

And is not the above an argument in favor of the moderate use of alcohol? We are nervous, tired, worn-out mentally and physically, and we want something to blunt our sensations. We take a glass of wine and feel better; then we sleep, and awaken refreshed, and why should we not?

Has any man, or any group of men, the right to tell the individual just how he shall safeguard his health? I think he has not; for the simple reason that it 
would be impossible to enact any single law of health that would be properly applicable to all men, every man being different.

When a man turns to alcohol to "drown" the sorrow of some great misfortune, he is merely striving. to produce an effect that Nature herself frequently produces. Not that I would argue that sorrows should be drowned in drink-far from it.

But I do maintain that when a man or a woman is greatly overwrought, a moderate amount of some light alcoholic beverage is not only harmless, but very beneficial, in that it preserves, by a temporary blunting of both psychical and physical sensibility, the bodily powers.

The effect of alcohol upon the stomach is to stimulate the secretion of gastric juice. That truth Sir Victor Horsley acknowledges on page 157 (Alcohol and the Human Body), where he says: "Alcohol stimulates the flow of saliva and gastric juice." Then on page 160 he says: "Anything [referring to alcohol] that depresses these gastric nerves [He has just "shown" that alcohol does that] enfeebles the muscular movements of the whole stomach and delays digestion."

So, according to Sir Victor, "Alcohol stimulates the flow of saliva and gastric juice"; yet, that effect "depresses these gastric nerves, enfeebles the muscular movements of the whole stomach and delays digestion." (?)

Again, on page 154, he informs us that "the blood vessels of the stomach are also sensitive and delicate 
as those of the eye"; and that, therefore, if we put a drop of brandy into the stomach, it will smart as severely as though we had dropped it into the eye.

Perhaps; but, though I am not partial to brandy, I would rather risk a drop of it in my stomach than in my eye. Still, the reader may try the "simple" experiment if he wishes.

I confess myself unable to follow Sir Victor Horsley's reasoning.

There is a widespread notion that the drinking of liquids, alcoholic or otherwise, with meals, dilutes the gastric juice, and thus retards digestion. That is so only when an excessive quantity of liquid is consumed. No food can be assimilated before it has been liquefied by the juices of the body. That is why Nature prompts us to drink while, or directly after, eating.

If a piece of meat is put into a test tube containing gastric juice, the digestion of the meat will begin, continue for a time, and then stop. If water is now added, the digestion of the meat will immediately recommence-an experiment showing very prettily how water stimulates digestion.

The moderate drinking of wine, therefore, or of ale, or of beer, at meals, is a valuable aid to digestion, not only because of the alcohol, but also owing to the water it contains.

We have spoken of the rapidity with which alcohol is oxidized within the body; and, of course, the more oxygen is supplied, through the lungs, the more alcohol can be oxidized. That point is interesting, as it explains how longshoremen, furniture movers, and 
other hard-working men can often drink large amounts of alcohol, with apparently no harmful effects. Their heavy muscular work, with its necessitated increased intake of oxygen, enables them to burn up and to utilize amounts of alcohol that would intoxicate those less active.

Professor Atwater proved that alcohol is oxidized in the body up to 98 per cent. "But," says Ernest Gordon, "if there is here a fuel value, it is an inadequate one, since the temperature of the body falls when this firing is used. The blood vessels of the skin, expanded under alcohol action, let the warmth escape."

We agree; and it is that property of alcohol which makes it valuable to lower the temperature of the body, particularly when its bare surface is exposed. Indeed, alcohol has been found most useful to employ both externally and internally in cases of high fever.

"Further," avers the same author, "the burning of alcohol in the body withdraws oxygen from the tissues and hinders the oxidation of other supplies in the organism, especially of the fats. Unburnt pathological [diseased] fat is, in this way, deposited in the most various parts of the body."

Terrible if true; and, if untrue, a terrible untruth. We have already shown that such a statement has no basis of fact. The reader will not fail to notice, however, how popular that oxygen-devouring quality of alcohol, with its dire consequences, is with the AntiAlcoholists.

If the body is in good condition, owing to a sensible 
mixture of nutrients, it seems to prefer to use fat and carbohydates, in order to save albumin; and, in an experiment of supplying alcohol instead of carbohydrates, the body used the alcohol, as formerly it had. used the earbohydrates. Moreover, the final result was the same as when the carbohydrates had been used; the organism saving about the same quantity of albumin.

That alcohol is very easily digested is proved by the fact that the carbohydrates can not be digested as such, but only after they have been changed into sugar and finally into alcohol.

The effect of alcohol upon the muscle proper depends upon the amount administered; a little alcohol enabling the muscle to work longer than normally, while a large amount is detrimental to its full effciency.

"Alcohol," says Starke, "does not exercise a noxious influence upon the organs, when taken in rational quantities."'-Nature teaches us that when she forms alcohol within the body.

Prohibitionists call alcohol a poison, because it "disturbs" function. The truth is that it alters function. Neither is that property peculiar to alcohol. Many other substances, known to be not only harmless, but necessary, alter function. The proteins, carbohydrates, hydrocarbons (fats), milk, and even water, alter functions. That is why we take them. We change every moment, and we must repair the damages due to those changes by introducing periodically various kinds of extrinsic, afterward becoming intrin- 
sic, substances.-Breathing causes profound changes.

Again, Prohibitionists will say "paralyze," when they mean simply "reduce." While the choice of terms is a mere matter of taste it is noticeable that the enemies of alcohol, instead of choosing words expressing truly their ideas, select those used generally in a "bad" sense.

When we are overtired, and our nervous tension is high, we take some alcohol to reduce the tension; but no Anti-Alcoholist would use "reduce" in such a sense: He would select "paralyze," for its sinister implication. Moreover, he delights in speaking of alcohol's "narcotic" effects, knowing well that "narcotic" suggests ether and chloroform.

If alcohol "narcotizes," so do muscular work, fatigue, wholesome food, grief, darkness and quiet, narcotize. But we would say they were sedatives and induced functional rest.

How often are our prejudices revealed by our choice of words! When a college boy, whose father happens to be a millionaire, gets drunk, disturbs the peace, or steals a sign, it is a "prank." If a man, out of work, seizes a stale loaf of bread for his starving family, he is a "thief," and is sent to the "Island." A beloved boy is "full of animal spirits"; a disliked boy is "a little devil." A poor man is a "crank" and a "grouch"; one rich and famous has "the eccentricities of genius." - And so it goes.

But let us return to alcohol. Experimentation aside, everyone, who drinks moderately, knows that alcohol has an exhilarating effect upon the nervous 
system. A secondary effect is a deadening of sensibility to matters outside our main thoughts for the moment. It is true that the laboratories tell us that alcohol does not exhilarate us; but we do not care for laboratories. We feel that we are exhilarated, and that suffices.

That alcohol has a stimulating effect does not require scientific, or pseudo-scientific proof. Our very language shows it. We say a man is "sober," meaning that he is quiet and serious. A tipsy man is not "sober" in any sense, but lively, talkative, silly, and sometimes aggressive.

It is curious that, while alcohol stimulates the thinking and creative faculties, it dulls the perceptive ones, not by "paralyzing" the latter, but by so intensifying absorption in what is occupying the mind for the moment, that little or no attention is given elsewhere. Thus alcohol concentrates attention upon one theme, which may explain the greater force and brilliance of certain writers and speakers after a few glasses of wine.

Occasionally such concentration is not desirable. For example, a poet, whose natural bent was imagery and rhetorical expression, might not run a swift-moving automobile so carefully after indulgence in alcohol; as, while thinking of an effective distich, he might collide with a telegraph pole.-There are times when alcohol should not be taken.

It is generally known that soldiers in the heat of battle do not feel even severe wounds.

Excitation of the brain, whether by alcohol, fight- 
ing, or intense concentration of the mind, diminishes reflex sensibility.

Regarding alcohol's general physical effects in a hot climate, I quote the following extraordinary narration:

"Fergusson [Notes and Recollections, 1846] saw at St. Domingo the 67th Regiment march a few miles in a dry rocky country, the men having had a full rum ration issued to them. Very many fell out, nineteen died actually on the road, and the remainder arrived 'in an indescribable condition of exhaustion.' " 1

Surely, Dr. Fergusson, whose statement is approvingly quoted by Sir Horsley, meant that the regiment marched, not "a few miles," but a few hundred miles, without pausing to eat, drink or breathe. Otherwise it is incredible that nineteen picked men dropped dead in their tracks, and the remainder arrived "in an indescribable condition of exhaustion."-All because a full rum ration had been issued to them!

Not that I would impugn the veracity of Dr. Fergusson; but $I$ resent that any man should expect his hearers to believe that a full rum ration, even though aided by a tropical sun, could have been primarily responsible for so many sudden deaths.

Let us see. A regiment consists usually of ten companies; and a company is made up of from sixty to one hundred men. Hence the regiment mentioned could have consisted of no more than one thousand

1 Alcohol and the Human Body, p. 295, by Sir Victor Horsley, M.D. 
men. So, during the march of those "few miles," the regiment's death-rate was nearly two per cent.

Shade of Bacchus! Each man would better have undergone a major surgical operation, than have quaffed a full rum ration before walking his "few miles."

Seriously, I do not doubt that nineteen men, out of the complement of one thousand, died. The assertion, however, that one "full rum ration," taken just before a "march of a few miles in a dry, rocky country," was the cause of every one of those nineteen deaths, is so preposterous that I would not waste time and space discussing it, were I not desirous of showing my readers how many Anti-Alcoholists, including some who are eminent, misrepresent, by innuendo, when not directly, the physical effects of alcohol. Instead, let us have the truth, the whole truth, and nothing but the truth.

But not yet is Sir Victor Horsley content with the degree of dire dread of alcohol which he believes he has inspired in all drinkers; for on page 300 of his book, we read shudderingly of the truly fearful effects of the venom of snakes. The connection between snake venom and alcohol we shall discern presently.

A frightful picture Sir Victor draws when he remorselessly turns us inside out that we may see better what takes place while the snake poison circulates lethally in our doomed veins. And now comes the "connection."

"These lethal agencies in snake venom," the Doctor 
continues grimly, "thus exert injuries on the system parallel in every way [Italics mine] to those caused by alcohol, chloroform, etc."

Gadzooks! Methinks that in the brain of even my alcoholized organism the moral glimmers: Better far to be bitten by a venomous snake than to drink one glass of beer?-Honesta mors turpi vita potior.

Returning now to sanity, we conclude that alcohol in moderation; that is, in the form of mild alcoholic beverages, such as, beer, ales, light wines, etc., so far from being injurious, produces no unpleasant action or reaction whatsoever, but increases appetite, invigorates digestion, and favors repair. 


\section{CHAPTER XXIV}

\section{ALCOHOL, LIFE INSURANCE AND LONGEVITY}

LiFE insurance companies assert that abstainers live longer than drinkers. Such a statement from such a source deserves serious consideration. First, we know that the average span of life for man has, within the last decade, materially been lengthened; and also, that the consumption of alcoholic beverages in general, throughout the United States, is now, approximately, two thousand million gallons, yearly. Yet has man's life been prolonged. But that may have been in spite of, and not because of, alcohol. At all events, let the point pass. It will be fairest and most instructive to discuss this question from all angles.

Suppose the Life Insurance Companies have proved by figures that drinkers have not lived so long as abstainers, they have not proved alcohol responsible for the drinkers' shorter lives. They have shown merely that men of the type who drink have, as a rule, died sooner than those of the type who do not drink.

The crucial question, therefore, is not whether or not abstainers live longer than drinkers; it is, would men, who feel the need of alcohol, live longer, did they resist that need, and not drink?

That question, of course, can not be answered posi161 
tively. Nevertheless, I shall attempt to show that it is at least extremely doubtful that such men, particularly those of nervous type, who now drink moderately, would be either healthier or longer lived should they resist violently their alcoholic need, and forswear drinking absolutely.

Usually drinkers are not so careful of their health as non-drinkers. They keep later hours, smoke more, eat more, are fuller-blooded, and enjoy more of the good things of life generally.

Among poets, prose writers, musicians, artists, actors, and other intellectuals, who work hard mentally, many drink more or less. They become "wornout," and crave a stimulant to overcome their "nervous" fatigue. Naturally they take alcohol; and there is no proof that, were beings of high-strung and intensely nervous temperament deprived of alcohol, they would be better off or would live longer. They drink, because they feel the need of it; and, if they could not drink, perhaps their irregular hours for working, eating, and sleeping, would kill them sooner.

The same is true of those who work overhard physically-longshoremen, truckmen, furniture movers, iron workers. They, too, feel the need of alcohol, but these more from physical, than from nervous, exhaustion; and they also might not be able to withstand so well the strain of their killing work, were alcohol denied them. Their practical experience-though at variance with the findings of the laboratories-is that, without alcohol, they would sooner succumb to the fatigues incident to their laborious occupations. 
Now, it may be a fact that nervous, highly-strung persons who work very hard mentally, and who drink, and big powerful men, who work very hard physically, and who drink, do not live quite so long as do those who live more easily, and who do not drink. Yet what warrant have we for assuming that, because most of those men happen to drink more or less, their lives are shortened by the alcohol rather than by their strenuous work? Nay, may it not well be that alcohol prevents the constant work under high tension from still more weakening their health and curtailing their usefulness.

As a matter of fact, men who drink are different nervously and muscularly from those who do not drink; and that difference engenders in the drinker a multitude of habits, besides the habit of drinking, which are not peculiar to the non-drinker. So that, whether the drinker's life is shortened-if it is shortened-by his one habit of drinking, by his concomitant habits, or by his temperamental makeup, would be difficult to determine.

Why it is that men of great talent, or even genius, should be partial to alcohol, we can not say. And neither can we say that, without alcohol, their work would be better, or that they themselves would be healthier. Some affirm that they would; but such have not the sublime modesty of that great agnostic, with superintellect, Herbert Spencer, who, when questioned as to his belief in a future life, answered simply: "I affirm nothing; I deny nothing; I do not know." 


\section{THE WHOLE TRUTH ABOUT ALCOHOL}

The points argued and the evidence presented so far in this book seem to show more or less conclusively that alcohol, when used moderately, is not harmful, but, in many cases, beneficial. We believe, with John Fiske, that "Alcohol diminishes the friction of living, and bridges over the pitfalls which the complicated exigencies of modern life are constantly digging for us."

And suppose we consider human experience, ignoring statistics, which are unreliable, and laboratory experiments, which are conflicting, is it quite reasonable we should be asked to believe that a substance, which nearly all persons use, and have used from time immemorial, for stimulation, comfort, and surcease from their sorrows, is a poison destructive to our life, health and happiness?

Reformers who talk confidently of the immense benefit to humanity of National Prohibition, forget that there will always remain in the world millions who will still crave alcohol. That cut off, they will perforce take something else, which formerly they would not take, because they deemed alcohol the less destructive of the two. Does the reformer think that result, and it is logical, would be a benefit?

Natural instinct can be trusted somewhat; and it is probably that those who do not drink, should not, and that those who do drink may be obeying a natural need which ought to be satisfied.

If it be true that nervous, hard-working persons who drink, are likely to die, as a rule, a few years sooner 
than abstainers-and the Insurance Companies claim that they may die only one or two years sooner-they might, for all we know, die still sooner, should they, with their peculiar nervous temperament, abstain also.

Lives experiencing no need of stimulants probably waste less rapidly, and, for that reason, may be more lasting than those continually sapped by constant tip-toe wear and tear.

Again, the very fact that a man abstains from alcohol suggests that he abstains also from too much food; and as few men take sufficient exercise, abstinence from overeating has doubtless considerable to do, too, with the prolongation of the abstainer's life. Moreover, as we have already said, the abstainer is likely to be especially careful of his health generally. As a rule, he does not smoke, and he is moderate in all animal indulgences. In a word, many abstainers live on a comparatively low plane; and a low plane may mean a long life.

Really, taking into consideration accomplishment and usefulness, it would seem better to have lived vigorously and effectively a slightly fewer number of years, than to have lived sedately, carefully, and long, but to less purpose. Of course I do not mean to say that there are not many abstainers who are leading capable, useful and noble lives; but-speaking generally - of the men who have accomplished most, the majority have been at least moderate drinkers.

Let us now discuss more in detail whether ab- 
stainers, during their alleged protracted existence, look healthier, feel better, are stronger and accomplish more.

It is well known that certain invalids live long; also that delicate persons often cling to their slender hold on life with astonishing pertinacity. Cornaro lived longer than a century by observing a rigorous diet that would hardly have satisfied a professed ascetic. His death is said to have been eaused by his exceeding his strict menu one day by a few ounces. A famous ascetic lived to a great age upon a diet of bread and water alone.

All which suggests that mere length may not be life's most important asset. Certainly Cornaro and the long lived ascetics were not extraordinarily proficient or efficient during their prolonged existences. Some turtles live for hundreds of years; but who would be a turtle? The natives of the Balkan peninsula, comprising Servia, Roumania and Bulgaria are famous for their longevity and number of centenarians, but not for anything else. A raw-boned, sorrylooking nag may live as long as, or longer than, a sleek race-horse, or a broad-chested strong draft animal; still, the nag is worth little.

A powerful body, a robust appetite and a healthy look add greatly to the zest of life, as well as to efficient daily accomplishment; yet such an one may have a subtle defect in some organ or a weak spot in one of his arterial walls which may cause him to die sooner than many of his weaker and less efficient neighbors. Indeed, the robust live so much more intensely than do 
the sickly and delicate that, in some cases, owing to their high health and not to alcohol, they may not live quite so many years.

Mere muscular strength, therefore, while highly desirable and admirable, does not guarantee a long life.

There is no doubt that the strong live more strongly and get more out of life than do the frail, who are often valetudinarians. Afraid to work or to eat, to drink or even to smoke, the latter's mere existence is usually miserable. On the other hand, persons with a large stock of health are not extraordinarily careful of themselves, because they feel that in their case great care is not necessary. Hence the healthy are more likely to drink and to smoke than are the unhealthy whose condition obliges them to be careful.

Soon we shall see just why the healthy may live no longer than, and sometimes not so long as, the delicate; and that often their superabundant health may itself bring about their demise, irrespective of whether they drink alcoholic beverages or not.

To take another animal than man. It is conceivable that extra feeds of oats would make an underfed horse more efficient, without having the ultimate effect of much prolonging his life. Many sorry "nags" live to a good old age.

So, men and women may take beer, ale, or stout with their meals and, if undernourished, the effect would be augmented appetite and greater enjoyment, accompanied, of course, by an increased consumption of wholesome food. Thus the immediate result would be increased efficiency, if not from 
the beer directly, then at least from the beer indirectly, through improved appetite and gustatory pleasure. But, in the cases we are supposing, would life insurance statistics, purporting to show that moderate beer drinkers were not quite so long-lived as abstainers, change by an iota the salient fact that a moderate consumption of beer with meals resulted in a present gain in health and efficiency? I believe they would not.

When we compare macroscopically, and not microscopically, the respective physiques of moderate drinkers and non-drinkers, in which class do we find the greater number of robust persons?

The answer may well be left to the reader's own observation and experience; but at least it is true that moderate beer-drinkers are usually well-nourished and strong, as compared with teetotalers, many of whom, through weak digestion, fear to drink even one glass of good beer.

Look at the sturdy Germans who have drunk beer from childhood, or at the strapping Irish whose tonic par excellence is Guinness' Stout.

Every one has, of course, many erroneous ideas. One is that disease attacks chiefly the delicate and weak and leaves almost untouched the robust and strong. Herbert Spencer, the great philosopher of modern science, taught that doctrine: That the infectious diseases kill the people who, for the good of the race, ought to die; that they weeded out the unfit.

Yet, that is not always the case; nor is it true of all diseases. Moreover, the strong, when attacked by 
disease, often-to use a popular phrase-take the disease hard, and succumb more quickly than do the frail, when attacked by the same disease. Why this is so we shall see presently.

Dr. Victor C. Vaughan, an able and celebrated physician and scientist, had heard that typhoid fever attacked by preference the weak and physically unfit. That dictum Dr. Vaughan neither believed nor disbelieved but, like a true scientist, he investigated to find out the truth.

Dr. Vaughan, however, admits that, when he began to study typhoid fever in the American army in 1898, he was impressed with the popular idea that the less robust men would furnish the larger number of cases of typhoid fever, and that the case mortality of these comparatively feeble ones would be very great. "For that reason," says Dr. Vaughan, "we decided, although it meant a great deal of work, to trace back the medical history of every man who had had typhoid fever as far as we could. With many of the regular soldiers this was possible. We carried all back to the time of enlistment, and in the regular army this meant a good many years on an average. We expected to find that the weaklings, so far as there are weaklings in the Army, had typhoid fever and that they died from it. So we collected a vast amount of information trying to prove this thing. Before we got half-way through it was quite evident that it proved just the opposite thing.

"Out of 16,000 men who were under health-who had been frequently on sick report-about 7 per cent. 
of them had typhoid fever. Out of 42,000 men, who were never on sick report, and who had practically never been ill in their lives, some 18 per cent. had typhoid fever, and that wasn't the most striking thing. Over 90 per cent. of the men who died of typhoid fever were men who had never been seriously ill.

"But why is it," Dr. Vaughan asks, " that the case mortality is more among the robust than it is among the weak?" And he answers: "Because for the very good reason that the robust man puts up a big fight against the infectious disease, and he either overcomes it speedily or, what is more likely to happen, nature overdoes the thing, kills off the bacteria too rapidly and death results." 1

Quite naturally Dr. Vaughan and his associate investigators concluded it was their discovery that typhoid fever kills off the robust rather than the weak - until they read the history of the plague, by Thucydides, five hundred years before the Christian era, in which "the fairest, the strongest and most robust" furnished the greatest number of victims.

One old Irish writer, about three hundred years ago, describing an epidemic of typhus fever, says: "It went through the country picking out the strongest, the most robust, just as you or I would go through a flock of sheep picking out the best."

Another Irish writer points to the fact that among the poorly-nourished, the institutionally-fed, the mor-

1 A Biological Concept of the Structure of the Protein Molecule, by Victor C. Vaughan, M.D., Long Island Medical Journal, May, 1916. 
tality from typhus fever in Ireland was but one out of twenty-three; whereas, among the doctors, the nurses and those who dispensed charity, that is, the wellnourished and healthy, the death-rate from the same disease was one out of three.

The infectious diseases, like war, kill off the strongest, the most vigorous, the most robust, and, like war, they lead to the deterioration of nations. We should have, therefore, no compunctions in doing all we can to stamp out the infectious diseases.

It will be interesting now to make plain just why certain infectious diseases, like typhoid fever, are more fatal to the strong than to the weak.

The period of incubation of typhoid fever is from eight to ten days. During that period of incubation, before the disease is manifested, the patient is not ill; in fact, he often feels unusually well. Yet it is then that the typhoid bacilli within him are multiplying with enormous rapidity, and still they do him no harm. But, after about eight days, the body cells begin to learn how to destroy the invading organisms, and quite suddenly they attack them vigorously. Then the trouble begins; and the symptoms and lesions of the disease are due to the rapid destruction of the bacteria by the cells of the body.

Now the body cells of a strong, vigorous man are more numerous and husky than are those of a weakling, and consequently the former's body cells kill many more bacteria in a given time. Of course that seems desirable, and would be so, were it not for the fact that the destruction of the bacteria by the body 
cells liberates a poison, to which, as we have said, the symptoms and lesions of the disease are due. In the case of a very vigorous man, nature frequently becomes too eager and overdoes; in fine, she kills so many bacteria in so short a time that she kills the host also-the unfortunate man.

From the foregoing we conclude that if, as Dr. Vaughan's careful investigations have shown, it is true that the strong and healthy are, as it were shining lights for the infectious diseases, it may be that the slightly less average expectation of life by the moderate drinkers may be owing more than occasionally to their excess of vigor rather than to their mild indulgence in alcohol; the vigorous and strong being more likely to drink and to smoke than the delicate who are often so solicitous of their health as to be afraid to do almost anything.

Here the reader may exclaim: "What! Is strength, then, detrimental to long life?" The reply is that, in certain cases, it may be; while, in other cases, it may be just the opposite.

But, in any event, strength is not detrimental to either mental or physical efficiency during life; and, without health and strength, life is usually such a burden that its prolongation is only punishment.

So the question we started out with resolves itself into this: If moderate drinking does not positively favor longevity-and I do not say it does not, but quite the contrary -is moderate drinking conducive to greater immediate health, happiness and efficiency?

That question has, I hope, been already answered 
satisfactorily. Nevertheless permit me to append the following facts, which are history: Turkey, whose prowess in the present world war, either in strategic achievements or in force of arms, has not astonished mankind, is a non-alcoholic nation dominated by Germany; China is a non-alcoholic nation, famed more for its opium than for its progressiveness, and China was severely beaten by Japan some few years ago.

Finally, let us look at Belgium, with a population of only about $8,000,000$. The Belgians are the greatest beer drinkers in the world, consuming three times as much beer per caput as the people of the United States. Yet at Liège 100,000 heroic Belgians displayed sufficient efficiency to meet successfully three times their number of Germans, inflicting a loss admitted by Germany to total 42,714 and paralyzed for thirteen days, according to General LeClereq, military member of the Belgian commission, "the invasion which after forty years of preparation was expected to be irresistible."

Now how do the figures of the Life Insurance Companies agree with our reasoning?

The New York Life Insurance Company shows that among those who had taken "cures" for chronic alcoholism, but were temperate at the time of their acceptance, the extra mortality was 70 per cent.-A fairly high rate, which possibly would have been less, and probably would not have been more, had the alcoholics not reformed.

And the evidence grows stronger from the following: "In the experience of forty-three companies 
among those who had taken a cure for alcoholism, but [who had] remained total abstainers up to the time of acceptance, the mortality was 35 per cent. above the normal. Those who had been heavy drinkers, but who had reformed without taking a cure [probably many did not wholly reform] showed an extra mor. tality of [only] 32 per cent., doubtless because of stronger will-power and sturdier nervous constitution." 1

According to the Northwestern Mutual's experience, "temperate beer- and wine-drinkers showed a mortality of only about 3 per cent. in excess of abstainers, while whiskey-drinkers and heavy beer-drinkers showed a death rate 25 per cent. higher than the abstainers.

The foregoing bears out only what is popularly known: That excess in drinking, especially in spiritdrinking, is more harmful than moderation. And we could argue that the very slightly higher mortality rate of 3 per cent. among the temperate beer- and wine-drinkers could be accounted for by their having possessed slightly weaker will power and less sturdy nervous constitution, than had been possessed by those who had shown superior moral strength by abstaining altogether.

In order to determine more clearly how far the general mortality in different countries appears to stand in direct relation to the consumption of alcohol, Dr. Ulrik Quensel, Professor of Pathology at the Univer-

1 Atlantic Monthly, November, 1916, Alcohol and Life Insurance, by Eugene Lyman Fisk. 
sity of Upsala, prepared a table in which he showed that, while the mortality of the men in Finland was 23.31 per thousand, their average annual consumption of alcohol in liters, during the years 1891-1900, was only 2.04 per caput-a high death rate with a very low consumption of alcohol. On the other hand, he found that in France the mortality rate was 21.86 per thousand (lower than in Finland), while their annual consumption of alcohol, per caput, was 20.80 ; in Belgium the figures were 22.03 , mortality rate, and 14.00 , consumption of alcohol; in Italy they were 23.35, mortality rate, and 15.20, consumption of alcohol. Dr. Quensel gave other figures, which it is not necessary for me to give, as none showed the slightest connection between the quantity of drink and the incidence of mortality.

Commenting upon the result of his investigations, Dr. Quensel remarks: "The table indicates in general that there is no parallelism between the mortality statistics and the consumption of spirits. There are evidently other factors which determine mortality as a whole for the country, among which may be mentioned the influence of infant mortality, of infectious disease, and the general condition of hygiene."

Once again we must utilize statistics, but this time to sustain our contention that the alcohol evil is not nearly so widespread or so serious as its exaggerators would have us believe. And once more we quote from Mr. Fisk's paper.

“At my [Mr. Fisk's] request, two companies followed back for a number of months their recent ap- 
plications, which were in such form that the total abstainers could be distinguished from the users of alcohol. In the Postal Life 64 per cent. were abstainers; in the Germania Life 55.8 per cent. were abstainers. The rejection rate, excluding those who were rejected on account of intemperance, was about the same in the two classes of applicants, suggesting that total abstainers are in fact only average people, not a small group of 'health cranks.'

"In the New England Mutual an analysis of 180,000 cases insured during the past sixty years shows 24 per cent. abstainers and 11 per cent. rarely using alcohol, or about 35 per cent. practically abstaining from alcohol. ...

"The experiments of the Life Extension Institute, among the individuals it has examined, is along similar lines. These examinations were for hygienic or lifelengthening purposes, and included large groups of supposedly healthy average people whose employers had subscribed for this service. Among industrial workers 45 per cent. were abstainers. Among commercial workers (low average age) 72 per cent. were abstainers."

Now, obviously, if such a goodly percentage of persons in all positions of life abstain entirely from alcohol, there must be also a large percentage who use alcohol moderately; so that, there can be left out of a total population only a small percentage who use alcohol to excess.

Why, then, is there need of National Prohibition? To safeguard a few hopeless inebriates, unquestion- 
ably defective, thereby enormously inconveniencing as well as injuring the health and happiness of practically the entire normal population?

And, finally, would it be worth while; or, to put it less selfishly, would it be possible, by the most drastic legislation actually to save our few habitual drunkards? According to the evidence furnished by Dr. William A. White, in a paper published in the Interstate Medical Journal, it would not.

In his paper Dr. White cites the statistical paper of Haycraft, in which that author summarized his observations of the effects of prohibition in several of our prohibition states, where prohibition had been in operation for a considerable number of years.

"Haycraft's conclusion," says Dr. White, "was no less striking than unexpected at that time. It was to the effect that the statistics clearly indicated in those states that, as the consumption of alcohol had been diminished and as drunkenness had been lessened, the admission to the insane asylums and poor-houses had progressively and correspondingly increased. [Italics mine.]

"If we do not instantly discard such a conclusion as this ; and will stop for a moment to give it careful consideration, we must be struck by the probability of its truth, and by its important social significance.

"Such a conclusion can only mean that the alcoholic as such is a mental defective in some way, and that if his mental deficiency does not show as indulgence in alcohol, it will later show as frank mental disease, or as that type of deficiency which leads to 
pauperism. When we understand better the fundamental conditions which underlie the symptom, alcoholism, we may be able to do something more definitely constructive about it." 1

A curious side of Dr. Fisk's paper, excerpts of which we have used, giving him due credit, is that it was written against alcohol and seems to favor National Prohibition. It occasionally happens, however, that we are hurt by our own petards.

Of course, Life Insurance statistics, like other statisties, should be taken cum grano salis in their classifications. Many so-called moderate users of alcohol might be really immoderate users; for, even though the companies should carefully investigate statements in this regard, it would be uncommonly difficult to learn whether certain applicants actually and at all times were strictly moderate. So many factors, other than alcohol, influence the life and health of the individual, that to ascribe the sporadic higher mortality of certain drinkers to a single substance, alcohol, is hardly fair. Besides, among the insured non-abstainers are always a certain proportion of those who indulge immoderately, and these would necessarily lower considerably the average length of life in that section.

One not wholly insignificant factor having to do with the slightly longer life of abstainers, assuming that a fact, is that often they are unusually economical, and hence are free from the worry to which the immoderate drinker is especially subject owing to his

1 New York Medical Journal, January 20th, 1917. 
improvidence and consequent inability to provide properly for his family.

Another point, Life Insurance tables appear to show that between the fat and the thin, the latter are the better risks. Now, alcohol, lessening as it does tissue waste, and being therefore a sort of substitute for food, particularly when the alcoholic drink is beer, tends to put on flesh. And, further, alcohol in moderation, because it stimulates and facilitates digestion augments the desire for food. Hence, those who use alcohol, may, though not necessarily, eat too much and become too fat. Then, when fat, a man is not so inclined to exercise; and a lack of exercise is, as I shall show later, a primary if not the primary cause of heart disease, arteriosclerosis, and other diseases.

Nevertheless, I would not blame alcohol for making men fat, that effect proving only its wholesomeness, but I would blame the fat for not controlling their gluttony, and for being too indolent even to try to exercise.

Regarding the greater mortality of the fat, its verce causce are obviously, not alcohol, but often gluttony and, to put it plainly, sheer laziness.

The assumption that the health of those who drink beer exclusively and immoderately, is affected solely by the three or four per cent. of alcohol contained in the beer, seems to me arbitrary. There are in beerbesides alcohol--malt, hops, and, in impure beer, resin; also, there is a great deal of water in beer. Hence, if obesity, with its train of ills, results from 
excessive beer drinking, is it not reasonable to suppose the exaggerated adiposity to be due, less to the trifling quantity of alcohol, than to the nutrients and water ingested with the beer, to say nothing of the increased consumption of unneeded food resulting from the stimulated appetite?

We come now to how alcohol may be used to promote health and longevity.

Every one knows that the full-blooded and wellnourished are subject to diseases to which the anaemic, ill-nourished and frail are not so subject. The socalled plethoric type may suffer, or die prematurely, from gout, rheumatism, arteriosclerosis, angina pectoris, apoplexy, various forms of nephritis (inflammation of the kidneys), and of heart disease; or they may succumb more or less early to diabetes, acute indigestion, intestinal derangements, or pneumonia.A truly formidable list! On the other hand, thin, anæmic subjects are especially prone to constipation, chronic dyspepsia, pernicious anaemia, ulcers and cancer of the stomach, fevers, pulmonary tuberculosis (consumption), and chronic nephritis, caused often by a systemic deficiency of water.

While the above attempted classifications of the various diseases to which the stout and the thin are respectively subject, are rough, they are approximately accurate.

Now as facts are practically useless, unless applied, how may we utilize the knowledge embraced in our classifications for the furtherance of life and health?

I contend that, when properly used, alcohol will 
promote health and prolong life; but all types of men should not use alcohol in the same way, in the same quantity, and at the same times.

The plethoric (full blooded) should be sparing in their use of alcohol, should avoid overeating, and should take more vigorous exercise; obviously, so as not to increase their plethora, and hence their susceptibility to the diseases to which they are already liable.

Contrariwise, the thin should drink alcohol freely, though, of course not excessively; thereby increasing their appetite, and, as a consequence, their intake of food. Were such a regimen pursued by the too thin, while it would not make them over fat, it would take them out of the class of dyspeptics and consumptives, and would thus tend to benefit their health and to prolong their lives.

Used in the ways indicated, alcohol would be an agent for good; for all will agree, including the Life Insurance Companies, that both the super-fat and the super-thin-extreme types-have a poorer expectation of life than have those of medium physique who, naturally, are not especially subject either to the diseases peculiar to the over fat, or to those other quite as dreadful diseases peculiar to the too thin.

In other words, neither the underweights nor the overweights are, in the language of the Insurance Companies, nearly so good risks as are the proper weights; therefore, for longer life, it behooves the too fat to reduce, and the too thin to put on flesh. If alcohol, therefore, favors the formation of flesh-and 
that quality is conceded to alcohol even by the Prohibitionists-it should be good at least for those described as "painfully" thin.

That the foregoing, which is important, may be perfectly clear, I sum up as follows: The obese and full-blooded are subject to certain diseases; the thin and anaemic are subject to certain other diseases; while those neither too fat nor too thin are especially subject to no diseases. Therefore, the medium or "just right" condition, from the view-point of health and longevity, is the most desirable.

Now, as alcohol, owing to its stimulating effect upon the appetite and the gastric secretions, is a valuable food adjuvant, and, as such, undoubtedly favors flesh formation, it follows that, to attain longer life, the obese should curtail both their alcohol and their food, and increase their amount of exercise; whereas the thin and anaemic, would they prolong their lives by escaping the many diseases to which their constitutional poverty renders them liable, should increase their consumption of alcohol, thereby improving their appetite, and increasing their intake of water and of nourishing food.

From the above, we reason that, should National Prohibition be enacted, the ill-nourished and anaemic would be its chief victims ; they being doomed to perpetual tenuity, unless some substance to replace alcohol could be found, and that is doubtful.

Abstainers are generally poor water drinkers, but they drink coffee and tea; beverages which, as we have shown, congest the internal organs, and constant con- 
gestion may cause first functional, and finally organic, disease. (Alcohol and the Human Body, p. 148.)

There are, of course, two sides to all questions. Let us, therefore, take up a neglected side of another question-the alleged wholesomeness of candy and "soft" drinks. We are told that candy and syrup sodas are harmless, because they make nobody drunk. Yet the harmlessness, either of a beverage or of an article of food, is not proved by the absence of only one effect that another beverage has when used to excess.

"Soft" drinks are not, in my opinion, always health-giving. Indeed, if gastric sensations indicate anything, lemonade, sarsaparilla, ginger ale, and soda water slopped with syrup, are more acutely poisonous than are alcoholic drinks.

Let a man drink ten glasses of the deadly sweet syrups, flavored with soda water-usually dispensed in drug stores which make prescriptions a specialtyand the druggist would hurriedly have to exercise his "specialty." - If he should bring the patient "round," he would do well.

Yet what healthy man could not drink ten beers, and be none the worst for it?

Viewed symptomatically, there is no doubt as to which would be the more active poison, the "sickish" sweet soda water, or the light, wholesome beer.

I well remember attending a dance one hot summer night at an Armory. Of course, no intoxicating beverages were furnished, but there was plenty of lemonade. It was hot; I danced, perspired, and, afterward, 


\section{THE WHOLE TRUTH ABOUT ALCOHOL}

I drank a considerable quantity of lemonade. Later, I suffered from the worst colic of which I have recollection.

Granted that sweets do not intoxicate; nevertheless, they are injurious to many persons. In the first place many tons of the candies and soft drinks daily consumed are dangerously adulterated; and, even when pure, the great amount of sugar they contain is deleterious in excess-much more so than an equal quantity of light beer.

How many young women and men have ruined their stomachs and other portions of their digestive apparatus by eating habitually excessive quantities of candy! And very many persons can not eat even a moderate amount of sweets without suffering acute gastric distress.

Indeed, it would not be difficult to argue, and, were statistics available, it could probably be proved that candy and sickening-sweet concoctions, significantly called "soft" drinks, have done infinitely more harm and are responsible for more ruined digestions and permanently spoiled appetites than is even the demon rum.

It is unfortunate, because inevitable, that the blacker side of most questions is given undue prominence. It is in that way that prejudice displaces justice, and we get distorted views of nearly everything.

The number of persons whom light table beers and wines have helped is legion. We never hear of those; but one can not visit even a moving picture show anywhere without seeing in a majority of the pictures 
displayed all the repulsive evils of excessive drinking. I remember one particularly in which a bloated hard-faced saloon keeper lay in wait for customers outside his door, literally dragged them into his dram shop, and there plied them with liquor until they became stupefied.

Of course, such constant and exaggerated reiteration of an occasional evil creates an entirely wrong impression of the commonness of the evil.

Not so often are stories told like the following:

In an editorial, Resisting Power of Old Men, the New York Medical Journal for December 2, 1916, says: "A man, aged eighty-five years, who was in the habit of taking frequent nips of any drink in which his friends would join him, was taken ill with pneumonia. Dr. Russell, of Birmingham, saw him with me [Dr. William F. Box] in consultation on the fifth day of the attack, and we agreed that he had no chance of surviving, but the crisis came on the twelfth day. He made an uninterrupted recovery, and lived for two years afterward. 'The patient had a loud systolic bruit [murmur] at the apex of the heart ever since I had known him, which was about eight years."

Dr. William F. Box, a practitioner of Stratfordon-Avon, who communicated the foregoing case originally to the British Medical Journal, told also of another patient.

This was a man, over ninety-three years old, who had been operated on, at the age of seventy-nine years, for a strangulated inguinal hernia [rupture]. He 
recovered, although he also had a loud systolic bruit at the apex of his heart.

But the most interesting point in the above cases is the further statement of the physician that in both those very old men "the arteries were elastic, and there were no signs of high tension."

Unfortunately, the editorial does not state whether the second man, aged ninety-three years, was in the habit of taking frequent "nips" or not. But certainly the first one was, and that, without injury to his arteries, and without raising his blood-tension to the danger point.

Now, if alcohol were the "virulent poison," which the myriad anti-alcohol books declare it is, how could it be that a man "in the habit of taking frequent nips" - a confirmed tipler-should, when eighty-five years old and having a damaged heart, survive pneumonia, afterward living to the great age of eightyseven years?

The organs of all human beings are only human; that is to say, that, while there may be superficial differences in powers of resistance, human organs being of like physiological and histological structure, if alcohol in large doses should poison the organs of some, it would poison the homologous (like) organs of all. In short, as a poison, the effects of alcohol, in a given quantity, would be universal and inevitable, exactly as would be the effects of such poisons as arsenic, paris green, strychnine, carbolic and prussic acid, morphine, chloroform, etc.;-all which kill in excessive doses. 
Moreover, Prohibitionists aver specifically that "alcohol is absolutely destructive to the vascular system." If that is so, why did not alcohol absolutely destroy the vascular system of the man, who, in spite of having been "in the habit of taking frequent nips," died at the advanced age of eighty-seven years?

Instead, alcohol, though used in this old man's case habitually to excess, had no deleterious effect upon his vascular system, but left "his arteries elastic, with no signs of high tension." -Convincing proof that alcohol is not a poison, or else that the man who drank it habitually to excess was not human.

My readers will understand that $I$ am not trying indiscriminately to "knock" all Prohibitionists, many of whom are honest; I wish simply to tell, as fully as my limited powers permit, the truth, the whole truth, and nothing but the truth, about alcohol.

To give a common instance of how an effect is ascribed to a cause which really has had nothing to do with the effect, I may mention that whenever a man noted in any particular field-art, science, or finance-dies suddenly from heart disease, "overwork" is invariably given as the vera causa of the premature death.

Of course, in such cases, overwork does not mean physical overwork; it means unremitting application in the pursuit of the intellectual specialty. And yet, by no possibility, could too constant application of the brain to anything cause heart disease. It is quite true that continued mental strain could be an indirect cause, by occupying sedentarily all one's time, part 
of which should be spent in some physical exertion.

The true cause of heart disease, when not inherited or due to infection, is underwork-that is, physical underwork.

Heart disease may follow syphilis, rheumatic fever, arthritis, tonsillitis (?), arteriosclerosis, infectious fevers, or overstrain ; it may accompany lipoid (fatty) degeneration of the cor muscularis induced by bodily inactivity; or, it may be inherited; but heart disease is never caused simply by excessive brain-work.

Hugo Muensterberg, the noted German philosopher, died recently in a class-room in Cambridge, while delivering a lecture. He was only fifty-three years old. The cause of his sudden demise was given as "heart disease brought on by overwork."

But had Professor Muensterberg been in the habit of taking regular vigorous exercise, he would probably not have died at so early an age. The fiat that his "death was due to heart disease brought on by overwork" is illustrative of the loose way we have of explaining all untimely and unfortunate occurrences.

In much the same way, certain physicians and scientists, who really should know better, ascribe all varieties of diseases, incapacities and deficiencies to even the moderate use of alcohol; when, as a matter of fact, alcohol, moderately indulged in, could not produce a tithe of the effects shouldered upon it.

To conclude this chapter I quote the following from Dr. J. Starke (Alcohol-The Sanction for Its Use) : "The mode of living of the oldest inhabitants [in Germany], among a great number of people, has been 
twice examined; once, for example, that of the oldest people among 400,000 inhabitants of large cities. Both times there were found among the oldest men, not only sensible alcoholists [moderate drinkers], but men who were accustomed to heavy drinking, and men who had all their lives committed alcoholic excesses. And this, notwithstanding the fact, that the examinations were carried out among the inhabitants of different parts of Germany, that the examinations lay many years apart, and that both examiners independently of each other, were really convinced that something detrimental to alcohol would be found.

"He who expects to live especially long, because he abstains from alcohol, may experience a bitter disappointment." 


\section{CHAPTER XXV}

\section{ALCOHOL AND DEFICIENCY}

I MAINTAIN that chronic alcoholism is proof of deficiency. The stuff of which normal men are made is, in the chronic alcoholic, lacking. Habitual drunkards were never normal. Always they have been weak, selfish, conceited, and indifferent to others' and to their own welfare; also they have been deficient in average power to react against the common vicissitudes of life. To warn a confirmed inebriate not to drink, is like telling a coward to risk his life for another. Both know their duty, but it is not in them to do it.

Prohibitionists contend that drunkards are likely to have deficient children. They are. The question is, however, is such transmission due to the alcoholic excesses of the parents, or to the parental deficiency clearly shown by the habitual drunkenness? Surely, it would be strange if ruined stock should produce anything perfect; although it might beget a good throw-back.

Who will deny that chronic inebriety is a sign of deficiency? And if that is so, defective parents are, of course, more likely to have defective children than are normal parents. Yet alcohol is blamed. 
The argument that, because some of the children born to parents who drink alcohol, are defective, alcohol caused the defectiveness, reminds me of the old lady Christian Scientist who had a cat. Kittens were born to the cat, and the good old lady, noticing that they were blind, prayed assiduously that their eyesight would be made perfect. And, behold, after ten days, their eyes were opened, and they saw! Whereupon the old lady exclaimed triumphantly, "Christian Science did it!"

Said Dr. Percy Smith in his Presidential Address before the Section of Psychology of the British Medical Association:

"No doubt in many cases the alcoholic is a person who starts life with an unstable nervous system; he has either alcoholic, or insane, or neurotic inheritance, and, to a certain extent, he is defective $a b$ initio [from the beginning] in self-control, and goes without much resistance into the paths of chronic alcoholism."

In the evidence given by Dr. Robert Jones, Medical Superintendent of the Claybury Asylum, before the Inter-Departmental Committee on Physical Deterioration, he deposed:

"In regard to the effects of alcohol upon the descendants, anything which devitalizes the parent unfavorably affects the offspring, and clinical experience supports this in the lowered height and impaired general physique of the issue of intemperate parents. It also records the fact that no less than 42 per cent. of all periodic inebriates relate a history of either 
drink, insanity, or epilepsy in their ancestors." - In other words, their progenitors were in some way defective.

During our constant struggle for existence, Nature is continually weeding the sub-normal-the unfit, by causing them to destroy themselves. Insane, epileptic, and alcoholic stocks gradually die out.

Normal persons do not drink habitually to excess, any more than they eat to excess. The normal man is temperate in all things; hence, an inordinate appetite for strong drink argues abnormality and defectiveness.

It is almost universally believed, even by those who approve of the temperate use of alcohol, that the habitual use of this substance may create a craving for its repeated use. I do not believe that is true, excepting in the case of defectives; and defectiveness would manifest itself eventually in some way, if not by use of alcohol.

I would repeat here that common experience has shown that, when young adults are allowed beverages of light alcoholic content at the family table, they are less likely to become immoderate drinkers in mature age, than are those to whom alcohol in any form has been religiously forbidden.

I, myself, have used alcohol moderately but regularly for the past twenty-eight years; and, from my own experience I can state positively that the older I become the less alcohol I consume. Twenty years ago I used to drink whiskey occasionally, but I grew 
not to like it. Now I drink ale exclusively, and not much of that. Sometimes a glass at luncheon; usually a glass or two at dinner, and, if I have been up late and intensely occupied mentally, I drink a glass just before retiring, and most refreshing and satisfying I find it.

The drinking of alcohol produces three conditions, depending upon the amount consumed. A moderate amount results in stimulation; when more is taken, intoxication may follow; while an excessive quantity produces stupefaction.

In the stimulation stage, the natural disposition, or idiosyncratic ego, is intensified: The witty become brilliant; the joyful, exuberant; the agreeable, affectionate; the choleric, ugly; and the melancholic weep. If more alcohol is then taken, the various traits, after undergoing a still greater but temporary intensification, moderate; then are reduced rapidly until the stage of stupefaction is reached, which may fall into narcosis and end in coma, if the total consumption has been beyond reason.

The alcohol habit is induced in those who drink for stupefaction-not for stimulation. Obviously, for the production of stupefaction one must drink some strong spirituous liquor, and a great deal of it; and if that procedure is repeated often, the organism becomes accustomed to the powerful stimulation, learns to depend upon it, and at last demands it as the price of its continued functioning. Nor is that the worst; for, as the organism grows more resistant to the effects 
of the alcohol, its demands increase until they become almost insatiable.

Thus the confirmed inebriate's craving for alcohol becomes so massively systemic that in the end his power to resist, always weak, but finally awakened by his late realization of the consequences of his habit, collapses utterly.

That habitual intoxication to the point of almost daily narcotization is not good for the organism, goes without saying; and yet, certain "old soaks" live to a ripe old age.

Occasional intoxication, however, is not especially harmful, as the brain recovers from stupefaction, when not too often repeated, completely. The reason is that stupefaction is not, strictly speaking, an unnatural condition of the brain. The fatigue products cause more or less stupefaction, and conduce to sleep, where normal stupefaction is complete. We speak of one as being "stupefied" with sleep, when he can hardly keep his eyes open.

It is not, therefore, the stupefaction that injures the excessive drinker, so much as it is the ever increasing amounts of alcohol, fusel-oil, etc., which he finds necessary to produce it; for, undoubtedly, alcohol, like everything else, when in excessive amounts, acts destructively, if not poisonously, upon the human organism.

The Medical and Surgical Report of Bellevue and Allied Hospitals, New York, furnishes the following interesting table of answers given by inebriety patients to the question, "Why did you begin to drink?" 


\begin{tabular}{|c|c|c|c|}
\hline Sociability & 52.5 & per & cent. \\
\hline Trouble & 13. & “" & “6 \\
\hline Medical Use & 9.3 & “" & 66 \\
\hline Occupation & 7. & “ & “ \\
\hline Out of Work & 5. & "“ & “ \\
\hline Unknown & 5. & “6 & “ \\
\hline To be thought Sporting & 1.2 & ، & “6 \\
\hline
\end{tabular}

Thus more than half of the inebriates drank because they liked it-were weak, goodnatured, and liked to be "sociable." Trouble did not trouble many so much that they took to drink-showing innate indifference in most. Being "out of work" worried seriously only five per cent.-indifference again. And, "to be thought sporting" hardly figured at all as a cause (1.2 per cent.), as practically only one inebriate out of every hundred cared a rap what anyone thought about him-once more indifference.

In The Anti-Alcohol Movement in Europe (Ernest Gordon), we read of instances in France and Germany, where employers of large numbers of men erect canteens to sell beer, wines and liquors. They, then, for their own profit, encourage their workmen to drink, and succeed in making many drink much more than is good for them; for, those who do not drink freely are discharged, upon slight pretexts, and so lose their only means of a livelihood.

But such abuses are not arguments against alcohol; they are merely damning evidence of tyranny which should be suppressed by all means. 
In the same book are described drinking bouts of the German University students. They are disgusting. But who is advocating disgraceful drunken orgies?

It is comparatively easy to enumerate "horror stories" of the evils of alcoholism. Its effects are terrible; and alcoholism should be fought, just as gross immorality, venereal diseases, and evils of all kinds should be fought. But to cure sporadic inebriety it seems hardly necessary to tell the whole normal world that it must drink no alcoholic beverage whatsoever.

The Commission of Internal Revenue reports that for the fiscal year, 1916-1,182,193 barrels of beer less were consumed than for 1915.-Let the people alone, and they will learn to drink less.

Anti-Alcoholists claim that alcohol causes defective lactation and ovulation, and leads to sterility. On the other hand, many eminent physicians aver that beer, ale, and stout increase the flow of milk, and do not produce sterility.

Sir Victor Horsley states that the daughter of a drunkard can rarely suckle her child. That might be; for the daughter of a drunkard-a defectivewould be likely to be defective in more ways than the one of not being able to suckle her own infant. Yet that does not prove that moderate drinking vitiates the power of suckling.

Furthermore, many ladies of the aristocracy, who confine their drinking habits to coffee and tea, when they find themselves unable to breast-feed their infants, are glad to employ the wives and married 
daughters of workmen, who drink more or less, as wet nurses.

The German Empire has grown, in thirty years, from about forty, to sixty millions of people; showing that nations can considerably increase, despite the use of alcohol.

The statements of Prohibitionists regarding the influence of alcohol upon fecundity are contradictory. For instance, Professor Horsley remarks: "As [von] Bunge truly observes, we speak of a child's tissues as delicate and liable to injury by alcohol, but how much more delicate is the ovum."-But Dr. Edwin F. Bowers, another "anti," says: ${ }^{1}$ "The germ cells are much more difficult to poison or to affect unfavorably than are any other cells in the body." Then, again, says Dr. G. von Bunge, Professor in the University of Basil, this time more emphatically: "All should avoid alcoholic poison-the children, because it is especially injurious to the youthful organism; grown persons, because it is even more injurious to the germ cells [italies mine] ; the aged, as an example to others."

Could we be convinced by mere words, such impassioned utterances might impress. But, while we ponder, steps forth an English alienist, Dr. Branthwaite. This gentleman, however, wishes to warn against the danger of allowing chronic alcoholics to propagate their kind, and, being methodical, he collates amazing statistics to sharpen his "point."

In an address at the Stockholm Congress, Dr. 1 Alcohol-Its Influence on Mind and Body, p. 80. 
Branthwaite stated that, "out of 646 women admitted [to some hospital], who were drunkards of the most advanced type, 386 were either married at the time of admission, or widows. These 386 had given birth to 2,079 children, an average of 5.3 per head. Fifteen had brought ten or more children into the world, and one as many as seventeen!"

Pretty fair fecundity for "women drunkards of the most advanced type," and the more astounding in that we had been told that alcohol was the "poison" par excellence that attacked the "springs of life." We should have thought that such a "poison," as alcohol has been "indisputably" proved to be, would have had an immeasurably more deleterious effect upon the feminine germ cells [ova].-Well, we never really know, do we? After having given his convincing statistics Dr. Branthwaite made a strong plea for the necessity of surgically crippling the procreative parts of all chronic alcoholists.

Professor Horsley (Alcohol and the Human Body, p. 264) speaks of the frequency of the "overlaying" of infants by drunken mothers. He says: "The drowsiness and lethargy of the alcohol-taking mother is recognized as a frequent cause of the overlaying of infants."

Doubtless Sir Horsley meant to say "overlying"; but that is unimportant-a mere lapsus cerebri. We are inclined to believe, however, that, in many cases, the "drowsiness and lethargy" of those poor mothers have been "caused" as much by chronic overwork, as by chronic alcoholism. 
A cause, which we have not yet mentioned, but which has undoubtedly had much to do with the comparatively high mortality rate of the children of inebriates, apart from the inheritance of any parental deficiencies, is general neglect.

All know that drunkards are selfish, weak-willed, lazy, and lacking in self-control. If they love their wives and children, they love drink more; and, when they spend most of their wages for whiskey, not a great deal is left for rent, clothing, fuel, and food. As a consequence, their homes are squalid, filthy, comfortless, and cold; their wives are dejected and hopeless; while their children, besides being insufficiently nourished, are covered only with dirt and rags. Moreover, the miserable little ones, upon whom the sins of their fathers are heavily visited, receive none of that kindness and loving care usually lavished upon those more fortunately born.

A pathetic picture that makes the heart ache; and, were alcohol the cause, I would shout against it in clarion tones. But is alcohol the cause of such misery? I believe absolutely that it is not. The cause is man.

Myriad temptations beset everybody; alcohol is but one. Bank clerks see and handle money daily; only the thief steals it. Certain poor men, with families to support, bet on race horses;-a reason that the "sport of kings" should be stopped? Some men flirt with and seduce other men's wives;-should we therefore suppress women? Burglars prey upon the wealthy; - an argument against the acquisition of 
property? The vice of gluttony is widespread;-so, we should condemn delectable foods as "temptations"? There are drug fiends, hundreds of thousands of them; yet drugs are needed by the sick and suffering, and no government would forbid their use.

Then, because that benign gift, alcohol, is abused by some men, should all men spurn that gift?

If the temptations of money, sports, women, property, food, drugs, and drink, are not resisted by all men; not the temptations, but the men who make temptations out of what are in themselves good, should be eliminated. Upon the man who drinks immoderately, and upon him alone, rests the curse of drunkenness.

Always, when man's desires have been powerful, has he acted them out, despite law. Penalize him, and he will do secretly what he once did openly. But change his desires, and no law will be necessary to change his conduct.

Yet, there is no doubt that the evils of excessive drinking are great. Hence, saloons, as to their number, their hours for remaining open, and their methods of conducting business, should be strictly regulated. 


\section{CHAPTER XXVI}

\section{ALCOHOL AND POVERTY}

Is drink the cause of poverty? Prohibitionists say it is ; but let us reason a little. That poverty and excessive drinking are often associated is conceded; yet that far from proves excessive drinking to be the cause of poverty. It is the usual reasoning: Post hoc, ergo propter hoc. ${ }^{1}$

Men who drink to excess are generally lazy, shiftless, irresponsible and selfish; they have also deficient brain power. Hence, these defects, coupled with lack of ambition and aversion to industry, are the more logical causes of their poverty. Succinctly, temperament, rather than intemperance, seems the chief cause.

According to a report of the Committee of Fifty, the intemperance of parents or guardians was found to be the cause of the destitution of children in 45 per cent. of the cases they investigated. But here also temperament was probably the magna causa. Parents, who are not organically defective, care for their children, and do not drink to excess.

Frequently, the pangs of hunger, suffering from cold, and, sometimes, fear of poverty, lead to the drink habit.

1 After this; therefcre, because of this. 
And there are those who believe that poverty is not caused by intemperance. Others do not know, but try to find out. Mr. Charles Booth became so strongly impressed with the importance of liquor as a cause of pauperism that he made a thorough investigation in the almshouses and Homes of England, to find that drink figured but slightly as a cause, but that a large number of the cases was due to old age and sickness.

So overjoyed was Mr. Booth at his unlooked-for discovery that most paupers who had become a public charge had not been reduced to pauperism through vicious habits, that he advocated universal old age pensions in England.

The great investigation of the causes of pauperism, by the German Imperial Statistical Bureau, disclosed the fact that in only 2.1 per cent., of the $1,367,347$ cases examined, could the pauperism be attributed to the abuse of liquor; while Dr. Bohmert's study of 77 German cities resulted in the still lower figure of 1.3 per cent.

The report of the Economic Sub-Committee to the Committee of Fifty, of investigations conducted in New York and Baltimore, concluded that 23 per cent. and 21 per cent., respectively, of the cases of pauperism in the two cities, were due to drink; those higher figures being accounted for by the fact that, in their investigations, liquor was considered as an indirect, as well as a direct cause.

The pauper statistics from Magdeberg, for 1895, found 4 cases of "intemperance the cause," among 
2,260 permanent paupers. Among the poor and the paupers of Stuttgart, Dr. H. Rettich (1898) found that .09 per cent. of the 2,164 males had become dependent through drink, and, among 1,505 females, not even one.

Further investigations by the Committee of Fifty resulted in the following interesting information: Of 6,450 cases of distress seeking relief from charitable organizations in Baltimore, Boston, Buffalo, Cincinnati, and New York, in the year, 1891-92, 11.4 was the average percentage of the poverty that had been traced to drink. Among the applicants brought to their miserable condition by alcohol (?), were about twice as many white males as there were negroes. White males applied for relief about twice as often as did females. Married women were found to be more given to liquor drinking than were unmarried women; and the reverse was true in regard to married and unmarried men. Immorality among single women employed as domesties was found to be common. Prostitutes sought relief from charity, because of disease, rather than because of intemperance. That women came to want more often than did men, because of the intemperance of others, was found, as a matter of course.

In respect to nativity, it was found that very few native Americans of American extraction had to apply for charity, on account of their dissolute habits; most of the applicants having been foreigners. Among the latter, the Irish ranked high; the Hebrews very low; and the Italians still lower. 
"In stating causes of distress among 7,500 cases dealt with by the United Hebrew Charities of Chicago, in 1893-95, the superintendent of this organization does not mention drunkenness as a cause in a single instance." 1

The most recent study of the relation between drink and poverty is one published by the Alcohol Commission of Norway, collated by the Central Statistical bureau of that country. The inquiry embraced all persons who had received public poor relief in 1910 . In the cities, drink was put down as the chief cause of poverty in 1.8 per cent. of the cases, and a contributing cause in 4.8 per cent. Habitual drunkenness, during earlier years, was found to have been a cause in only 2 per cent. Corresponding numbers for the rural districts were 1.2, 0.8 , and 2.5 per cent. - a total of 4.5 per cent. No similar study of any magnitude has been made lately in this country, so we are unable to say how closely percentages here would correspond. But nowadays charity workers are more chary of ascribing poverty to drink. They recognize that often ill-health, indolence and crushing economic conditions hold the chief place.

1 Economic Aspects of the Liquor Problem, p. 72, by John Koren. 


\section{ALCOHOL AND CRIME , 209}

and Wales was 15 per cent. higher; but the crimes of violence-namely, common assaults, aggravated assaults, assaults on constables, felonious and malicious wounding-decreased 1.62 per cent.!" (Introduction to Judicial Statistics, 1901.) 


\section{CHAPTER XXVIII}

\section{ALCOHOL AND DISEASE}

Space and the reader's time are too valuable to permit enumeration of the host of diseases that advocates of prohibition claim are caused by alcohol.

Arteriosclerosis (hardening of the arteries), atrophy, (wasting) of the liver and kidneys, nephritis, (inflammation of the kidneys), "fatty" heart, cirrhosis of the liver, arthritis (inflammation of the joints), and gout,-are just a few of the ills for which alcohol is made primarily responsible.

In respect to gout, a light wine would do less harm than meat; while in some diseases of the heart, a glass of port would be not so injurious as much water. As to the claim that the moderate, but continued, use of alcohol causes arteriosclerosis, atrophy and cirrhosis of the liver, nephritis, et al., it is well to consider that proof is wanting that even immoderate drinking causes any one of those diseases; the fact being that many heavy drinkers have lived with sound organs to a great age. Again, there is the additional fact that abstainers have those diseases as well as drinkers.

In order to prove alcohol the vera causa of any disease, it would be necessary to show that, without alcohol, the disease could not occur.

Obesity and fatty heart, for both which conditions 210 
alcohol is blamed, are probably caused by excess of food, deficiency of exercise, and, in the case of heavy beer drinkers, by the enormous fluid intake-to say nothing of the additional absorption of the considerable cereal nutrient contained in beer. Perhaps also, the excessive amount of liquid imbibed overworks the kidneys as well as the heart; and that, in time, might produce disease of one or both of the organs.

"A man can quite ruin his blood vessels and his heart by daily increments of the fluid ingested, even if it be only water." (Starke.)

Nevertheless, excessive drinking, whether of beer or of whiskey, may lead to disease. But, while the chronic dram drinker, ingesting less liquid than the beer drinker, shows shrinkage, so that he becomes lean, ill-nourished, haggard and wizened (partially dried up), the heavy beer drinker becomes bloated, broadened, relaxed and fat.

Quite a contrast, which could not be accounted for in the two cases by the alcohol alone, since that substance is taken both by the spirit and the beer drinker. Hence, the different effects must have other causes than alcohol, such as, habitual ingestion of different amounts of liquid and of nourishment.

Naturally, the effect of a great deal of alcohol and a little water, is different from that of a great deal of water and a little alcohol; for, alcohol having an affinity for water, tends to "dry up" the dram drinker, but not the beer drinker, seeing that, in the latter's case, the consumption of water far exceeds the consumption of alcohol. 
Furthermore, the diseases peculiar to the excessive whiskey drinker are not the same as those to which the heavy beer drinker is susceptible; the former being prone to atrophies of eertain organs, and to diseases of the nervous system; whereas the diseases of the latter are likely to be chiefly circulatory, with dilatations, softenings, and fatty degenerations, often of the heart.

But the idea that the elimination of alcohol would largely eliminate disease-using the term disease in a wide sense-is phantastic, to say the least, considering the small part alcohol actually plays in the production of disease-excepting, of course, in the cases of excessive spirit drinking.

Further proof that overnourishment and underexercise, rather than the alcohol ingested, bring on heart disease and gout, is shown by the fact that those disorders are prevalent in the obese, who eat heartily and exercise little, irrespective of whether they drink alcohol or not.

All know that the shaky, thin, undernourished dram drinker rarely has heart disease or gout-at all events, one does not usually associate those particular diseases with inebriety. When we think of the whiskey toper, our minds advert to delirium tremens, mania à potu, paralyses, and nervous disorders generally, but not to gout, rheumatic fever, or heart disease.

Consumption is a disease which the chronic inebriate occasionally contracts, but, then, his abstinence from proper nutriment, rather than his overindulgence in alcohol, is the predisposing cause; consumption-the 
disease of the poor-attacking usually the undernourished. Yet I think the sane element in the medical profession will agree, when I say, that even the hard liquor drinker, who retains his appetite for food, is no more liable to tuberculosis than is any other human being.

There is no end to the "knocks" administered to the Demon Alcohol. Let there be an increase in carnal assaults upon children, or an increase in accidents, disease, divorce, idiocy, brutality, criminality, murder, lunacy, barrenness, impotency, morbidity, suicide, illiteracy, poverty, mendicancy,--and all are laid to alcohol.

For a long time it was believed universally that paresis, a slowly progressive and incurable degeneration of the brain cells manifested by a partial paralysis, was due to alcohol and "fast" living. Now every physician knows thàt paresis, popularly, "softening of the brain," is a parasyphilitic affection; that is to say, it is a consequence of syphilis, and of nothing else. Locomotor ataxia is another parasyphilitic disease, once thought caused by overindulgence in alcohol and sexual intercourse.

That syphilis is frequently a potent cause of kidney disease, appears strikingly in a paper on The Prevalence of Syphilis in the Insane Negro, published in a recent number of the New York Medical Journal.

The author says in this regard: "Although this paper deals with the prevalence of syphilis in the insane negro, I can not refrain from mentioning that twenty-six cases showed renal [kidney] involvement. 
Stengel and Austin, in speaking of syphilitic nephritis [kidney inflammation due to syphilis], mention a chronic form in which syphilis is the etiological [causative] factor. It is in the later stages of syphilis that amyloid [waxy, starch-like] and interstitial kidneys [kidney degeneration characterized by the gradual substitution of connective, for the normally functioning, tissue] are common. These authors believe that there exists a parenchymatous type of nephritis [inflammation of the true kidney tissue] due to syphilis, characterized by albumin, hyaline [glass-like, translucent] and granular casts, with occasional tendency to produce oedema [puffiness, swelling] of renal distribution.

"Out of eighty-four cases of nephritis they found sixty-six with syphilis as a possible cause of the disease. [Italics mine.] Of the eighteen remaining there existed in eight an unquestionable history of syphilis or a positive Wassermann [a serum test for syphilis], or both. In six no Wassermann was secured; while, in four, syphilis was definitely excluded. There is no doubt that our cases bear out their [Stengel's and Austin's] statements.

"The coincidence of syphilis and nephritis in a middle-aged man, without apparent cause, suggests that syphilis no doubt is a factor in the chronic form of nephritis, and further study in this direction suggests itself."

Certainly a remarkable finding, that, out of eightyfour cases of nephritis in insane negroes, in only four 
was syphilis definitely excluded as a causative factor!

The importance of the above in casting doubt upon alcohol as a cause of nephritis [kidney disease], in many cases, can hardly be overestimated, if we remember the steady increase in renal disorders during the past six years, and consider how common syphilis, or at least some syphilitic taint, is among the general population.

Many of the statisties, showing the number of deaths alleged to have been due directly or indirectly to alcohol, which are triumphantly pointed at by the Anti-Alcoholists, are very misleading, as it is manifestly impossible to know positively that alcohol has had anything whatever to do with such and such deaths-excepting those from acute alcohol poisoning, alcoholic coma, or delirium tremens.

In the Anti-Alcohol Movement in Europe (Ernest Gordon), we read a compilation, drawn from sources all over the globe, of the evils of drink, of the crimes committed under its influence, of instances of insane and bestial drunkenness, of alcohol's poisonous effects upon the mind and body, etc., etc.

But anyone, who searched with sufficient pertinacity, would find many hundreds of examples of the ravages of far less evils than alcohol.

In Mr. Gordon's book, and in Sir Victor Horsley's 'Alcohol and the Human Body, to mention only two, not one good word is said intentionally of alcohol, and that, to me at least, seems not fair, but savors strongly of bias. Indeed, Sir Victor Horsley goes 
so far as to say that syphilis, which everyone knows is caused by a specific germ, a spirochaete, is caused indirectly by alcohol.

On the other hand, in the present book, it has been found necessary, in the cause of fairness and the whole truth, to say some bad as well as much good, about this extraordinary substance, which once our Lord, Jesus Christ, compassionately changed water into.

The extravagance of asseveration, in parts of The Anti-Alcohol Movement in Europe, borders upon the ludicrous. For example, on page 68 , we are told that "The miners of the Borinage, who drink spirits and petroleum, often a litre a day, have become a race of dwarfs."

Now, as we are not told that the miners of the Borinage were in the habit of drinking their spirits and petroleum as babies, we fail to see how even that vile mixture could have affected their stature. If it be meant that their pernicious habit caused them to beget undersized offspring, we would still be in the dark as to whether it was the alcohol, the petroleum, or their anaerobic occupation, which had so sadly truncated them.

Again, in the same informing book, on page 70, Dr. Presl, quoted by Mr. Gordon, tells us that, "The advancing alcoholism in Bohemia is showing itself in forced sales of farms, and in the decreasing militaryphysical value of those summoned to the colours. The region most affected begins at Tabor and spreads over the Bohemian-Moravian plateau. In the deep- 
cut valleys numerous crétins live under the poorest conditions. The chief crop is potatoes for distilling and a great number of distilleries are to be found here."

Are we then to infer from the statement of Dr. Presl that the prevalence of cretinism in "the deepcut valleys" of that region is one by-product of the great number of distilleries to be found there?

We might, if we did not know that cretinism is supposed to result from certain atmospheric and topographical conditions, which are not well understood, associated with hereditary predisposition and unsuitable diet; and that deficient functioning of the thyroid gland is also a contributory cause-but, alas, no authority mentions cretinism and alcohol in the same breath. At all events, thyroid extract has been administered to cretins by physicians, often with marked benefit.

And now listen to this horror story.

"On Sunday nights, and on the nights of the numerous church festivals," said a speaker at the Tenth Congress against Alcoholism, "one sees in the country [Belgium] sights of savagery unparalleled among civilized people. Bands of persons in an advanced state of intoxication and armed with knives or revolvers, fight among themselves or attack passersby, just for the pleasure of shedding blood. They leave wounded and frequently dead persons on the roads. Their attacks on property are often incredible. They break windows, smash in doors, destroy fences, and ravage fields and gardens, and often set fire to build- 
ings. Recently at Eckeren, near Antwerp, a band of drunkards from a tavern raided a workman's house, dragged his wife out of bed, and clubbed the husband to death.

“'These brutes do not drink hard liquor, but alcohol in the form of from ten to twenty glasses of beer. This drink [beer] is the chief stimulus to crime in the country in Belgium, as distilled drinks in the cities. There has been in the country at large a considerable diminution in the consumption of distilled liquor, but that of beer constantly increases and with it eriminality rises." . . .

But just think, Mr. Speaker, of how many drink beer, and who, yet, never dream of clubbing husbands to death, or of ravaging fields and gardens, or even of setting fire to buildings !

Then, too, kindly explain-if alcohol instigated all the crimes you have so graphically enumerated-why should such crimes increase when, according to your own statement, less alcohol is consumed? For, if you remember, you said that, as the consumption of distilled liquors-containing much alcohol-has decreased, and as the drinking of beer-containing very little alcohol-has increased, so has criminality risen.

In short, if the theorem be true, that the more alcohol is consumed, the more crimes are committed, how could it be that in Belgium crimes should decrease as the consumption of alcohol increased; so that there it would be the more alcohol, the less crime, and the less alcohol, the more crime. Really we do not quite understand, unless it could be that the enor- 
mous intake of that usually harmless substance, water, should make the Belgians insane!-But let us continue.

"We saw some years ago at a village kermess a young and inoffensive stranger literally cut to pieces with knives by some persons who had been drinking beer. This simply because his Dutch accent had aroused their anger. Hundreds of savage peasants stood around applauding and throwing stones at the dying man. The name of this charming place should be known. It was Wavre Notre Dame, in the province of Antwerp.

"This is the effect of beer, which some naïve persons would have us use instead of spirits." 1

I have quoted the above at length to show to what absurd exaggeration a fixed fanatical belief will sometimes carry a man. It is a fair sample of the hodgepodge honeycombing the book. Evidently, the speaker at the "Tenth Congress against Alcoholism," whoever he was, did not like beer; and if he did, would any reasonable quantity of that mild beverage-even "from ten to twenty glasses"- - cause him to see a tithe of the horrible things he declares he was an eye-witness of? Fanaticism seems to have been in him more potent than alcohol.

And what manner of men must those Belgians be, if ten glasses of beer could cause them to commit such atrocious crimes! If the stories are true, and we have no reason to doubt the "speaker," we perforce conclude that the Belgians alluded to

1 Quoted in Anti-Alcohol Movement in Europe, pp. 68-69. 
were themselves infinitely viler than the vilest beer.

Another speaker, this time at the Seventeenth International Congress against Alcoholism, had this to say: "In his passion for alcohol the peasant becomes the cause of a morbid heredity, of social downfall. From the union of these degenerates follows either sterility, or a vitiated offspring $a b$ ovo. The children retain an indelible stamp, the stigmata of alcoholism, and, when they reach maturity, they procreate, in their turn, weaklings, idiots, epileptics, brains of an arrested development, furrowed with misery and corrupted with sickness to which they soon succumb. From this sad state of things comes the frightful depopulation which threatens our country." [France].

Thus alcoholism, according to this speaker, tends to destroy itself, by inducing "sterility," or, if there are children, "a morbid heredity," to which "they soon succumb."

Now while we agree that chronic alcoholism is an evil which tends to destroy itself, we refuse to believe that that condition, or disease, is so widely prevalent in France that: "From this sad state of things comes the frightful depopulation which threatens our country." Alcoholism, could hardly be the "cause" of the depopulation of France!

Let us now discuss alcohol as a "cause" of tuberculosis.

"Without alcohol," says M. Reinach, "the rural populations of France would be practically untouched by tuberculosis. As it is, alcoholism is destroying the 
peasantry of the healthiest and most beautiful regions by inducing tuberculosis." 1

We, not being omniscient like M. Reinach, do not hold with him that, "without alcohol, the rural population of France would be practically untouched by tuberculosis." We do not know. We believe, how- . ever, that there would still be some tuberculosis even in the rural populations of France, were there no such substance as alcohol.-But we have not M. Reinach's faith.

On page 65 of the same entertaining volume, we are apprised that: "All the investigations made by our colleagues, Drs. Jacquet, Legendre, Faisans, Barbier, de Lavarenne, and by the Société des Médicins des Hôpitaux, of Paris, have been decisive."

Two "decisions" will do; others being in like vein.

1. "On a basis of 717 cases of pulmonary tuberculosis, observed three years at the Hôpital Boucicaut, I [one of the above physicians] have been able to affirm that, en bloc, eighty per cent. of the workmen under my care are alcoholists, and that nine-tenths of the Parisian workmen above thirty years, affected with pulmonary phthisis [consumption], are alcoholists."

2. "Of 2,000 cases of nervous disorder cared for in one year by Professor Raymond at the Salpêtrière, 1,350 had alcoholism as efficient cause."

In regard to "decision". No. 2, we have already shown that, among those with "nervous disorder," more drink because they are insane, than are insane because they drink. So, until Professor Raymond

1 Quoted in Anti-Alcohol Movement in Europe, p. 61. 
proves that, out of his 2,000 cases, 1,350 were made insane by drink, we reserve the right to remain sceptical. At present it seems probable that, of the 1,350 who "had alcoholism as efficient cause," many had original psychoses which were fallow ground for alcohol to work upon.

In regard to "decision" No. 1 , we would say that probably 80 per cent., or more of the normal workmen in France, drink, more or less; and that perhaps even nine-tenths of the ordinary Parisian workmen, above thirty years, drink also.

Hence, the conclusion of the learned physician that, of the 717 cases of pulmonary tuberculosis, 80 per cent. were alcoholists, and that nine-tenths of the Parisian workmen, above thirty years, affected with pulmonary phthisis, were alcoholists, would be more valuable, if we knew just what this physician means by "alcoholist." But that term, whether intentionally or unintentionally, he does not specify.

Again, it might well be that a large percentage of those who found that they had tuberculosis, would take to excessive drinking to blunt their misery and worry over their desperate condition.-But let that pass; and let us ask, instead, what is an alcoholist?

Strictly speaking, an alcoholist is anyone who ingests the least quantity of alcohol. Thus, one who drinks one glass or two glasses of wine, or two or three glasses of beer, daily, is an alcoholist. We can not believe, however, that such moderate drinking would either induce consumption, or drive a man mad. 
It is common knowledge that men who drink beer or ale are generally well nourished. Also, it is wellknown that men of such type are not subject to pulmonary phthisis; that lingering disease usually attacking the poor, anaemic, and undernourished. Indeed, there is a wide-spread belief that the inhalation of vapors arising from beer vats will occasionally arrest the progress of phthisis. But that is a "cure" of which I have no personal knowledge.

Sir Victor Horsley, writing of consumption and alcohol, quotes "a great French physician, Dr. Brouardel":

"Alcoholism is in effect the most powerful factor in the propagation of tuberculosis. The most vigorous man, who becomes alcoholic, is without resistance before it."

Respecting the above, while I am not writing in favor of, but on the contrary, am strongly against alcoholic excesses, any man of ordinary intelligence knows that Dr. Brouardel's statement is, to say the least, an exaggeration. Every human being is more or less exposed to tuberculosis all his life; yet, every chronic alcoholic, who is necessarily among those exposed, does not contract tuberculosis-some do, of course, but not all. Neither would a roundup and thorough physical examination of all chronic inebriates reveal the presence of well-defined tuberculosis in even a majority of them.

How easy it is to be deceived by "cures" for consumption, and, especially, by statistics, true on their face, but of no real significance, is shown in a paper, 


\section{THE WHOLE TRUTH ABOUT ALCOHOL}

by Dr. Maurice Fishberg, The Traditional Fallacies of Tuberculosis, which appeared in a recent issue of the New York Medical Journal. Dr. Fishberg speaks with the authority of long experience as Clinical Professor of Medicine in the University and Bellevue Hospital Medical College. He says:

"Close analysis shows clearly the fallacy of testing statistically a remedy for tuberculosis. The fact is that over 50 per cent. of the patients suffering from pulmonary tuberculosis will, without any treatment whatever, survive five years after the onset of their disease, and remain more or less efficient at their occupation.

"So that, when discoverers claim that their several diverse remedies will cure more than half the cases, they are safe in their claims, provided their remedies are at least harmless. And if the discoverer asserts that only selected cases are suitable for his cure, he may prove that seventy-five per cent. of his cases are benefited. In fact, he may use distilled water, bread pills, or even prayer, and he will get the same results."

Dr. Fishberg's assertions seem the more plausible when we consider that it is a notorious and ascertained fact that over 90 per cent. of those upon whom autopsies have been made showed healed tuberculosis lesions of the lungs, proving that at some period of their lives they had had tuberculosis and had recovered without medicaments or other treatment.

As showing, again, how even the most eminent sci- 
entists may be mistaken in their "infallible" tests, I take the liberty of quoting a little further from Dr. Fishberg's paper.

"Some six or eight years ago when the cutaneous tuberculin test [a specific reaction to the injection of tuberculin] was considered a valuable diagnostic procedure, a positive reaction was deemed a sure indication of tuberculosis disease in a child of school age. But, when we found that over seventy per cent. of children gave positive reactions to tuberculin, we ceased to consider it of importance."

But if physicians of standing were incredulous as to the infallibility of the test, not so were some of the opponents of alcohol.

With hands upraised in righteous horror they proclaimed the fact that, of every hundred children "tested" for tuberculosis in the schools, seventy were found to be infected with that dreadful disease; and that "fact" was given as "proof" that the human race, owing to alcohol and to nothing else, was degenerating with such awful rapidity that nearly three-fourths of the next generation were withering in the blossom of their tender childhood!

We come now to alcohol as a "cause" of cancer.

Of course all strictly monopartisan Prohibitionists hold alcohol to be the cause of the steady increase in carcinomatous growths during the past decade.

Now, that alcoholic excesses do, in some cases, increase liability to cancer, may be true; for the frequent potions of heavy drinkers, particularly spirit 
drinkers, irritate the mucous lining of the stomach, thus possibly predisposing to ulcer, which, in its turn, may predispose to cancer.

But I am not willing to admit the further claim that the moderate, or occasional, indulgence in the milder alcoholic liquids, such as beer, predisposes to cancer in the slightest degree; seeing that, in such cases, there is no true or unusual irritation.

If it were true that alcohol in small quantities did irritate the stomach, then would the ingestion of all carbohydrates and sugar be dangerous, inasmuch as all starches and sugars are split up, by the bodily ferments, into alcohol, carbonic acid, etc.-a fact, which I notice Anti-Alcoholists carefully refrain from mentioning. They say simply the half-truth that "starch and sugar are changed into carbonic acid, water, and other substances."

I shall go further by saying that, in my opinion, moderate indulgence in the lighter alcoholic beverages, by improving appetite and nutrition and thus favoring an increase in body weight, acts as a preventive of cancer; that disease attacking chiefly those who, through poverty, or, worse, ill-health, become insufficiently nourished.

Before dogmatizing from the history statisties of diseases generally, it would be well to remember, particularly when alcohol is given, by too often prejudiced observers, as the "cause" of such and such disease, that, when some hundreds or thousands of cases are collated and their histories taken, most of the patients, when questioned, will acknowledge some 
present or past indulgence in alcohol, simply because a majority of the population drinks or has drunk more or less. In truth, one who has never at any time in his life tasted any kind of alcoholic beverage would be a rara avis.

Hence, when we read that so many per cent. of the cases of such and such disease "showed a history of alcoholism," we should be cautious in accepting the implication before we have learned just what was meant by "a history of alcoholism."

Did it mean the history of one who confessed to one glass of beer every twenty-four hours, or of one to whom an average of a glass of beer every hour had not been unusual? Or did "a history of alcoholism" relate to a steady dram drinker, or to one to whom indulgence in a single "finger" of whiskey constituted an epochal episode?

We, therefore, request sincere Prohibitionists kindly to be more specific in their reasons for their "decisions" hereafter; as we believe that most of the statistics, laboriously compiled for use in the numerous vicious attacks upon alcohol, have been entirely too easily found.

While turning the pages of Sir Victor Horsley's Alcohol and the Human Body, I was surprised to find that, on page 128 , that eminent scientist ascribes to alcohol the production of that life-blasting disease, epilepsy. He states :

"The disease known as epilepsy is characterized by convulsive seizures, which are due to varying forms of brain excitation. Consequently, it is produced by 
different causes. Thus certain drugs, especially $a b$ sinthe and alcohol, are particularly excitants of the cerebral cortex, and produce epileptic fits. [Italics mine.] ... .

"Chronic alcoholic patients frequently become epileptic."

The above assertions are so astounding that I believe few physicians would be willing to go on record as agreeing with Dr. Horsley. Many physicians of the highest repute now consider epilepsy a true germ disease.

Not long ago, Dr. Reed published a paper on epilepsy, in which he positively declared, not only that epilepsy was caused by a specific germ, but that he had succeeded in isolating from blood cultures obtained from epileptics a new micro-organism, which, in his opinion, produced epilepsy. He called the organism, bacillus epilepticus; and that has since become known as "Reed's bacillus."

Dr. Reed's discovery, however, it is only fair to state, was made some time after the publication of Sir Victor Horsley's book.

We acknowledge that alcoholic excesses could excite convulsions only in those who are either potentially or actually epileptics.

Another scientist, Dr. Legrain, blames alcohol for both adiposity and tenuity. He says: "Fatness and sometimes leanness, all sorts of non-assimilations, are the signs [of alcohol] which are apparent."-It seems that alcohol, like the man in the fairy tale who drank the Atlantic ocean, can do anything. 
Sir Victor Horsley kindly shows us on page 132 (Alcohol and the Human Body) six separate drawings of corpuscles, or nerve cells, magnified 750 diameters. No. 1 is a fine, robust corpuscle, which it is a pleasure to look at; No. 2 is, alas, degenerating; while Nos. 3, 4, 5 and 6, appear sick, sicker, still sicker, and moribund. Their purport is to demonstrate pictorially the ravages of that old enemy alcohol upon that first healthy corpuscle, blushing in the pride of his young strength.

At first, I was inexpressibly shocked at the melancholy sight those sick and rapidly degenerating corpuscles presented, until, reading an explanatory note, I learned that the last five photo-micrographs had been taken from successive drops of the fluid "taken from the spinal cord of [a] patient who died after a lingering and painful illness brought on by alcohol." [Page 135.]

Then I breathed more easily as I reflected that probably No. 6-the sickest cell-had been photographed synchronously with the man's death-which painful event no doubt had disagreed with his cells even more than had alcohol.

Strangely enough, Professor Horsley, in discussing pneumonia, grants that the pneumococcus produces that disease; but he avers that alcohol "opens the door and lets him in." As he puts it: "The alcohol habit depresses the healthy resistance of the body to the organism"' [pneumococcus].

Now I had thought that a stiff dose of hot water, whiskey and sugar, given to one who has been thor- 
oughly chilled, by perhaps an involuntary immersion in the winter time, had more than once averted pneumonia.-But possibly I am wrong.

To conclude this chapter fittingly I would most respectfully suggest that Sir Victor Horsley, or some equally eminent scientist, raise cultures from alcohol, isolate something, and call it, say, the alcohococcus. For, only a naked germ, formidably named, could plausibly be made responsible for every ill to which our flesh is heir. 


\section{CHAPTER XXIX}

THE NON-ALCOHOLIC CAUSE OF MAN'S PHYSICAL DETERIORIATION

Every thing, event, or happening has a cause. In certain ways man has been steadily deteriorating for the last hundred years. Obviously, his deterioration has been physical, and not mental; for, mentally he has always advanced, and is still advancing rapidly.

I shall now try to show the true cause of man's continuing physical deterioration. In my demonstration I shall give no hearsay evidence, but just facts deduced from actual personal experience covering a period of thirty years.

While the fact of man's progressive physical deterioration is known to physicians and scientists, none seems, as yet, to have discovered the cause. The Prohibitionists say that it is alcohol ; Anti-Smoking Societies declare it is tobacco; others aver it is immoderate coffee and tea drinking; and still others that it is the general hurry, scurry and worry of all civilized peoples.

My personal experience has been that the cause lies in none of those. I have hurried, worried, and scurried all my life; I have always drunk coffee and tea; I have smoked, at times, incessantly; and I have 
indulged in alcohol, in the form of cream ale, daily, for the last thirty years. But, though forty-six years old, I have not, as yet, physically deteriorated in the slightest degree.

Nevertheless, there remains the stubborn fact of a certain physical deterioration in the general populätion; and as no effect is without a cause, what, then, is the cause?

If, in this book, I have succeeded in convincing any that alcohol has been greatly maligned, that many of the vicious attacks upon it have had no basis of real evidence, of reason, or of common sense; that, in a word, its influence for evil and as a deteriorator of the human race has been, at least, greatly exaggerated-I say, if I have done this, it is but right that I should reconstruct where I have destroyed, by demonstrating the true deteriorator, or cause; and that, in so far as I am able, I purpose to do.

It is true that science has reduced the general death rate from 20.57 per 1000 of estimated population, during the year 1900 , to 13.89 per 1000 , during the year 1916. It is true also that science has reduced the infant mortality rate from 125.6 per 1000 births reported, for the year 1910, to 93.1, for the year 1916 .

Now how have those death rates been reduced? By better hygiene and sanitation, and by better control. of infectious and contagious diseases, even to the point of blotting out some, in certain localities, and of greatly limiting the scope and virulence of others.

Thus, the annual deaths from tuberculosis, typhoid [ fever, measles, scarlet fever, whooping cough, diph- 
theria and croup, have decreased considerably, proportionally to the population, since 1910 .

On the other hand, the number of deaths from other diseases has either not decreased, or has increased considerably, proportionally to the population, since 1910.

For example, pneumonia claimed about as many victims in 1916 as it has in previous years; while the death rate for acute bronchitis, for the year 1916, showed an increase.

And now we come to the "certain ways" in which man has deteriorated. Science has done its best; it has helped man much, and all it could. But science has failed in certain respects.

For, there are still other diseases, more serious than any I have enumerated, which have not only not decreased, but have greatly increased. These diseases are chiefly circulatory, and are peculiar to adult life. They are apoplexy, heart diseases, Bright's disease, nephritis (acute and chronic), diabetes, and cancer.

The prevalence of those latter diseases has been increasing steadily, especially during the last ten years; while diseases of the heart, during that same length of time, have increased by 33 per cent.!

Now it is peculiar and extremely significant, in view of what I shall have to say presently, that the only diseases which science has found itself unable to cope with are the circulatory diseases.

Why is it, scientists have repeatedly asked them. selves, that we have fought successfully all diseases, excepting the circulatory diseases; and that only the 
latter have increased, certain of them enormously, in spite of our most strenuous offorts?

Faulty diet, cry most; alcohol, cry many; tobacco, cry some; but none thinks of the true cause-perhaps because of its simplicity.

If the reader will notice, the diseases which science has been able to control, often to a wonderful extent, have been the true germ diseases, proved to be infectious and caused by specific micro-organisms; in other words, every germ disease is due to a specific entity, which science has, in most cases, isolated, classified, and afterward been able to destroy by some other specific entity known to be antidotal to it.

Some contend that heart and kidney complaints, and cancer, are likewise germ diseases; but their assumption has not been proved, and is probably incorrect. No doubt they are favored by a sluggish circulation, seeing that they are circulatory diseases, not commonly met with in children, or in those whose circulation is active.

Time was when man was as healthy as now are the feral animals. In the sweat of his body he earned his bread, and, incidentally, his health, strength and repose. He degenerated when he became luxurious; becoming at the same time nervous, sleepless and strengthless (asthenic).

Hence, while the wild animals have been steadily eliminating the diseases peculiar to their species, man's civilization, and often Sybaritic luxury, have multiplied his diseases, both in their variety and in their virulence. 
Of all the circulatory diseases, heart disease is the most prevalent in adult life. In children, heart disease, unless congenital, or there is an hereditary predisposition to it, is rare.

I remember reading lately the report of the result of an examination of the hearts of all public school children in this city (New York). The figures, showing the number of cases of heart disease among those children, I have not by me, but they were so extremely low that the committee which had conducted the examinations expressed their great gratification that the hearts of such a large number of children had proved to be sound.

It is common knowledge, also, that young adults do not, as a rule, suffer from cardiac derangements.

Heart disease, therefore, is prevalent only among the middle-aged and the elderly; and, consequently, is more often acquired than inherited. All which, too, is in keeping with the biological law that acquired characters, or defects, are not inheritable.

Now why do so many of those born with normal hearts acquire some disease of that organ only after they have reached or passed middle-age? Why do they not oftener acquire heart disease when they are young? For, certainly, the human animal subjects his heart to far greater and longer-continued strain when he is young and vigorous, than when he is old and comparatively inactive.

The answer is that heart disease is caused, in probably ninety-nine cases out of every hundred, by a 
sluggish circulation induced by habitual physical inactivity.

But the laity do not know that. I was talking the other day with a retired fireman about fifty years old. He spoke about the exercise he used to take when in the fire department. I asked him if he still exercised. He said, "Oh, no. I don't think it's good for a man of my age to take any active exercise; it's apt to bring on heart disease." And that man was above the average in intelligence. Truly the public needs information more than reformation!

Fire horses that gallop through the streets hauling a heavy engine are withdrawn from active service when they become old, because they are then not quite so quick as young horses; but their strenuous exercise, even when they are very old, rarely "brings on heart disease." While men are not horses, they are like horses in that they are animals; and active exercise is as good for one animal as for another.

Children romp and play-are seldom quiet. Young adults go in for athletics, run, play base-ball, football, work in a gymnasium "to get strong," swim, row, wrestle and box. Thus, their circulation, regularly stimulated by exercise, remains active, except in the hours of repose; and, as a consequence, rarely in early life is any circulatory disease acquired.

Now let us see what happens after the young man has been graduated from his high school or college. As soon as possible thereafter he begins his serious work in life by entering some business or profession. He becomes a man, and, as a man, casts away childish 
things. Play is for children, and athletic sports are for boys. He has no time for such frivolities, but buckles down to work. At last his constant application is rewarded, and he becomes a leading lawyer, a wealthy financier, an eminent physician, or a famous surgeon.

His brain does not give out? Certainly not; for he uses that constantly, and so keeps it in good condition. But what about his arteries and his heart, and his kidneys?

$\mathrm{He}$ is now past middle-age, but he is successful, and he smiles. His heart begins to bother him, and he becomes breathless after slight exertion; so he visits a doctor. A physical examination shows that his arteries have hardened, grown brittle, and have lost much of their normal elasticity; but, compensatorily, his heart has enlarged (hypertrophied) to overcome the increased resistance of his now less yielding blood tubes, and to make up for their withdrawn assistance, when they used to expand and contract with each cardiac systole (contraction) and diastole (expansion).

Yet he lives fairly comfortable physically, enjoying his wealth, until his heart fails seriously, a blood vessel bursts in his head, or his kidneys become chronically inflamed and slowly poison him.

That is a picture which has become far too common; for it could generally be easily avoided.

When a young man, fresh from his college football or base-ball team, robust and strong, splendidly nourished, and with a fine appetite, enters seriously 
upon his business or profession, he suddenly changes all his habits of life. But his excellent appetite, acquired by his constant exercise in the open air, remains. He eats, therefore, for years, as well as he used to; but as he no longer exercises, his intake of food is now excessive.

As a consequence, his circulation, missing the powerful stimulation of out-door sports, to which it had become pleasantly accustomed, grows sluggish; and it is that sluggish circulation, permitting the gradual deterioration of his arteries, heart, and kidneys, that at last causes his premature death.

"Athletes die young," is an old saying. But it is not the athletics but the profound after indolence, reducing, as it does, the once active circulation to sluggishness, and thus inducing some one of the deadly circulatory diseases, which is responsible, in the last analysis, for the athlete's death.

Better to convince the reader that my contention that a sluggish circulation may result in a general vascular degeneration, is no idle phantasm, but a cold, demonstrable fact, I present the following analogy :

Physicians know that if a man's prostate gland becomes so hypertrophied (enlarged)-a common condition in old men-as to occlude the neck of the bladder, so that the man can no longer perform the act of micturition, but has always to withdraw his urine by means of a catheter, that, after a few years of "catheter life," the urethral canal becomes hard, collapsed, brittle, and perfectly inelastic. In normal 
men, however, the urethral canal, owing to its being repeatedly expanded by the stream of urine during every ordinary urination, remains soft, pliable and elastic throughout life.

Now, owing to their alternate expansions and contractions, corresponding with each systole and diastole of the regularly beating heart, all the big and little "canals," arterial, venous and capillary, which constitute our vascular system, should retain also throughout life, or, at least, until extreme old age, their normal softness, pliability, resiliency and elasticity. But, if one, when middle-aged, or considerably past middle-age, does not continue to take, regularly, suffciently active physical exercise, his circulation will gradually become sluggish, often to the point of almost stagnation, when the delicate walls of his ramifications of minute tubes, missing their daily exercise of alternate stretchings and relaxations, will begin to degenerate, stiffen, and harden, precisely as do the walls of the urethral canal when they are not expanded normally by the urinary stream.

Such a condition is called by the learned, arteriosclerosis. But, scientific opinion notwithstanding, arteriosclerosis is not caused by alcohol, by tobacco, by an excess of proteids, or by any errors of diet whatsoever.

A sluggish circulation, gradually induced by years of practically no physical activity, fails to exercise properly the myriad walls of the extensive tubing appertaining to the vascular system; and that, by permitting the deposition of noxious substances, produces 
hardening, and finally the walls' more or less complete degeneration (atheroma), or calcification.

We learn from elementary physiology that vigorous muscular exercise increases greatly both the force and frequency of the heart-beats, quickens the circulation throughout the entire body, raises blood pressure, and doubles, trebles, or even quadruples, for a time, the intake of oxygen.

Those effects are considerable, and, when one has accustomed his body to their extraordinary stimulation, it is impossible to think that such stimulation can be suddenly withdrawn permanently without profound detriment to the whole circulatory system.

There is no exception to the physiological law that non-use degenerates structure. So, when we consider how many men rarely if ever perform any kind of active muscular work, to increase the force and frequency of their heart-beats, should we be astonished that so many, and every year more than during the previous year, acquire arteriosclerosis and heart disease, even as early as middle-age?

Not even the so-called working classes do the actual physical work that once they had to do in order to live. Conductors stand pretty much all day, and ring up fares; motormen turn a lever to start, and another one to stop, the car; while clerks, book-keepers, bar-tenders, waiters, accountants, salesmen, floorwalkers, business and professional men-all lead sedentary lives; at all events their occupations are "light." Even factory workers, for the most part, only guide and adjust machinery. 
When night comes, the workers, many of them having stood most of the day, are tired; but they have not exercised, in the sense of having greatly stimulated their circulation. The strain of long standing, of ordinary walking, and of trifling arm and lifting movements, are not sufficiently active exercises to maintain, for any length of time, the circulatory system in vigorous health.

Of course, I would not say that, nowadays, no men do actual hard work. Furniture movers, truck drivers, iron-workers, longshoremen, farmers, and common laborers, perform really hard manual labor. But their work, besides being excessive, is not precisely active, but slow, heavy, and more or less musclestiffening. And yet, despite those drawbacks, workers in the harder vocations, are healthier, and are less liable to circulatory disease, than are those whose occupations are sedentary.

Perhaps I had better say something more about walking. It is called "the universal exercise"; and doctors strongly urge their patients to walk, assuring them that it is "the best of all exercises."

I beg to differ with the doctors. Walking in the open air is a great deal better than sitting in an overheated room; but walking is by no means "the best of all exercises."

Boxing, wrestling, hand-ball, throwing the "medicine" ball, active games, running, jumping, rowing, and swimming, are infinitely better exercises than walking.

Suppose we only walked a horse, could the horse 
run a good race? And if he could not run a good race, never having been accustomed to running, would he be a good horse?

But a man is not a horse!-True, but every man should be able to run a hundred yards without dropping dead from heart disease.

Nevertheless, walking might be "the best of all exercises" for certain persons-invalids, the very feeble and old, and those with organic heart trouble.

But for most persons walking is too gentle. The normal body needs to be shocked, stirred, and shaken from centre to periphery, to remain a good body, free from circulatory disturbances.

Yet, that arteriosclerosis, and its associate, heart disease, are due either to a faulty diet, or to the moderate habitual use of alcohol, is an idea which is very firmly intrenched. Only to-day I came upon the following:

"The great trouble with diets is that we are apt to generalize too much. We say, 'Because meat is harmful to these people, it is bad for the whole human race.' That is not true. It is harmless up to the point where we become idiosyncratic [especially sensitive] to it.

"It seemed to me in studying the development of arteriosclerosis that I could find its origin in a great many instances in acquired food idiosyncrasies. Up to a certain time the man's digestion and metabolism [nutrition] might have been in very good shape, but at some time in his life he had a great nervous strain, 
or a severe illness, like typhoid fever, a severe surgical operation, a profound food poisoning, or some accidental physical knockout. Then the trouble began. "One man became idiosyncratic to eggs. As a boy, one Easter, he gambled for, eggs, won a great many, and ate them all. He became very sick, and after that eggs made him sick even in the smallest quantity. He also later manifested arteriosclerosis. "I knew two men who were captains on Long Island Sound. Every night the steamboat stopped and took on oysters, and the men formed the habit of gorging themselves with oysters. These two men became idiosyncratic to oysters from the large quantity they consumed, and acquired arteriosclerosis from which they died. So there are any number of people in whom I feel sure of this origin of arteriosclerosis." 1

Now Dr. Bishop may be an eminent man and an experienced physician; yet, I fear, that in the reasoning I have just quoted, he has fallen into that pitfall, always in the pathway of the scientist, Post hoc; ergo, propter hoc. ${ }^{2}$

He says that a man who became idiosyncratic to eggs "later manifested arteriosclerosis." Also, that this patient, as a boy, had eaten so many eggs at one time that he "became very sick, and after that eggs made him ill even in the smallest quantity."

1 Metabolism, Arteriosclerosis, and Diet, by Louis Faugères Bishop, A.M., M.D. Read before the Practitioners' Club, Newark, N. J., November 6, 1916.

2 After this; therefore, because of this. 
Dr. Bishop's conclusion from those data is that the man's idiosyncrasy to eggs, or the egg poisoning from which he once suffered, or both, caused his later manifestation of arteriosclerosis.

But, no doubt, there are many persons, who have become idiosyncratic to eggs, through having eaten too many at some time, who, yet, do not, and perhaps never will, manifest arteriosclerosis. In fact, food idiosyncrasies are so extremely common, that few persons do not possess one or more of them. But, certainly, not every person with a food idiosyncrasy afterward acquires arteriosclerosis.

It seems to me, therefore, that before placing the blame for that insidious disease, in the egg-eater's case, it would be necessary to know a great deal more about him than his painful idiosynerasy to eggs.And that information Dr. Bishop no doubt had, but we have not.

So, we ask: What were his age and weight? What was his occupation? And what were his habits?

He may have been old and fat; his occupation may have been sedentary; or he may have been a hearty eater of other foods than eggs, and have taken little or no active exercise. Hence, he might have manifested arteriosclerosis if he had never seen an egg.

As for the two steamboat captains on Long Island Sound, who had "formed the habit of gorging themselves with oysters," they, no doubt, spent a great deal of their time in the open air; that gave them a huge appetite, which they used to satisfy with oysters, and, at the same time, they probably indulged in very 
little active exercise-steamboat captains, as a rule, making others work, rather than themselves.

Now, much nutriment and little exercise doubtless favor arteriosclerosis; so, I can not agree with Dr. Bishop that, if other steamboat captains wish to escape arteriosclerosis, they must not chew, but eschew oysters or excesses of any other one kind of food, lest they become idiosyncratic to it, and, later, owing to their idiosyncrasy, manifest symptoms of arterial disease.

I would advise them to eat less of everything, and to do some of the manual work which others under them are obliged to do.

I, myself, happen to know a man who has become idiosyncratic to clams. Once, at a clam-bake, he ate a great number of clams, just how many I can not remember. He became very sick, and now he can not eat even one clam, without immediately manifesting distressing symptoms. This man is forty-five years old. Incidentally, he drinks to excess; yet, he is strong, has a clear, healthy skin, and looks ten years younger than his age. As yet, he has manifested no symptoms of arteriosclerosis; but that may be because his occupation, happening to necessitate considerable physical exertion, overcomes the baleful effects of his idiosyncrasy.

I have a colored cook, forty-six years old, who is not arteriosclerotic, in so far as I know, but she has become idiosyncratic to port wine. She says that she used to "love" port wine, until, one evening she drank a great deal too much of it. Now, although she 
might look upon wine when it was red, she can not bear the sight of port wine.

Finally, in his interesting paper, Dr. Bishop says that the trouble (arteriosclerosis) begins often after a man has sustained some great nervous shock, such as "a severe illness, like typhoid fever, a severe surgical operation, a profound food poisoning [such as Dr. Bishop's egg-man and oyster-men, and my clam-man underwent], or some accidental physical knockout."

But, again, Dr. Bishop's reasoning is, Post hoc; ergo, propter hoc, as a great many men, on this uncertain sphere, sustain some sort of nervous shock, usually during the period of middle age; yet, not all, nor even a majority, of them, afterward manifest arteriosclerosis.

Consequently, I at least, can not see that Dr. Bishop's hypothesis is tenable.

Lest I be misunderstood, and perhaps accused of deliberately and flippantly placing in a wrong light the learned contention of Dr. Bishop that some profound food poisoning, resulting in an idiosyncrasy to that particular food, is often a cause of arteriosclerosis, I would add that I am aware that many eminent men, besides Dr. Bishop, believe that arterial disease is produced by the entrance into the circulation of some poison derived from some certain food. Yet, there is no proof that vascular degeneration is thus caused; and, until there is proof, I refuse respectfully to accept the hypothesis.

I agree with Dr. Bishop, however, that certain persons with beginning arteriosclerosis may be hyper- 


\section{MAN'S PHYSICAL DETERIORATION 247}

sensitive, or idiosyncratic, to certain animal proteins, without knowing it; and that when those proteins are withdrawn, such a person's health is benefited. But many persons overeat, and if they will not exercise, the next best thing one can do for them is to reduce their amount of food. 


\section{CHAPTER XXX}

HOW TO PREVENT PHYSICAL DETERIORATION

I SHALL take up now the effects of alcohol, and, incidentally, of tobacco, upon my own organism.

As a boy, I was delicate and thin; but I was born with a love for athletic exercises, and that afterward proved my salvation.

When a scientist tells me, among others, that if I do a certain thing, certain results will follow; and, further, if the scientist purports to show, by certain laboratory experiments, why those results must follow, that they are, in fact, inevitable, he may succeed in convincing me that he is right, unless I happen to know absolutely that, given the conditions, the results actually do not follow. In the latter case, the seientist, be he never so clever, and the greatest of all scientists, would, in my opinion at least, be wrong.

Now, an eminent scientist, Sir Victor Horsley, tells us that "alcohol used daily, but in the strictest moderation [italies mine], deteriorates the cerebrum, until the man becomes careless of dress, loses his affection for his family, and ultimately so subordinates his habits, desires, and the welfare of himself and of those connected with him, that, to obtain drink, he will lie, scheme, and even rob." -But that is so manifestly untrue that comment would be superfluous. 
Again, we are told by another quite as eminent scientist that "Alcohol, in moderate quantity [italics mine], reduces efficiency, destroys energy, weakens thought, paralyzes physical endurance, and lowers enormously the whole muscular tone."

Now, I know, not from hearsay, nor from laboratory experiments, but of my own knowledge, that the above statements are worse than exaggerations; they are wholly untrue.

I have used alcohol, moderately, but daily, for the last twenty-eight years, and I have also smoked, sometimes rather immoderately, during that same period of time; yet, at my present age of forty-six years, I find myself in the most vigorous mental and physical health that I have ever known. In saying that, I am aware that the vast majority of men are not nearly so strong and enduring at forty-six, as they were at twenty-six; but their deterioration is not owing to their age: It is because they have discontinued the vigorous use of their physical powers.-More about that further on.

And here it may be asked why do not the mental powers of the intellectual element in our civilization wane in the same degree, and with the same rapidity, as do their physical powers?-For, at sixty, or seventy, most brain-workers are feeble physically, and in their greatest vigor mentally.

The answer is that such men use their brains steadily and with progressive intensity up to old age; and that constant vigorous use prevents deterioration.

To go on with my personal history. I am six feet 
and one-half inch in height, in my stockinged feet, and I weigh about two hundred pounds. In so far as I can judge, I possess, with a great amount of physical energy, considerable capacity for sustained mental work.

Two years ago I could push up, without undue strain, to arms' length above my head, simultaneously, without jerk or jump, two dumb-bells weighing eighty pounds each, eight times in succession; and, after a short rest, I would then push up from the shoulders to arms' length above my head two dumb-bells weighing eighty-six pounds each, four successive times. Sometimes, but not often, I smoke a cigar while I am pushing weights.

At present, I make it a practice to exercise regularly, three times a week, with two seventy- and two eighty-pound dumb-bells, which I "curl" and "put up" with ease from five to eight times. Afterward I indulge in lighter exercise with a ponderous friend, who is about forty years old, and who, in spite of having drunk alcohol moderately most of his life, is also strong and healthy, by tossing to him, and catching from him, a twenty-two pound "medicine" ball, continuing that exercise for about a half-hour. Then I do a few hand-stands, and wind up my fairly strenuous exercise by punching for about five minutes a heavy, freely-swinging, canvas punching-bag.

In addition, every morning before breakfast, I do some stretching exercises, touch my fingers to the floor and bend backwards ten times; I then do ten side-bending, and ten twisting movements, finishing 


\section{HOW TO PREVENT DETERIORATION}

usually with a hand-stand. I also do neck exercises to keep the neck muscles firm and vigorous.

Those morning exercises occupy no more than five minutes, and I find them excellent, not for the development of strength, but for keeping the trunk and shoulder muscles pliant and elastic.

With me, the putting up of heavy weights is a hobby, which, however, I would not force upon others. Assuredly, all men can not "put up" heavy weights; nor is it in the least necessary that they should. But there are plenty of active exercises, which all can do, or, by a little perseverance, learn to do; and any exercise, if vigorous, is a splendid stimulant for the heart and, consequently, for the entire vascular system, with which the heart is connected.

Running, boxing, wrestling, hand-ball, base-ball, tennis and swimming, are all fine exercises for the circulatory apparatus.

Yet there are many, whose occupations are sedentary, and for whom any of the above exercises would be too violent. For those, permit me to recommend an universal exercise, which can be engaged in safely by the young, middle-aged, or old, of either sex, and which will occupy far less time, do a great deal more good, and be much more enjoyable, than would be long monotonous walks-the exercise is "playing with the medicine ball."

The medicine ball can be made to order by any upholsterer, or it may be obtained at any sportinggoods' house. The ball is covered with stout canvas, or leather, strongly sewed, and is filled with a mix- 
ture of shavings, or sawdust and sand. Its great advantage is that it can be made any desired weight.

A ball suitable for women and children should weigh from five to ten pounds; and ten pounds would be heavy enough for some men. Others could use with greater advantage, balls of from fifteen to twenty pounds.

Ten minutes of vigorous play, daily, with a ball of the proper size, tossing it from one to the other, or to others, if more than two are playing, will put the players into a profuse perspiration, will increase and strengthen their heart action, and, at the same time, much quicken their respiration and general circulation. Should the players wish open-air exercise, they may throw the ball in the privacy of their back yards, donning sweaters and gloves in cold weather; or they may toss the ball on the beaches, in summer, as some now do.

The ordinary way of hurling the ball is to allow it to rest on the upturned palm, the arm being bent, and held close in to the shoulder. From that position it is thrown to the other player by thrusting the arm out, springing slightly from the knees, and "following" with the body, as one does when "putting" the shot.

But, after throwing with the right arm, the next throw must be made similarly with the left arm, to insure bilateral development.

Another "throw," excellent for the abdominal muscles, and hence a corrective of constipation, is executed by hurling the ball with both hands from over and a 
little behind the head. Still other throws will suggest themselves to the players.

Physicians frequently urge certain of their patients to walk five or ten miles every day. But such long walks, besides consuming much time, soon become so monotonous and tiresome that few will repeat them for more than a few days, - and who can blame them?

Why should not physicians recommend, instead, a few minutes' vigorous play with the medicine ball, especially since that exercise can be precisely regulated, is general, employing muscles ordinarily little used, and so gets better results within a much shorter time than would walking?

Throwing the medicine ball exercises vigorously all the muscles in the body, including even those of the neck; and such a general exercise is, of course, of more benefit to the general circulation than would be any local exercise.

I firmly believe, therefore, that, if the vast army of sedentarians who at present constitute a large majority of our population, would indulge in that pleasant play exercise, for only five minutes every day, deaths from premature hardening of the arteries (arteriosclerosis) and its concomitant, heart disease, would soon become as rare as they are now common.

"Few men," remarks Dr. Henry G. Bugbee, "reach middle life retaining physical vigor." If that is so, most men should be ashamed; for, to retain the physical vigor possessed in youth, it is necessary merely to continue to employ that vigor, at least occasionally, by suitable exercises; or, if there be little 
original vigor, to set determinedly about cultivating it. I have seen many men who had very little vigor to start with, acquire a great deal of it, by judiciously progressive exercises.

Before resuming the narration of my own experiences, I would explain that no weak vanity or idle desire to boast has prompted me to detail what I myself have done, and still do (at the age of forty-six years), athletically. That I have done solely in the cause of truth, and, particularly, to refute, not by theories, or hypotheses, but by absolute counterfacts such "scientific" statements as: "Alcohol, in moderate quantity, reduces efficiency, destroys energy, weakens thought, paralyzes physical endurance, and lowers enormously the whole muscular tone."

Now, if alcohol really produces all those deleterious effects, why did it not produce them in my case?

Let us reason. If alcohol plus exercise produce great physical vigor, as I have just incontestably shown in my own case that they do; and if, on the other hand, alcohol plus no active exercise "destroy energy, weaken thought, paralyze physical endurance, and lower enormously the whole muscular tone," as the Prohibitionists assert that they do, since they have not considered exercise as a factor at all; then, the lack of active exercise, and not the alcohol, must be responsible for these latter bad effects, particularly as we absolutely know that many men who take no active exercise, and who use no alcohol, are, nevertheless, weak, lack energy and endurance, and have generally a considerably lowered muscular tone. 
I repeat that I have drunk ale moderately for nearly thirty years, consuming daily from four to eight glasses. I have also, during that time, been a constant smoker of strong cigars. Yet, despite those "dissipations," I do not lack energy, but am strong and vigorous; neither have I had rheumatism, gout, heart disease, or other circulatory disturbances. My immunity $I$ ascribe not to the ale, but to the fact that I have regularly taken vigorous physical exercise.

But, were my heart weakened, my general muscular tone lowered "enormously," and my nerves shaken by my steady smoking, and my regular moderate drinking, would $I$ be in my present healthy and vigorous condition? Certainly I would not.

If the objection be raised that I, possibly, am an exception, or that I happen to be peculiarly insusceptible to the ordinary effects of alcohol and of tobacco, I would answer that such objection is illogical; for, I, being human, would be vulnerable, with other humans, to any cumulative poison. The only explanation remaining, therefore, is that alcohol is not the cumulative and degenerative poison which some scientists claim it is.

Prohibitionists there are, who assume a high mental and physical superiority over those who drink the lighter alcoholic beverages. But Prohibitionists and ingeniously contrived experiments notwithstanding, there are men whose red blood has been neither poisoned nor in the least deteriorated by moderate daily increments of alcohol covering a long period of years. 
My father, Dr. Austin Flint, was a moderate drinker. For as long as I can remember, he was in the habit of drinking the heavier imported beers, regularly and moderately every night. But he, like myself, never drank liquor, and he never drank during the day. He died suddenly in his eightieth year. When younger, he was fond of gymnastics, and exercised regularly; and I believe now that if he had not wholly given up his exercises, when he became old, he would be alive to-day.

Another point. There are certain would-be regenerators of degenerate mankind who aver that moderate drinking, regularly indulged in for a considerable time, leads to immoderate drinking. That, experience does not show, as there are many more moderate, than immoderate drinkers; and the moderate drinker, being as a rule normal, rarely becomes a heavy drinker. In my own case, I can say that I drink now less than formerly.

It is a curious fact that physicians, with all their scientific knowledge and thorough understanding of hygiene and sanitation, are shorter lived, as a class, than are the average of the general population.

According to the Journal of the American Medical Association, 2196 physicians, in the United States and Canada, died during the year 1916. If that number include all the deaths of physicians-hardly a justifiable assumption-their annual death rate, estimating the total number of physicians as 158,000 , would be 14.08 per thousand. The general death rate for Greater New York, for the year 1916, was 13.89 per 
1000 of estimated population. For the year 1915 it was 13.93.

The chief causes of death, for that year, among physicians, were, in the order named, senility, heart disease, pneumonia, cerebral hemorrhage, accident, surgical operations, and nephritis. The average age at death was 59 years, 11 months, and 5 days.

Further, we learn that 337 of the deaths were from senility; 324 from diseases of the circulatory system; 261 from diseases of the nervous system; 231 from respiratory troubles; 225 from general diseases; 129 from digestive disorders; 105 from genito-urinary diseases; 112 from accidents; 98 from surgical operations; 39 from suicide; and 15 from homicide.

Although comment is hardly necessary, I would remark that, judging from the prevalence of the circulatory diseases among physicians, they, fully as much as others in the community, require considerably more active physical exercise.

It may well be that, after all, the proletariat know something about the care of their health. Personally, and I am only one among many millions, I should hate to have anyone, be he savant or physician, direct my private habits; inasmuch as, though not a physician, I have succeeded in developing a strong and enduring physique from an originally weak and delicate one; and that I have done simply by means of a sufficiently plentiful plain diet, made appetizing by a little good ale and regular active exercise. In the sweat of my body I have earned my good dinners-and enjoyed them. 
I have had advice-lots of it; but I followed my own ideas. Scores of physicians advised me, when I was young, that violent exercise was harmful, and that, if I persisted in using heavy weights, I would become old before my time. Yet, fortunately for my health, strength and well-being, there was no law to stop me from exercising as I pleased; and, so, I persisted.

At present my heart is as sound as a United States bond, and, although I weigh nearly two hundred pounds, I can run rapidly up three ordinary flights of stairs, two steps at a time, without the least breathlessness, and with little acceleration of my heart action.

But, lest it be thought I imagine my heart to be stronger than it really is, I shall be explicit.

It is 9.20 P.M. At 7.30 P.M. I finished a fairly hearty meal consisting of two fried eggs, four slices of bacon, two potato cakes, six slices of rye bread and butter, two pieces of cake, two large glasses of cream ale, a large cup of coffee, and one glass of water. Since the meal I have been writing, and, while writing, I have smoked two strong Havana cigars. After weighing myself on a Jones' scale, and, finding that I tipped the beam at 197 pounds, I took my pulse rate and found that it beat 73 times to the minute. I then walked down stairs to the basement, turned and ran rapidly up three flights of stairs, two steps at a time. At the top of the third flight I immediately took my pulse rate. It was 105 beats to the first minute; the second minute it was 83 ; and the 
third minute, 80. At no time was $I$ in the least breathless.

The next day I repeated the experiment, but at a different time. At half-past six o'clock in the evening, just before dinner, I carefully noted my pulse rate. It was 64 to the minute. I then ran as rapidly as I could up the same three flights of stairs, taking two steps at a time. My pulse, directly after I had reached the top of the third flight, beat 95 times to the first minute; the second minute it was 67 ; the third minute, 62 (normal); and the fourth minute, 63.-A better result than I obtained in the first experiment, obviously, because I had not had a hearty meal.

I think that any physician will agree with me that the above experiments showed my heart to be sound and fairly strong. So, if, according to Dr. Bugbee, "few men reach middle-age retaining physical vigor," it is their own fault, rather than the fault of their forty or fifty years, of alcohol, or of wholesome food.

My reasons for having described with such minuteness the effect of sudden violent exercise upon my own circulation, and, especially, upon my own heart, are two. First, to show how much too prone are some persons to ascribe effects to causes which have had nothing whatever to do with such effects; and, second, to demonstrate, by at least one concrete instance, the absurdity of making alcohol, even when moderately used, wholly responsible for the increasing incidence of heart disease.

If those pursuing sedentary occupations were not 
too indolent to do some kind of vigorous physical work occasionally-even though they should indulge in the light alcoholic drinks at luncheon and dinner-they would not have flabby muscles and weak hearts; they would not suffer from breathlessness upon slight exertion; and they would not feel chronically tired, nervous and dejected.

Health and strength have one price-physical exertion. That price the upper classes will not pay, because they fondly imagine it is not necessary. Instead, they seek as diligently as did Ponce-de-Leon and the alchemists of old, for the Fountain of Youth, or the Elixir of-Life; but call their identical goal, "The Science of Right Living."

Diet is the modern mania. A precisely balanced dietary, the ideally perfect food, is what all scientists are looking for, not realizing that should they find this ignis fatuus, it would be as useless for purposes of ordinary life as a thimbleful of water would be to quench thirst.

So intricately is the human organism constructed that from a variety it picks just the right quantities of this and that substance needed for its health as a whole, and rejects the rest. But, suppose the stomach were given some "scientific" food, containing the exact amounts of all the various substances required by the body, and no more, what would happen?

The stomach, the thirty odd feet of intestines, the kidneys, liver, etc., having no material (waste products) to work upon, would have their normal func- 
tionings so reduced, that they would soon atrophy (waste) and become hopelessly diseased.

While Metchnikoff was seeking scientific ways to destroy the bacteria which infest the intestinal coils, and which, he believed, caused senility, his heart, which he did not bother about, suddenly ceased functioning, and the great Metchnikoff died.

While Hugo Muensterberg was delivering a lecture on psychology in a class-room in Harvard University, he clutched at his heart, collapsed, and died before the eyes of his students.

The price of life is toil; but physical as well as mental toil. However much a man works with his brain, if he does not work also with his body, the brain's tenement, the body will corrode and rust, and at last clog the brain.

The brain not only thinks and schemes; it is the storage battery supplying the succession of nervous shocks necessary for the continued functioning of the body. The fly-wheel of the human machinery is the heart; the arteries, arterioles, veins, and capillaries, are the belts connecting the fly-wheel with the special nervous mechanisms of the vital functions and with those employed in pedal and manual dexterities. Once the fly-wheel (heart) stops, all the movements derived from it cease; nor can it be set in motion again, seeing that the storage battery (brain) died with its last revolution.

Now to keep that powerful fly-wheel and all the intricate machinery with which it is connected, running 
smoothly, it is necessary: First, that the machine (body) be supplied regularly with its proper fuel; and, second, to keep it bright, clean and well lubricated, it must be rid regularly of all ashes (waste products) and clinkers.

To do that, the whole machine must be speeded up, raked, and vigorously shaken down, by some active and general physical exercise; and, at stated intervals, it must be allowed to rest.

With every contraction of the heart, blood is forced through the arteries to all parts of the body; thence returning to the heart via the veins. Also, the veins and arteries, when normal, do their share of the circulatory work, by expanding and contracting their elastic walls with each systole and diastole of the great muscular pump.

Now, as I have said, in those who neglect active exercise, the blood circulates sluggishly, particularly after middle life; and, consequently, in such, vascular expansions and contractions are lessened, until, after a time, the walls of their myriad tubes, through disuse, lose, in great measure, their proper elasticity, and become brittle and hard. Then the heart, unable longer to depend upon its former allies' valuable aid, has to work harder and at a disadvantage; so that, at last, it, too, becomes deranged, and hypertrophies or dilates.

I repeat, therefore, that if one regularly exercises, not by walking-which some doctors assure everybody is "the best exercise," but which I assure my readers is wofully insufficient,-but by playing active games, 
boxing, or, best of all, for the reasons I have given at length, by throwing and eatching the "medicine" ball,-then the heart and its extensive circulatory ramifications, being alternately and normally expanded and contracted, will be adequately exercised, and hence, will not nearly so soon lose their proper pliability and elasticity.

Movement is LIFE; and stagnation is death.

And so, it would seem that not moderate indulgence in alcohol, nor smoking, nor overeating, nor all three, are causes of the physical deterioration manifested by the constant increase in the circulatory diseases; it is the result of an ever-widening physical indolence induced by too much prosperity.

The discovery that overeating and overindulgence in alcohol produce disease in the physically inert, is no doubt a true discovery; particularly as we know that even an idle horse will become diseased if we do not reduce his feed.

For the increase in the circulatory diseases, then, there remain two remedies. Either we may eat and drink less and grow healthier, without, at the same time, physically exerting ourselves; or we may exercise actively and regularly for a few minutes every day, and still enjoy the good things of life. For my part, I prefer to work and eat; but he may not eat, who will not work.

The pure physical joy derived from the consciousness of strength is indescribable. This morning I put up from the shoulder to straight arm above the shoulders, two eighty-pound dumb-bells, four successive 
264 THE WHOLE TRUTH ABOUT ALCOHOL

times. I did it with ease, feeling that I could have put them up six times had I wished. After I had replaced them on the floor, my whole frame tingled with a feeling of force that one must experience to know its pure satisfaction. And I thought: "It is worth while; strength is worth working for." 


\section{CHAPTER XXXI}

\section{A PRACTICAL PREVENTIVE OF APOPLEXY}

BEFORE concluding this book I must add a word about apoplexy. I am aware that the learned, in discussing this extremely common disease, which they call cerebral hemorrhage, lay its prevalence to errors in diet, mental overwork, and even to worry and anxiety. All that may be true, and, yet, I, not being learned, doubt that any one of the conditions mentioned could be more than a very remote cause.

The direct cause of apoplexy is, of course, a weakness of some part of the wall of some blood vessel in the brain. That weak spot, owing to a sudden increase of blood pressure, or to some obstruction or clot (thrombus) forming somewhere in the cerebral circulation, gives way, and the apoplectic stroke follows, with either a fatal result, or a more or less extensive paralysis.

Apoplexy is a circulatory disease, and is, therefore, caused, in my unlearned opinion, more by prolonged physical inactiveness, than by anything else.

The definition of "thrombus," in Gould's Medical Dictionary, is : "A clot of blood formed within the heart or blood-vessels, due usually to a slowing of the circulation or to alteration of the blood or vessel walls." [Italies mine.] 
Now, given a weakness in the wall of some cerebral blood vessel, and a thrombus forming near it will almost inevitably precipitate an apoplectic seizure (bursting of the blood vessel).

That fact every physician knows. Why, then, knowing the fact, does he not think that chronic physical inactivity, inducing, as it does, "a slowing of the circulation," may be more of a factor in apoplexy than "errors of diet, mental overwork, or worry and anxiety?" Is it because he is too learned to think of anything so simple? I can say that in all the "scientific" papers I have read on apoplexy, none makes allusion to a lack of exercise as being even a contributory cause.

There is an excellent preventive of apoplexy that is so simple that possibly only one unlearned would think of it.

All tree-growers know that when a tree is planted in an unsheltered spot, the limbs on the side of the tree facing the prevailing winds will grow stronger and thicker than will the limbs on the sheltered side of the tree. That is because the branches on the more exposed side are blown about and bent more by the strong winds than are the other branches. As a consequence, the tossed and twisted branches get more than their share of the tree sap, and, hence, being extraordinarily well-nourished, become especially strong and resisting.

In the same way the branches of the arteries and the veins, as well as the arteries and veins themselves, become stronger and more resisting, the more strongly 
their walls are expanded and stretched by the volume of blood flowing between them. But nothing so powerfully stimulates the circulation as does exercise; hence, exercise must best strengthen the walls of all the blood vessels in the body.

Unfortunately for the blood vessels in the head, however, the upright position, which all human beings assume for about two-thirds of their lives, militates against those particular blood vessels' being subjected to nearly so much pressure as all the other blood vessels are constantly subjected to ; and, consequently, the cerebral blood vessels, being weakest, are the first to snap, when old age, or prolonged inactivity, has caused a general weakening of the vascular system.

Apoplexy is, therefore, common among civilized peoples, but rare in the young, who are usually habitually active. ${ }^{1}$

Now, can we do anything to prevent apoplexy? I think we ean. "Hand-stands" are an excellent preventive; for, then, the blood, rushing into the head, distends the cerebral vessels, and thus strengthens them. But few, of the general population, can stand on their hands, or on their heads; but anyone can stand upon his feet, and, bending over, hang his head down, the while holding a deep inspiration, and, in that simple manner, he can force sufficient blood into

1 Of course, I do not mean to assert that a lack of exercise is the sole cause of apoplexy, or of heart disease; for many diseases, notably syphilis and rheumatic fever, cause often profound vascular degenerations. But $I$ do say that vigorous bodily exercise renders one much less liable to either. 
his head to distend and stretch its blood vessels. That simple procedure, repeated once or twice daily, and carefully executed so as not to increase cerebral blood pressure too strongly, should keep the vessels of the vertex healthy, elastic and resisting, and, hence, should prevent apoplexy.

Of course, anyone could think of the above, while only the learned could discourse cryptically about the sphygmomanometrical readings of high blood pressure, inadequate protein metabolism, toxaemia, arteriosclerosis, and atheroma.

Nevertheless, when logically considered, my advice may seem sound to those who may remember that " $E$ 'en out of the mouths of babes and sucklings cometh forth wisdom." 


\title{
ADDENDUM
}

\author{
ALCOHOL, ECONOMICALLY AND PRACTICALLY \\ CONSIDERED
}

ON April 2d, 1917, Woodrow Wilson, President of the United States, issued a proclamation that a state of war existed between this country and Germany. We have, therefore, entered into the world conflict.

As a consequence, Prohibitionists are renewing their agitation against alcohol, and are adding to their alcohol-lessening-of-efficiency arguments the more specious plea that now, in the present world crisis, the national prohibition of alcohol should be enacted to prevent the "enormous waste" of grain stuffs incidental to the manufacture of alcoholic beverages.

But their statements in this regard, as in other regards, are exaggerated, as there is by no means so great a waste of the grain used in the making of beverages containing alcohol as they aver that there is. According to the annual report of the Commissioner of Internal Revenue, 39,748,892 bushels of all kinds of grain were used in the production of distilled liquors, during the fiscal year, 1916; while the brewers' statistics, for the same year, showed that a little under $55,000,000$ bushels of grain had been utilized to make fermented liquors: The sum of the two totals amounting to something less than $95,000,000$ bushels of grain 
used for the entire alcoholic-drink industry.-And that grand total is about $530,000,000$ bushels less than the amount claimed by the College of Agriculture!

Moreover, the liquor men declare that, after the carbohydrates have been extracted from the corn, barley, etc., there remains 65 per cent. of the food value of the grain, which is dried and used as a valued cattle food, and that, therefore, 65 per cent. should be subtracted from the $95,000,000$ bushels, leaving only $35,000,000$ bushels as the amount of grain devoted solely to the production of alcoholic drinks.

The United States government figures show that during the year 1916, all the brewers in this country used no wheat, no oats, and no rye; but chiefly barley, some corn products, and a little rice.

Now barley is seldom used for human consumption, but is a valuable nutrient for cattle, especially after it has been crushed in the making of beer. Sörensen, a great Danish authority on pure food, has gone so far as to declare that there is no waste of cereals in brewing beer.-At all events, the total number of bushels of grains actually consumed in the manufacture of beer is less than $3 / 4$ per cent. of the grain production of our country.

I give the above figures that the American people may consider the universal prohibition proposition in the light of the whole truth, rather than through the blue glasses of recklessly "made" figures and comprehensive misstatements.

Again, real estate men assert that extreme prohibition measures would affect at least 900,000,000 dollars' 
worth of taxable hotel and restaurant property, and would throw real estate valued at a quarter of a billion dollars upon the for sale and to rent market.

Indeed, were there universal prohibition, the grave financial loss to this country of the millions of dollars of revenue derived yearly from the liquor traffic, should be obvious, to say nothing of the calamitous consequences of throwing thousands of men out of employment in these trying times. Then, too, the Federal Government would be obliged, for justice' sake, to indemnify all who had invested multi-millions of dollars in what has always been a legitimate industry.

It is significant of the general need of alcoholic beverages that, while many of the warring nations of Europe have become pinched for food, not one has forbidden the manufacture of such beverages. True, Russia has abolished vodka, and France has suppressed absinthe, but no nation has forbidden the moderate use of the milder alcoholic drinks, nor even of wine, whiskey and brandy.

Why, then, of all nations, should the United States, which is not now suffering, and which probably never will suffer, from the acute food shortage at present gripping most of Europe, enact National Prohibition as a measure either of health or of economy?

It is when peoples are racked, worn, pinched, and harassed by war that they especially need alcohol; and it is just then that they would not endure being deprived of it.

Another question which the war has quickened for 
judicial decision is, whether it would or would not be advisable to allow alcohol in the army. It would, as it seems to me, be a fatal mistake absolutely to forbid alcohol to the soldier.

If it has been found that alcohol does not increase the soldier's efficiency when he is about to fight, it has not been found that alcohol has harmed him after the fight, when he is in a condition of partial exhaustion. On the contrary, the experience abroad has been-and experience is the best teacher-that alcohol is invaluable, often indispensable, to the soldier, when properly used at the right time; at all events, certain amounts of alcohol are allowed regularly to all the soldiers in Europe in active service.

War time is not the ideal time for experiments; and suddenly, at such a crucial epoch as the present, to withhold all alcoholic stimulants from human organisms, which from time immemorial have been accustomed to them, might result in more than discomfort-it might be terribly disastrous.

All remember that the abolishment of the army canteen, a "reform" that certain well-meaning myopics instituted in peaceful times, resulted in an appalling increase in drunkenness and profligacy.

Doctors know that when habitual heavy drinkers abruptly stop drinking, they are then especially liable to delirium tremens. And many, apparently robust while they drank, have lost their health soon after they have reformed. I have personally known many such.

A habit is not a habit until after the organism has 
become adapted to, and, to a certain extent, has become dependent on, its effects. Nor is it only liquor drinking that is hard to break off. When one stops smoking, he feels it; and he experiences discomfort if he foregoes even his customary morning cup of coffee : His vague, uneasy feelings being due to the internal readjustments necessitated by the unaccustomed lack.

As I have stated in my chapter on Alcohol and Efficiency, it is not necessary that a substance should immediately increase efficiency in order to be valuable. Some drugs greatly increase efficiency temporarily, and are, for that very reason, dangerous, although they may be valuable in certain conditions.

Alcohol, however, does not reduce efficiency permanently; for, by relaxing tension, it induces rest, and thereby eventually increases efficiency.

In war time alcohol would be useful more for its soothing, relaxing and narcotic properties than for its stimulating effects. Yet would the physically exhausted soldier need alcohol to stimulate him; whereas worried, tired, and anxious civilians would need the same substance to dull their anxieties, to moderate their fears, and often to lessen their real hardships.

In regard to Prohibition by national enactment, the calm, unbiased opinion of that staunch churchman, Cardinal Gibbons, is well worth reading and taking to heart. 
CARDINAL GIBbONS ON THE NATIONAL PROHIBITION OF ${ }^{A L C O H O L ~}{ }^{1}$

"I would regard the passage of a Federal prohibition law as a national catastrophe, little short of a crime against the spiritual and physical well-being of the American people. ...

"I am firmly and unalterably opposed [also] to the enactment of [even] State-wide prohibitory legislation, for such sweeping measures mean that the rural districts, for instance, can force their sumptuary judgment upon the urban districts. This is a denial of self-government, an infringement upon personal liberty. Moreover, the liquor problem in the rural districts, and the liquor problem in the urban districts, are problems of vastly different aspects.

"To take only one feature of this difference: Experience has shown that prohibition can be enforced in the country, but not in the city. Thus, with Statewide liquor legislation, the rural districts can pass prohibitory judgment upon the urban districts, without any experience or knowledge of the latter's needs.

"The reasons against State prohibition apply with even greater strength against National prohibition. It requires no argument to show that the greater the distances that separate communities the less will be their sympathy with, and their knowledge of, each other's conditions and needs.

"Then there is this further reason, a reason that is so weighty that it alone should nullify all talk of

1 Published in the New York Times on April 29, 1917. 
National prohibition: If the prohibitionists succeed in mustering the necessary strength to enact their sumptuary law, one of two things is going to happen in the states that have had prohibitory legislation forced upon them-either these states will ignore the unpopular law, or that law will be enforced by Federal authority.

"All history shows that you can not legislate morality into a people; that the law that is enacted against the majority sentiment almost immediately becomes a dead law. ...

"The belief that legislation is a panacea for all social ills is one of the great evils of the day. To take the law out of its proper field is to make the law abortive, and abortive laws breed popular contempt for all legal authority. There is already a dangerous sentiment of this kind in our country. To add to it by enacting an abortive law of such universal significance as a national prohibition statute would work an incalculable injury to the spiritual well-being of the American people.

"To enforce in the various States an unpopular sumptuary law by Federal authority and Federal offcials would be so vicious in practice, so contrary to the spirit of American institutions, that none but the most fanatical prohibitionist could indorse it. But even such a fanatic should be given pause by a little reflection on the sinister precedent that would be established by such an enforcement of such a law.

"The history of the world down to the present time demonstrates the fact that people always have in- 
dulged, and, in all probability, always will indulge, in the use of alcoholic drinks. It is true that the use of wines and liquors, when abused, leads to lamentable consequences; yet, the best of things are liable to abuse. Take the tongue, for instance. We all know the social and domestic joy and utility derived from conversation, and yet the bad use of the tongue leads daily to lying and misrepresentation, to quarrels and slander, to bloodshed, and often to murder. But would we be justified in putting a padlock on our mouths because of the occasional misuse of the tongue?

"We should regulate the use of intoxicants, as we regulate the use of our tongues, by proper safeguards and restraints.

"What I recommend is the passage of laws that look toward the inculcation in the people of habits of temperance. I am an advocate of high license, and laws connected with it rigidly enforcing regulations for the conduct of drinking places. There should be heavy fines imposed for infractions of the laws, and if the violations are continued the license should be withdrawn absolutely.

"The American people already show a strong drift toward temperance. Drunkenness is no longer regarded, either in society or industry, with the goodnatured tolerance that it was only a few years ago. Widespread health instruction in our schools, colleges, newspapers and magazines is another great power for good. Then, too, our industrial and commercial life has increased so in complexity and in- 
tensity that the man who drinks to excess is inevitably eliminated.

"It is infinitely better for humanity if it is allowed to exercise its own will power rather than to attempt to drive it and to regulate it by laws. We develop a higher type of man spiritually-a better citizen, a better neighbor, a better husband, a better father-by requiring him to use his own initiative in moral matters, rather than by attempting to hold him constantly in legislative leading strings.

"I believe that we can attain national temperance, but I am firm in the belief that any enactment of a widespread prohibition measure is a long step backward." 



\section{INDEX}

Absinthe, 134, 135, 137, 138; per cent. of alcohol in, 38 .

Abstainers, longevity of, 161, 163; habits of, 165; health of, 166 ; physically considered, 82, 168; economy of, 178; and prohibitionists, 35 ; mentality of, 81,82 ; in tropics, 97, 98, 102; and candy, 102; and water, 102, 182; effects of tea and coffee on, 182,183 ; number of, $175,176$.

Abstemious countries, crime and poverty in, 208.

Abstinence, and disease, 210.

Active exercise, the heart, vascular system and, 262, 263.

Alcohol, effect on dog, 107; and efficiency, 92, 93, 103, et seq., 108, 109, 273; and deficiency, 34 ; opinions of sane scientists of, 36,37 ; and body temperature, 23, 102, 140; benefits of, 25, 102 ; sedative effects of, 25 , $26,110,111,273$; desire for, 6 ; in poor and in rich. countries, 81,82 ; per cent. of, in common drinks, 38; its part in history, 83; sweets and, 84-87, 102; sugar and carbohydrates changed into, by digestive ferments, 85, 86; in plants, 86; candy as a substitute for, 86,87 ; affinity for oxygen, 86,132 ; as a nutrient, sedative, and aid to digestion, 88; soldiers, sharpshooters and, 89-91; time to give, 91, 92, 109; relaxing effects of, 91, 92, 118, 119 ; effects of much, 92; necessity of, 90 ; in tropics, 97 , et seq.; as a stimulant, $110-115,117,118,119,124$; as a narcotic, 110, 111, 114; effect on heart and brain, 110 ; on orators and speakers, 110-113; on nervousness, 111 ; as a depressant, 111,112 ; effects on neuromuscular system, 118, 119; and famous men, 113; in diphtheria, 120-124; in typhoid fever, 123; made in human body, 126; easily oxidized, 132; effects when injected, 133, 134; effect on circulation, 146 ; on irritability and grief, 150, 151; on sensibilities, 152; and obesity, 179-181; and longevity, 180-182; and diseases, 181, 182; and vigor, 181, 182; and moving pictures, 184, 185; and two very old men, 186, 187 ; 
ills laid to, 213 ; alleged effects of small amounts, 249 ; in the army, 272 ; to soldiers in Europe, 272.

Alcohol Commission of Norway, effects of light and strong alcoholic drinks, 70, 71 ; regulations of saloons, 71 ; drink and destitution, 204.

Alcohol habit, 193, 194.

Alcohol medication, Dr. A. Jacobi, 119-122, 128, 129.

Alcoholic craving, and candy, 84.

Alcoholism, and defectiveness, 144 ; and fusel oil, 146; and pauperism, 177, 178; in Bohemia, 216, 217; in France, 220, 221 ; what it is, 227.

Alcoholist, definition of, 222 . Ale, wholesomeness of, 31 ; per cent. of alcohol in, 38; nutritious, sedative, and aid to digestion, 88: composition of English, 101; and nervous, overworked mothers, 106, 107.

Ale and beer drinkers well nourished, 223.

Amendment to constitution, 9 ; difficulty of repealing, 10 .

Americans, their need of relaxation, 106; nervous exhaustion of, 106, 107; and destitution, 203.

Animals, sexual excitement in, 6 ; effects on, of injections of alcohol, of absinthe essence, of extracts of pro- teins, of casein, 133, 134, 136.

Anti-Alcohol movement in Europe, effect of war upon, 88; absurd statements in, 216 ; savagery of Belgians, 217, 218, 219.

Anti-Alcoholists, unwarranted assumptions of, 132, 133, 134.

Anti-Saloon League of America, 7 .

Apoplexy, increase of, 233 ; a circulatory disease, 265 ; causes of, 265, 266; and lack of exercise, 265,266 ; commonness of, 267 ; rare in young, 267; prevention of, 267,268 ; and handstands, 267.

Army, alcohol in, 272.

Arteries, elasticity of, in two very old drinking men, 186 , 187; and exercise, 266, 267 ; of the middle-aged and elderly, 237.

Arteriosclerosis, 210; sluggish circulation and, 239, 240 ; diet, food idiosyncrasies, and, 242-247; nervous shock and, 242, 243, 246; diet, exercise and, 245, 247; animal proteins and, 247.

Arthritis, 210.

Ascetics, longevity of, 166 .

Aschaffenberg, 108.

Aschenbrandt, effects of cocaine, 116.

Atheroma, cause of, 239, 240. Athletes, premature deaths of, 238. 
Atrophy, of the liver and kidneys, 210.

Atwater, 154.

Author, age of, 249; effects of moderate drinking on, 249, 255 ; present vigor of, 249 , 250,255 ; height and weight of, 249,250 ; strength of, 250 ; exercises of, 250,251 ; no exception, 255 ; results of experiments on his own heart, 258, 259.

Authors, famous, and tuberculosis, 113.

Bacilli, typhoid, destruction of, $171,172$.

Balkan peninsula, natives of, longevity of, 166.

Barley, value of crushed, for cattle, 270.

Beer, desire for, and sedative effects of, 6 ; prohibition of, indefensible, 15; per cent. of alcohol in, 38; and drunkenness, 47, 48; wholesomeness of, ( $J$. Koren), 70; effect on health, strength and efficiency, 103, 167, 168; and Germans, 107 ; and bread, 142 ; composition of, 179; composition of Munich, 142; and cheese, 143 ; as a nutrient, 142, 143; consumption of, 196; and obesity, 210, 211; and the kidneys and heart, 211; effect of, on Belgians, 218, 219; and cancer, 225, 226.
Beer and wine, recommendation of, in Russia, 55.

Beer drinkers, efficiency of, 173 ; obesity of, 179,180 ; diseases of, 212.

Beer drinking, effects of excessive, 211.

Beer gardens, in Germany, 69.

Belgians, greatest beer drinkers, efficiency of, 173; alleged savagery of, 217-219; and alcohol, 218, 219.

Benedicenti, cocaine, 117.

Benedict, 108.

Benham, Dr. F. Lucas, health of abstainers in tropics, 97, 98.

Berezin, experiments on rabbits and carp, 110.

Beverages, alcoholic, grain used for, 269, 270.

Binz, 127; tissue waste, 129.

Bishop, Ernest C., drug addicts, 28.

Bishop, Louis Faugéres, arteriosclerosis and diet, 242247.

Blood, distribution of, effect of alcohol and of exercise on, 140, 146; of coffee and tea on, 140; stability of composition of, 133.

Blood vessels, and water drinking, 211.

Bodily warmth, and alcohol, 140.

Body, relaxing, by alcohol, 106; and exercise, 261, 262.

Booth, Chas., pauperism, 202. Bowers, Dr. Edwin F., work and drink, 23, 24; alcohol's 
affinity for oxygen, 132, 133; fecundity and alcohol, 197.

Brain, and alcohol, 106, 110, 147 ; stupefaction of, 194 .

Brain workers, 249 ; and alcohol, 162, 163.

Brandy, per cent. of $A$. in, 38 ; in pneumonia, 124.

Branthwaite, Dr., fecundity of drunkards, 197, 198.

Brewers, grain used by, 270.

Bright's disease, increase of, 233.

Bronchitis, 233.

Brouardel, Dr., alcoholism and tuberculosis, 223.

Bugbee, Dr. H. G., physical deterioration, 253.

Business men, and alcohol, 147.

Cafés, in France, 69.

Cancer, 233; and alcohol, 225, 226.

Candy, and alcohol, 84-87, 102 ; injuriousness of, 87, 183, 184; adulteration of, 184.

Canteens, 195 ; "reforming," 272.

Carbohydrates, become sugar and alcohol in body, 85, 86, 101.

Cardinal Gibbons, on National Prohibition, 273-277.

Carlyle, Thomas, and noise, 77, 78.

Casein, effects of injections of, 136, 137.

Causes, easy to mistake, 259.
Cells, alcohol, distilled water, salt, and, 139; alcohol and germ, 197, 198.

Centenarians, 132.

Champagne, per cent. of alcohol in, 38.

Character, of drunkards, 190, 199, 201; of criminals, 205, 206.

Chicago, nineteenth ward of, saloon conditions in, 65-68.

Children, of drunkards, 145; deficiency and destitution of, 190-192, 201 ; and tuberculosis, 225.

Chill, aborted by alcohol, 146 .

China, non-alcoholic and unprogressive, 173.

Christian Scientist, and the cat, 191.

Circulation, and exercise, 238; and arteriosclerosis, 238240 ; sluggish, 238, 262.

Circulatory diseases, prevention of, 263.

Cirrhosis, 210.

Claret, per cent. of alcohol in, 38.

Club, workingman's, 64, 65 .

Clubs, men's, 64 .

Cocaine, and fatigue, 115-117.

Coffee, prohibition of, 17; irritability, nervousness, insomnia and, 140, 147, 148, 150.

Coffee and tea drinking, effects of, $182,183$.

Committee of Fifty, labor unions, 20-22 ; importation of opium, 28, 29; stock yards of Chicago, 49, 50; 
intemperance and destitution, 201-203; convicts and drink, 205, 206.

Composition of blood, stability of, 133.

Consumption, inebriety, and undernourishment, 212, 213, 223.

Convents, girls in, 74 .

Convicts, and drink, 205, 206.

Cornaro, 166.

Corpuscles, blood, and alcohol, 229.

Cranks, 73.

Craving for alcohol, 192-194. Cretinism, in Bohemia, causes of, 217.

Crime, and drink, 205-209.

Criminals, habitual, 3, 4; character of, 205, 206 ; alcoholic craving of, 207; and women, 208; and cocaine, 117 ; sobriety of high-grade, 208.

Criminality, age of, 207; in Belgium, 218, 219.

Death, 263.

Defectiveness, and alcoholism, 144.

Deficiency and alcohol, 34, 190-192.

Delicate, the, morbidity of, 168, 169; incidence and case mortality of typhoid fever among, 169, 170.

Delicateness, of author, when a boy, 248.

Delirium tremens, 212, 272.

Denatured alcohol, effect of drinking, 54.
Denmark, saloons in, 70.

Department of Labor, consumption of strong, and of malt liquors, 19, 20.

Desire for alcohol, 5, 6.

Despair, and alcohol, 151.

Destitution, and alcohol, 201, 203, 204.

Deterioration, man's physical, 231.

Diabetes, 112; increase of, 233.

Dickens, Charles, and noise, 78.

Diet, and arteriosclerosis, 242-247; the modern mania, 260.

Diphtheria, alcohol in, 120124, 128, 129.

Dipsomania, 41.

Diseases, of the frail, and of the robust, 180 ; and alcohol, 181, 182, 210, 211; mortality from infectious, greatest among robust, 171 , 172 ; decrease of infectious, 232,233 ; increase of circulatory, 233, 234 ; control of germ, 234.

Distillation, private, easily accomplished, 45 ; in Sweden, 45-47; illicit, in Russia, 53, 54.

Dogs, and cocaine, 116.

Dominant races, and intoxicants, 82.

Draft, the, more rejections in "dry," than in "wet" districts, 82.

Drink, weakness for, 4; and poverty, 201; and crime, 
205-209; and disease, 210, 211.

Drink complex, 78, 79.

Drink problem, 57.

Drinkers, longevity of, 161163; not careful of health, 162; accomplish most, 165; physiques of, 168 ; mortality of, 174 ; small per cent. of, 176; heavy, and delirium tremens, 272; heavy, among oldest men in Germany, 188, 189.

Drinking, general desire for, and difficulty of preventing, 6; in Italy, Spain, Portugal, 39,40 ; "dry" territory and, 53 ; and horrors of war, 93 ; universality of, 144 ; sorrow and indifference as causes of, 144; and insanity, 144, 145 ; with meals, 153; effects of moderate, 160 ; and longevity, 172; health, happiness, efficiency, and, 172, 173; among German students, 196 ; cancer and, 225, 226 ; moderate, and inebriety, 256.

Drinks, effects of light, 39; prohibition of light, indefensible, 15.

Drug addiction, in prohibition states, 27, 28; increase of, 27, 28.

Drugs, prohibition of dangerous, 14.

Drunkards, children of, 33, 145, 190-192; defectiveness of, 34, 190-192; character of, 190, 199, 201; mortality of reformed, 173, 174; attitude of, toward prohibition, 79,80 ; always spirit drinkers, 38,146 ; dislike of alcohol, 145; prefer cheap liquors, 146; and women, 145; fecundity of women, 197, 198.

Drunkenness, evils of, cure and treatment of, 32,33 ; in saloons, 65,66 .

"Dry" states, number of, in 1916, 7.

"Dry" territory, and drinking, 53.

Economic reasons for temperance, 93-96.

Efficiency, and sleep, 92, 105; food, fatigue and, 104, 105; and alcohol, 92, 93, 108, $109,172,173,273$; hunger and, 103, 104; beer and, 103; definition of, 106; benefits of reducing, 105, 106.

Eggs, and alcohol, 126.

England and Wales, drinking and crime in, 208, 209.

Epilepsy, and alcohol, 227, 228.

Eroticism, and religion, 72, 73.

Ether, effects of, 114.

Ethyl alcohol, effect on guinea pig of injecting, 12.

Europe, prohibition in, 271.

Excitement, sexual, and alcohol, 7.

Exercise, effect of, on sex instinct, 7; on circulation, 
146, 238; on heart and vascular system, 240,251 , $258,266,267$; need of, 261, 262; physicians' need of, 257 ; result of giving up, 240; lack of, causes heart disease, gout, obesity, arteriosclerosis, and physical deterioration, 212, 235-237, $239,240,245,247,253,254$. Exercises, of author, 250, 251.

Fanatics, general and religious, 72, 73; hysteria of, 73,74 ; B. S. Talmey on, 7577.

Fat, the, mortality of, 179; gluttony and laziness of, 179 ; and alcohol, 179-182.

Fatigue, and efficiency, 104, 105; and cocaine, 115-117.

Fecundity, and alcohol, 197, 198.

Fergusson, effect of rum ration on a regiment, 158.

Fever, Dr. F. N. Pottenger on, 112.

Fishberg, Dr. M., tuberculosis, 223-225.

Fisk, Eugene L., mortality of heavy drinkers, 173, 174; abstainers, 175, 176.

Fiske, John, benign effects of alcohol, 164.

Flint, Dr. Austin, 256.

Food, and efficiency, 104; futility of scientific, 260, 261 .

Foreigners, intemperance of, 51, 203.

Frail, the, diseases of, 180; and alcohol, 181, 182.
France, cafés in, 69; tuberculosis in, 220-222.

Freud, effects of cocaine, 116. Fusel-oil, 146, 194.

Gambling, after prohibition, 55.

Genius, and alcohol, 113.

German Empire, growth of, 197.

German Imperial Statistical Bureau, alcohol and pauperism, 202.

Germans, sturdiness of, 168; efficiency of, 106, 107.

Germany, achievements of, 173 ; beer gardens in, 69.

Gibbons, Cardinal, on National Prohibition, 273-277. Gin, per cent. of alcohol in, 38.

Gordon, Ernest, 97, 135, 138, $142,154,195,215$; Bohemia and alcohol, 216, 217. Gout, 108, 210; causes of, 212 ; and whiskey, 212.

Grain, amount and kinds of, used for alcoholic beverages, 269, 270.

Grief, and alcohol, 150, 151.

Guinea pigs, effect of alcohol on, 127.

Habit, liquor, 207.

Habits, 272, 273.

Hand-stand, the, and apoplexy, 267.

Happiness, and moderate drinking, 172, 173 .

Haycraft, prohibition, insanity, and pauperism, 177. 
Head, lowering of, and apoplexy, 267, 268; blood-vessels in, 267.

Headache, anæmic, and alcohol, 147.

Health, and moderate drinking, 172, 173; of the proletariat, 257 ; price of, 260.

Heart, and alcohol, 110, 119, 147; diseases of, 210 ; causes of "fatty," 210-212; effect of beer and water on, 211; and exercise, 251 ; author's, $258,259$.

Heart diseases, and overwork, 187,188 ; increase of, 233 ; in childhood, youth and middle-age, 235 ; causes of, $235,236$.

Hearts, of the middle-aged and elderly, 237.

Heavy weights, 251.

Heroin, 14.

High license, of saloons, 69; results of, 70 .

Hippocrates, 120.

Hobson, 13.

"Horror" stories, 196.

Horse, walking a, 241, 242.

Horses, longevity of good and of poor, 167 ; fire, 236 ; feed of idle, 263.

Horsley, Sir Victor, sobriety in lumber camps, 22; alcohol for soldiers, 90 ; effect of alcohol on tissue waste, 129, 130, 131; alcohol and puppies, 143; internal organs, 148, 149; alcohol and the stomach, 152, 153; alcohol in hot countries, 158; snake venom and alcohol, 159, 160; suckling, fecundity, and alcohol, 196, 197; overlying of infants, 198; apparent bias of, 215 ; epilepsy and alcohol, 227, 228; blood corpuscles and alcohol, 229; pneumonia, 229; effects of small amounts of alcohol, 248.

Human organism, and the "perfect scientific food," $260,261$.

Hysteria, of fanatics, 73, 74 .

Idiosyncrasies, food, and arteriosclerosis, 242-247.

Ill-nourished, diseases of the, 180; and alcohol, 181, 182.

Indifference, of heavy drinkers, 144; a cause of inebriety, 195.

Individual, rights of, 30-32.

Indolence, 260 ; and physical deterioration, 263.

Inebriates, deficiency, character, and children of, 190192 ; and cheap liquors, 146; indifference of, 195.

Inebriety, causes of, 194, 195; delirium tremens, nervous disorders, consumption and, $212,213,223$.

Infant mortality, reduction of, 232.

Infectious diseases, decrease of, $232,233$.

Injections, effects of, of alcohol, of absinthe essence, of protein extracts, and of casein, 133, 134, 136. 
Insanity, hereditary, 145; syphilis and, 145; and alcohol, 144, 145; and inebriety, $145,221,222$; and prohibition, 177.

Insomnia, coffee, tea, and, 150. Instincts, indestructibility of, 5 ; reliability of, 164 .

Intemperance, decrease in, 19, 20 ; destitution and, 201204; rape and, 207, 208; among high-grade criminals, 208 ; of women, 203; of foreigners, 51, 203.

Internal organs, alcohol and the, 147; caffeine, theine, and degeneration of the, 148, 149.

Intoxicants, and sexual desire, 6; and dominant races, 82.

Intoxication, amount of alcohol necessary for, 114; other than by alcohol, 140, 141 ; occasional, 193, 194.

Invalids, longevity of, 166 .

Irish, robustness of, 168 .

Irritability, coffee, tea, alcohol and, 140, 150.

Irritants, as stimulants, 112 . Italy, drinking in, 39, 40.

Jacob, Captain, death throes of injected guinea pig, 134; absurd conclusion therefrom, 135, 137, 138.

Jacobi, Dr. A., Alcohol Medication, 119-124, 128, 129.

James, Dr. W. B., alcohol and the neuro-muscular system, $118,119$.
Jones, Dr. Robt., defectiveness of inebriates and their progenitors, 191, 192.

Japan, achievements of, 173 .

Kassowitz, effect of alcohol on dog, 107.

Kidneys, 237.

Kitchener, Lord, alcohol in army, 92.

Koren, John, amendment to Constitution, 10; prohibition in South, 11; illicit distillation in South, 53; results of prohibition, 53 ; decrease in spirit drinking, 20; beer and wine in Russia, 55 ; wholesomeness of beer, 70; drink and destitution, 204.

Kraepelin, 108.

Labor Unions, sobriety of, 20, 21.

Lactation, and alcohol, 196, 197.

Lecturers, and alcohol, 110113.

Lee, Dr. Frederick S., effect of alcohol on muscles, 127, 128.

Life, 263.

Life Insurance Cos., reformed drunkards in, 173,174 ; abstainers in, 175, 176; statistics of, not wholly reliable, 178; best risks for, 181 .

Liquor drinking, danger of, 38.

Liquor evil, less, when laws are enforced, 49. 
Liquor laws, necessity of, 49. Liquors, grain for fermented, and for distilled, 269, 270; prohibition of strong, 14, 15; decrease in use of strong, 20.

Local Option, 59.

Locomotor ataxia, specific cause of, 213.

Longevity, of abstainers, of drinkers, of hard physical workers, of brain-workers, 161,163 ; of ascetics, invalids, and the robust, 166 , 167 ; of good, and of poor, horses, 167 ; of natives of the Balkan peninsula, 166; strength and, 172; efficiency and, 172; moderate drinking and, 172, 180-182; of physicians, 256.

Lumberers, sobriety of, 22, 23.

Luxury, and disease, 234.

Magdeburg, relation of drink and pauperism in, 202, 203.

Malt beverages, sedative effects of, 15; increase in use of, 19,20 .

Man, limitations of, 3, 5; weakness and responsibility of, 4 ; per cent. of water in, 100 ; effect of cocaine on, 115-117; alcohol in tissues of, 138-140; temptations of, 199, 200 ; physical deterioration of, 231, 249, 253.

Meals, water, wine, or beer with, 153.

Meat-eating, harm of exces- sive, 15, 40; prohibition of, 18.

"Medicine" ball, benefits and advantages of, 251-253.

Memory, and alcohol, 118, 119. Men, effects of giving up exercise on, 237, 238; alcohol and famous, 113; temperance of normal, 192.

Metchnikoff, sudden death of, 261.

Mill, J. S., 78.

Miners of the Borinage, and alcohol, 216.

Misfortune, and alcohol, 144. Mixed infection, alcohol in, 120-123, 128.

Moore, E. C., saloon conditions in 19th ward of Chicago, 65-68.

Morbidity, of the delicate, and of the robust, 168, 169 .

Morphine, 14.

Mortality, increase of, in Russia, after prohibition, 54; of the fat, 179; from typhoid fever in army, 169, 170 ; from typhus fever in Ireland, 170,171 ; from infectious diseases, 171, 172; of reformed drunkards, moderate drinkers, and heavy drinkers, 173-175; of physicians and general population, 256,257 ; reduction of general, 232 .

Mosso, Ugolino, 115; effects of cocaine, 116, 117.

Moving pictures, and alcohol, 184, 185.

Muensterberg, Hugo, 188, 261. 
Muscles, effect of alcohol on, $127,128,155$.

Muscular work, heavy, and alcohol, 153, 154.

Narcotic, alcohol as a, 110, $111,114$.

National Prohibition, consequences of, 4, 5, 45; Taft on, 8,9 ; ratification of, 9 , 10; injustice and danger of, 16 ; tyranny of, 25 ; unjust to individual, 30,31 ; effect of, on normal men, 33 ; folly of, 34; civic deceit after, 52; by, and for, defectives, 80; no need of, 176, 177; economy plea for, 269 , et seq.; property and financial loss from, 270, 271; dangerous in war-time, 272; Cardinal Gibbons on, 273-277.

Neglect, and mortality of children, 199.

Nephritis, 210; in soldiers, 102; and syphilis, 213-215; increase of, 233.

Nerves, effect of alcohol on, 141.

Nervous disorders, and alcoholism, 221, 222.

Nervousness, allayed by alcohol, 111.

Nervous shock, and arteriosclerosis, 246.

Nervous system, and alcohol, 140-142, 156, 157.

Neurasthenia, coffee, tea, and, 150.

Neuro-museular system, effects of alcohol on, 118, 119.
N. Y. Life Insurance Co., mortality of reformed drunkards, 173.

Noise, 77, 78; effect of, on nerves, 150.

Northwestern Mutual Life Insurance Co., mortality of temperate beer, and wine, drinkers, 174.

Norway, saloons in, 70.

Obesity, and alcohol, 179-181; causes of, 210-212.

Opium, 14; increase of importation into Germany, 28, 29.

Orators, and alcohol, 110-113. Organs, internal, effect of coffee and tea on, 140.

Overeating, and arteriosclerosis, 245.

Overlying, of infants, 198.

Overwork, and heart disease, 187, 188.

Ovulation, and alcohol, 196.

Ovum, the, and alcohol, 197, 198.

Oxidation, and alcohol, 129131.

Oxygen, affinity of alcohol for, 132.

Paresis, specific cause of, 213. Pauperism, and drink, 177, 178, 202, 203.

Physical deterioration, of the middle-aged, 249, 253 ; prevention of, 253, 254; and indolence, 254, 263.

Physical exercise, of working classes, 240, 241. 
Physical exertion, and health, 260.

Physical strength, and alcohol, 140.

Physical work, heavy, and alcohol, 162, 163.

Physicians, need exercise, 257 ; longevity of, 256; death rate, and chief causes of deaths of, 256, 257.

Plants, alcohol in, 86, 140.

Pneumonia, 233; and alcohol, 229, 230; alcohol in, 124.

Poisons, as stimulants, 112.

Portugal, drinking in, 40.

Pottenger, Dr. F. N., on fever, 112.

Poverty, and drink, 201, 202; in abstemious countries, 208.

Presl, Dr., cretinism, 217.

Prohibition, gains in state, 7 ; referendum on, 10 ; in South, 10, 11; injustice of state, 58,59 ; fanatical, 7880 ; and insanity, 177.

Prohibitionists, craving for liquor of many, 78,79 ; unwarranted claims of, 132134.

Proletariat, health knowledge of, 257.

Property, and prohibition, 270, 271.

Proteins, effects of injections of extracts of, 12, 136; nutritious orally, 136, 137; animal, and arteriosclerosis, 247.

Psychology, of fanatics, 72, et seq.; of love, 75 .
Purity complex, 73.

Pulse, effect of alcohol on, 118, 119.

Quensel, Dr. Ulrik, mortality statistics and alcohol, 174, 175.

Rabbits, experiments on, (Berezin), 110.

Rape, and intemperance, 207, 208.

Ratification of National Prohibition, states necessary for, 9 ; injustice of, and difficulty of repeal of, 10.

Reed, Dr., epilepsy, 228.

Referendum on prohibition, 10.

"Reform," of army canteens, 272.

Reformers, Utopian, 164.

Reinach, tuberculosis and alcohol, 220, 221.

Religion and eroticism, 72, 73. Rettich, Dr. H., drink and pauperism, 203.

Rivers, Dr. W. H. R., effect of cocaine on fatigue, 115-117.

Roberts, Lord, and alcohol in army, 92.

Robinson, Dr. Beverley, alcohol in grippe pneumonia, 124.

Robust, the, longevity, habits, and morbidity of, 166-169; incidence and case mortality of typhoid fever, and other infectious diseases, among, 169-172.

Romeyn, tissue waste, 129. 
Root, Elihu, on Federal enforcement of woman suffrage, and, inferentially, of prohibition, on the states, $7,8$.

Rum, per cent. of alcohol in, 38.

Russia, results of prohibition of vodka in, 53-55.

Saloons, types of, 64 ; intoxication in, 65; in Chicago, 65-68; substitutes for, luxuries in, improvement of, high lieense of, and its results, 68-70; games, music, dancing, sociability in, 69; failure of temperance, 69 ; uniform taxation of, 70; graded taxation of, in Norway, Sweden, Denmark, 70; regulation of, 200.

Salt, and the body cells, 139 .

Schmiedeberg, 127.

Sedative, alcohol as a, 110, 111.

Sedentarians, flabby muscles, weak hearts, breathlessness, indolence of, 260; "medicine" ball for, 253.

Sepsis, alcohol in, 120, 123, 128.

Sexual desire, and intoxicants, 6.

Shadwell, A., poverty, vice, crime and drink, 208, 209.

Sharpshooters, and alcohol, 90, 91 .

Skin, effects of alcohol, caffeine, and theine on, 147.
Sleep, 194; and efficiency, 92, 105.

Sluggish circulation, and lack of exercise, 262.

Smith, Dr. Percy, defectiveness of alcoholic, 191.

Smoking, 55-57, 249, 255.

Snake venom, and alcohol, $159,160$.

Sociability, in saloons, 69.

"Soft" drinks, harmfulness of, $14,31,183,184$; adulteration of, 184.

Softening of the brain, specific cause of, 213.

Soldiers, and alcohol, 89-92, 272.

Sorrow, "drowning," 152.

South, prohibition in, 10, 11.

South America, effect of cocaine on natives of, 115 .

Spain, drinking in, 40.

Speakers, public, and alcohol, 110-113.

Spencer, Herbert, 163, 168.

Spirit drinking, effects of excessive, 211.

Sports, athletic, as exercises, 241.

Starke, Dr. J., 134, 141, 142, 155; heavy drinking of oldest men in Germany, 188, 189 ; effects of much fluid, 211.

Statistics, unreliability of, 178.

Stengel and Austin, syphilis and nephritis, 213-215.

Sterility, and alcohol, 196, 220.

Stimulant, alcohol as a, 112- 
115, 124; ether, strychnine and cocaine as, 114-117.

Stimulation, 193; effects of repeated, powerful, 38, 39. Stockard, Dr. Chas. R., eggs, guinea pigs, and alcohol, $126,127$.

Stock Yards Districts in Chicago, Committee of Fifty's report on, 49,50 .

Stokes, Chas. F., drug addicts, 28.

Stomach, and alcohol, 140, 152,153 ; and caffeine and theine, 147.

Strength, longevity, efficiency and, 172; of author, 250; joy of, 263, 264.

Structure, and non-use, 240.

Strychnine, effects of, 114, 115.

Stupefaction, 193, 194.

Sugar, changed into alcohol by digestive ferments, 85 , $86,101$.

Sutherland, alcohol in the tropics, 99, 100.

Sweden, private distillation in, 45,46 ; saloons in, 70 .

Sweets, harmfulness of, 14, 15, $31,183,184$; adulteration of, 184.

Sypnilis, and insanity, 145; and paresis, 213; and nephritis, 213-215; and alcohol, 215, 216; specific cause of, 216.

Taft, National Prohibition of Alcohol, 8, 9.
Talmey, B. S., on fanatics, $75,76,77$.

Tea, prohibition of, 17 ; irritability, insomnia, nervousness and, 140, 147, 148, 150.

Temperament, and drunkards, 201.

Temperance, economic reasons for, 93-96; practicability of, 71 ; and intemperance, 192 , 193.

Temperate, mortality of, 174.

Temptations, of man, 199, 200. Thrombus, 265.

Thucydides, 170.

Tissues, alcohol in human, 138-140.

Tissue waste, and alcohol, 129131.

Tobacco, 16, 17 .

Toxins, stimulation of, 112.

Trees, 266.

Tropics, health of abstainers in, $97,98,102$; and water drinking, 100, 102.

Tuberculin, 225.

Tuberculosis, pulmonary, 112; and famous authors, 113; and the undernourished, $212,213,223$; and alcohol, $212,213,220-223$; fallacies of, 223-225; tuberculin as a test of, 225; and children, 225.

Turkey, 173.

Typhoid fever, alcohol in, 123 ; in American army, 169, 170 ; incubation and pathology of, 171 ; resistance of body cells to, 171, 172 . 
Typhus fever, in Ireland, 170, 171.

Unger, Dist. Atty., drug addicts, 27, 28.

United Hebrew Charities Association, drink and destitution, 204.

Urethral canal, degeneration of, from non-use, 238, 239.

Valetudinarians, 167.

Vascular system, of two very old habitual drinkers, 186, 187; and exercise, 251.

Vaughan, Dr. Victor C., effects of injections of extracts from animal and vegetable proteins, vs. effects by mouth, 135-138; typhoid fever in American army, 169, 170.

Veins, the, and exercise, 266, 267.

Vigor, and alcohol, 249, 250, 254 ; and exercise, 254 ; and smoking, 249, 255.

Vodka, per cent. of alcohol in, 38.

Vogt, 108.

Von Bunge, Dr. G., fecundity and alcohol, 197.

Walking, as an exercise, 241, 242, 262.

Wartime, National Prohibition in, 272, 273.

Water, per cent. of, in man, 100 . palatable, 101 ; not always obtainable, 14; dis- tilled, and cells, 139; with meals, 153.

Water-drinking, in tropics, 100, 102; among abstainers, 102; heart, blood vessels and, 211.

Webb-Kenyon Act, 42-44.

Well-nourished, diseases of, 180 ; and alcohol, 181, 182.

Whiskey, per cent. of alcohol in, 38 ; effects of, 39 ; danger of, 115; in diphtheria, 122, 123,129 ; effects of much, 211, 212.

Whiskey drinkers, diseases peculiar to, 212.

White, Dr. Wm. A., prohibition, insanity, pauperism, 177 ; defectiveness and alcoholism, 177, 178.

Winslow, C. E. A., alcohol and efficiency, 108, 109.

Woman Suffrage, Elihu Root on Federal enforcement of, 8.

Women, drinking among, 203; weakness of criminals for, 208.

Wood alcohol, effect of drinking, 54.

Woodruff, Lieut. Col. Chas. E., health of abstainers in tropics, 97.

Working classes, work not generally arduous, 240, 241.

Workingman's club, 64, 65 .

Workingmen, general sobriety of, $21,32,33,58$; deprived of beer, 32 ; rights of, 58; deprived of drinking and smoking, 60, 61 ; savings of, 
61; habits and diversions Worry, effects of, 149, 150; of, 62 ; and the saloon, 64- and alcohol, 25, 26, 150. 68. 
124

Mi $\quad 1$

$\frac{1}{4}$ 


\section{DAY USE}

RETURN TO DESK FROM WHICH BORROWED

\section{LOAN DEPT.}

This book is due on the last date stamped below, or on the date to which renewed.

Renewed books are subject to immediate recall.

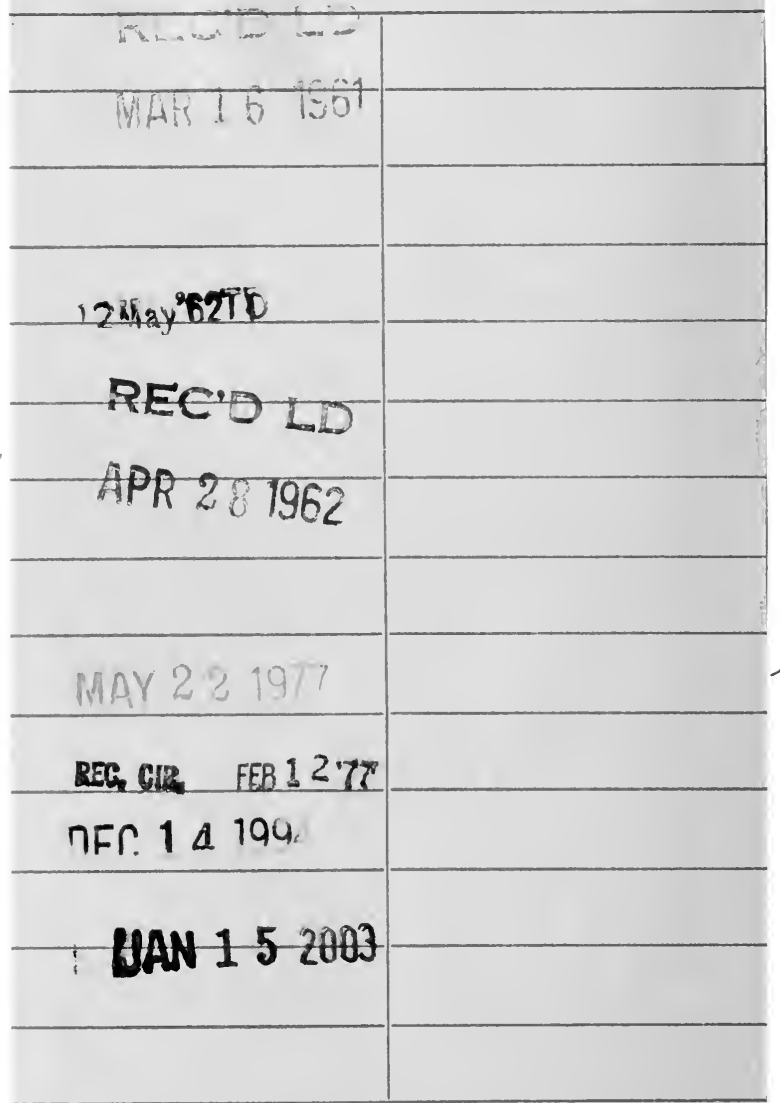


YB 07350

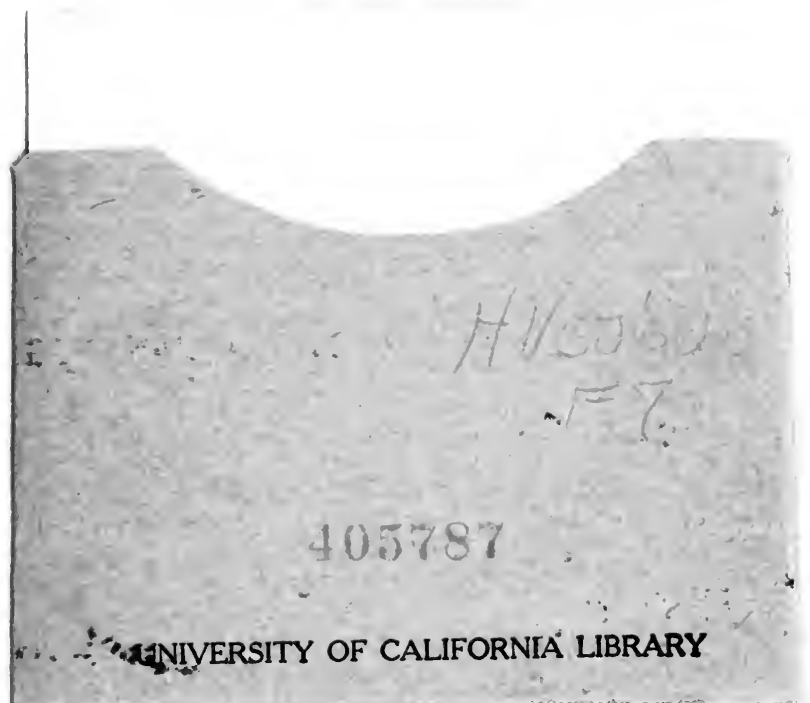


